Der Medizinischen Fakultät der Universität Göttingen

Eingereicht von Prof. Dr. med. W. Wuttke

\title{
Antagonisiert ein ER $\beta$-Agonist die Wirkung von ER $\alpha$ im Fett- und Muskelgewebe der ovarektomierten Ratte?
}

\author{
INAUGURAL - DISSERTATION \\ zur Erlangung des Doktorgrades \\ der Medizinischen Fakultät der \\ Georg-August- Universität zu Göttingen
}

vorgelegt von

\section{Jens Wellendorf}

aus

Georgsmarienhütte

Göttingen 2017 
Der experimentelle Teil der vorliegenden Dissertation wurde in Göttingen im Zeitraum zwischen März und Oktober 2007 in der Arbeitsgruppe Experimentelle Endokrinologie unter der Betreuung von Prof. Dr. med. W. Wuttke und Prof. Dr. med. D. Seidlovà-Wuttke angefertigt. Die schriftliche Ausarbeitung der vorliegenden Dissertation habe ich mit Beginn meiner ärztlichen Weiterbildungszeit 2009 in Bremen begonnen.

Dekan: $\quad$ Prof. Dr. rer. nat. H. K. Kroemer

Referent/in: $\quad$ Prof. Dr. med. W. Wuttke

Ko - Referent/in: $\quad$ Prof. Dr. rer. nat. C. Gründker

Drittreferent/in: $\quad$ Prof. Dr. med. H. Siggelkow

Tag der mündlichen Prüfung: $\quad$ 28.02.2018 


\section{Inhaltsverzeichnis}

INHALTSVERZEICHNIS

1 EINLEITUNG.

1.1 MOTIVATION ZUR VORLIEGENDEN ARBEIT …………....................................................................................

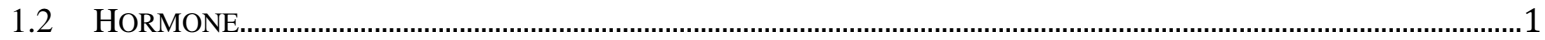

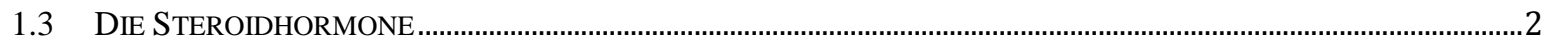

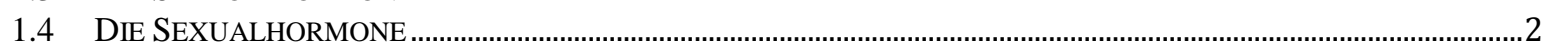

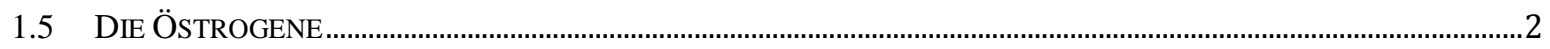

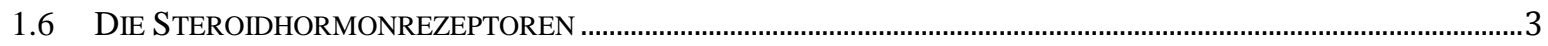

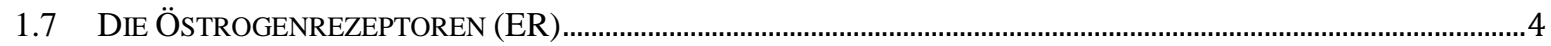

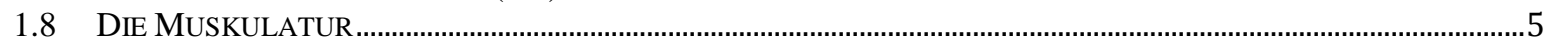

1.9 DIE MUSKELHYPERTROPHIE, MUSKELATROPHIE UND MUSKELREGENERATION …….......................................7

1.10 DIE ENDOKRINOLOGIE DES SKELETTMUSKELS ……………………………….............................................

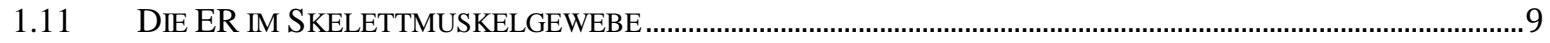

1.12 DER EINFLUSS VON ÖSTROGENEN AUF DEN SKELETTMUSKEL ………….................................................9

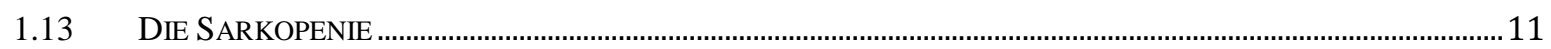

1.14 DIE PERI- UND POSTMENOPAUSE ................................................................................................................ 12

1.15 DAS METABOLISCHE SYNDROM …………………..........................................................................14

1.16 DIE VERÄNDERUNGEN DES FETTGEWEBES DURCH DIE MENOPAUSE ……................................................15

1.17 HORMONERSATZTHERAPIE ………………………….................................................................................16

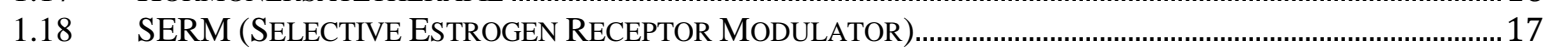

1.19 DIE VERWENDETEN TESTSUBSTANZEN …………………………………………..................................18

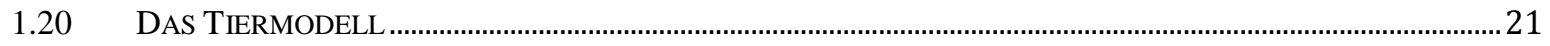

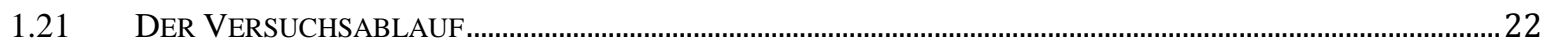

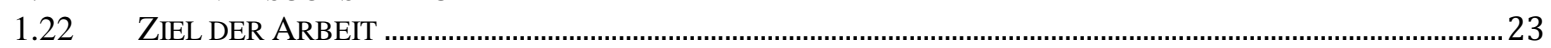

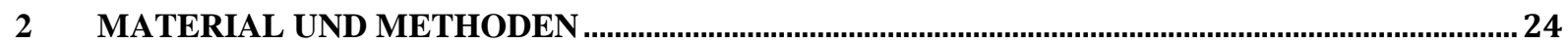

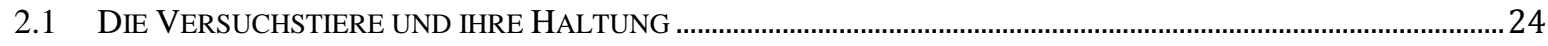

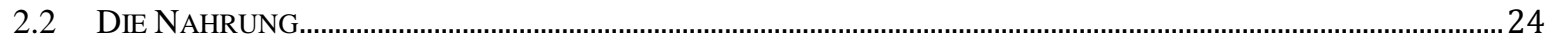

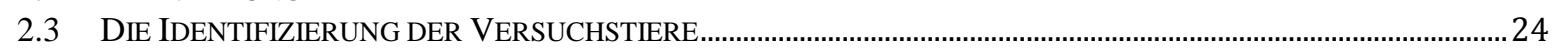

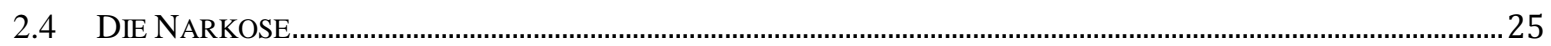

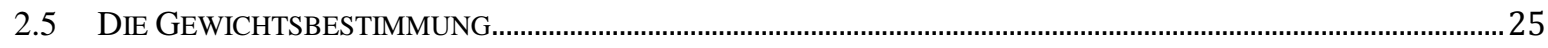

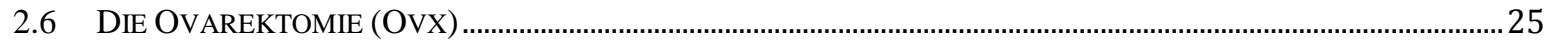

2.7 GRUPPENEINTEILUNG UND INJEKTIONSPLAN................................................................................................26

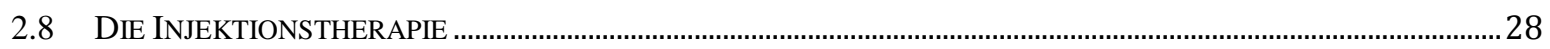

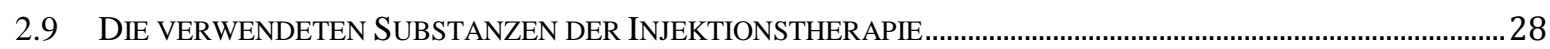

2.10 DIE ORGAN- UND PROBENGEWINNUNG...................................................................................................2

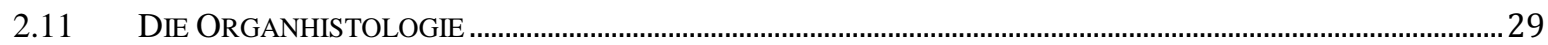

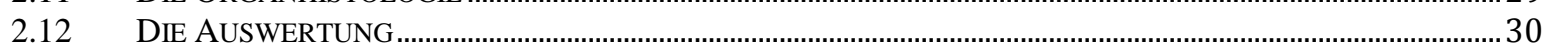

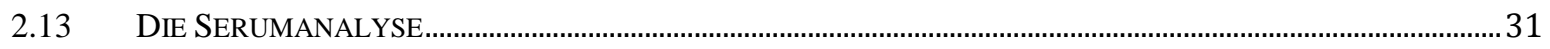

2.14 DER PERIPHERE QUANTITATIVE COMPUTERTOMOGRAPH (PQCT) …………............................................. 32

2.15 DIE STATISTISCHE METHODE ………………………................................................................................

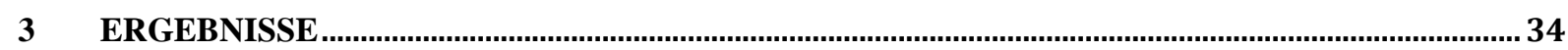

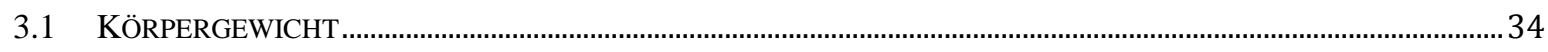

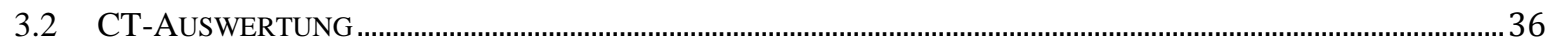

3.2.1 Fettanteil im abdominalen Bereich LWK 4/5 ............................................................................. 36

3.2.2 Fläche des Muskelgewebes im abdominalen Bereich LWK 4/5......................................................... 38

3.3 HISTOMETRISCHE ERGEBNISSE …………................................................................................................ 40

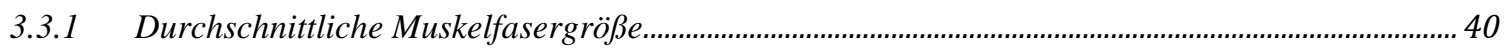

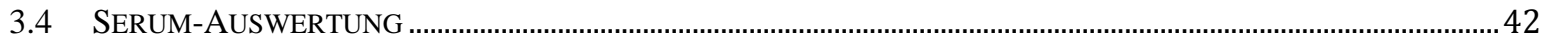

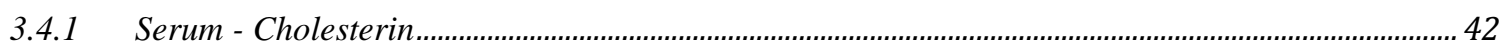

3.4.2 HDL 
3.4.3 LDL

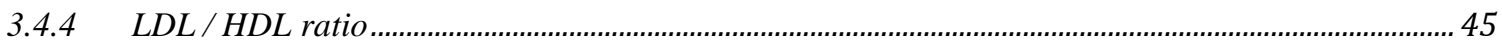

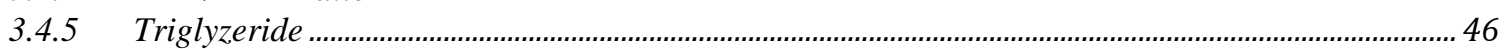

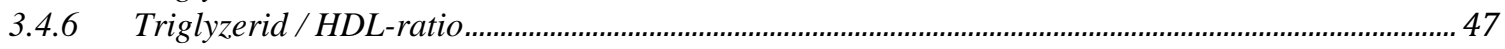

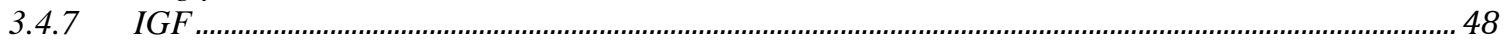

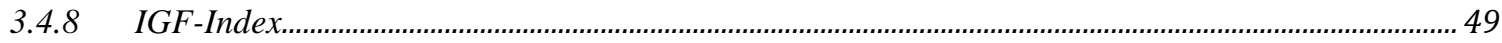

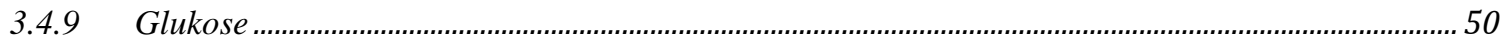

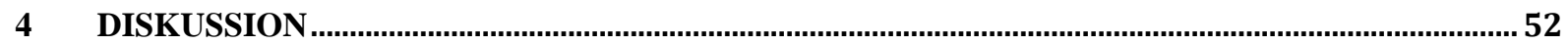

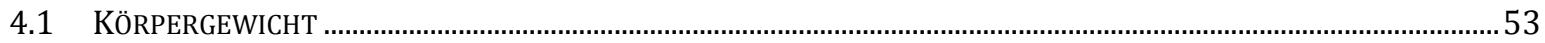

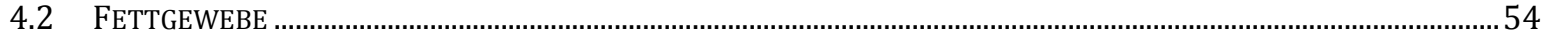

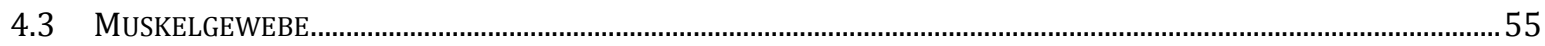

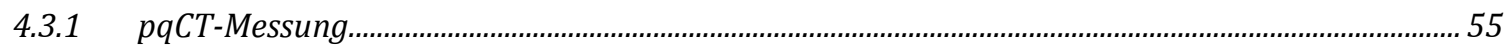

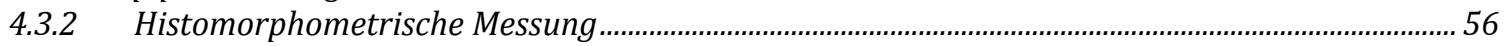

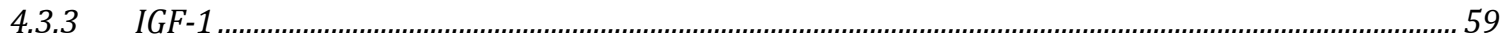

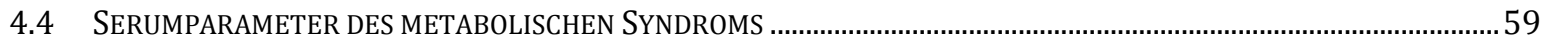

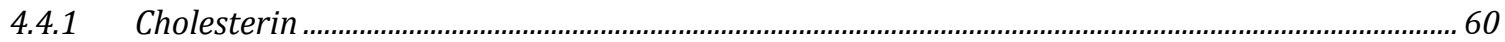

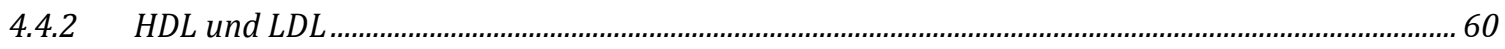

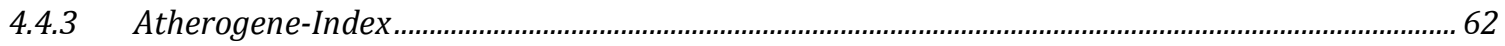

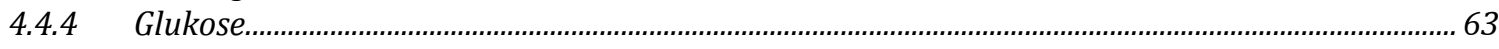

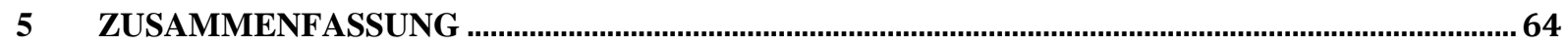

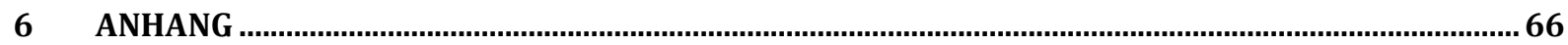

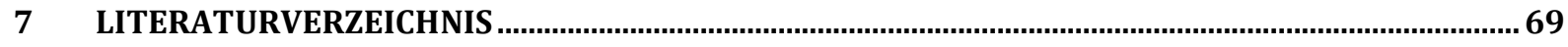

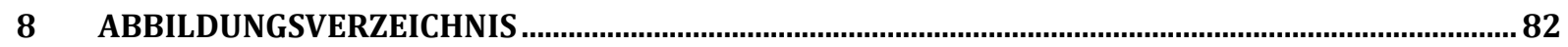

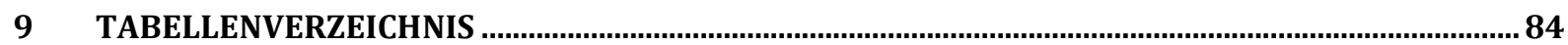




\section{Abkürzungsverzeichnis}

$\alpha \mathrm{ERKO}$

AF-1

AF-2

Akt

ANOVA

AP-1

BERKO

BMI

BMD

CT

DBD

DHEA

dl

DNA

$\mathrm{E}_{1}$

$\mathrm{E}_{2}$

$\mathrm{E}_{3}$

ER

ERE

ERKO

ERs

FSH

$\mathrm{GH}$

$\mathrm{GnRH}$

h

HDL

HE

HERS

HRE

HRT

IGF-1

KG

KHK

LBD

LDL
Östrogenrezeptor $\alpha$ Knock-out

Aktivierungsfunktion 1

Aktivierungsfunktion 2

Proteinkinase B

analysis of variance

Activating-Protein 1

Östrogenrezeptor $\beta$ Knock-out

Body Mass Index

bone mineral density (Knochendichte)

Computertomographie

DNA-Binding Domain

Dehydroepiandrosteron

Deziliter

Desoxyribonukleinsäure

Östron

Östradiol

Östriol

Östrogenrezeptor

Östrogen Response Element

Östrogenrezeptor $\alpha$ Knock-out

Östrogenrezeptoren

Follikel stimulierendes Hormon

Wachstumshormon

Gonadotropin Releasing Hormone

Stunde

High-density lipoprotein

Hämatoxylin-Eosin

Heart and Estrogen/Progestin Replacement Study

Hormon-Responsive Element

Hormone Replacement Therapy (Hormonersatztherapie)

Insulin-like growth factor

Körpergewicht

koronare Herzkrankheit

Ligandenbindungsdomäne

Low-density lipoprotein 
LH

LWK

M.

$\min$

mRNA

MTA

mTOR

NCEP

OP

Ovx

ovx

$\mathrm{pqCT}$

RIA

RT-PCR

S

s.c.

sham-ovx

SERM

SP-1

$\mathrm{T}$

TG

WHI

WHO

Wo

ZNS luteinisierendes Hormon

Lendenwirbelkörper

Musculus

Minute

messenger Ribonukleinsäure

Medizinisch Technische Angestellte

mammalian Target of Rapamycin

National Cholesterol Education Program

Operation

Ovarektomie

ovarektomiert

periphere quantitative Computertomograph

Radio Immuno Assay

Reverse Transkriptase Polymerase-Kettenreaktion

Sekunde

subkutan

Schein-Ovarektomie

Selectiven Estrogen Receptor Modulator

Stimulating-Protein 1

Tag

Triglyzeride

Women Health Initiative

World Health Organization

Woche

Zentrales Nervensystem 


\section{Einleitung}

\subsection{Motivation zur vorliegenden Arbeit}

Das Eintreten in die Menopause mit dem Rückgang der ovariellen Sexualhormonproduktion und schließlich deren Erliegen ist für die betroffenen Frauen zum Teil mit mannigfaltigen klimakterischen Beschwerden verbunden, die eine Einschränkung der Lebensqualität bedeuten.

Durch meine Weiterbildungszeit als Assistenzarzt in der Orthopädie/Unfallchirurgie habe ich regelmäßig Kontakt zu dieser Patientenklientel und ihren Beschwerden. Eines der bedeutendsten Leiden dieser Frauen ist das Übergewicht, welches sich bis hin zur Entstehung eines metabolischen Syndroms weiterentwickeln kann (Villa et al. 2008). Durch dieses menopausal bedingte Übergewicht neigen die Frauen häufig zu Verschleißerscheinungen der Hüft- und Kniegelenke, welche nicht selten am Ende eines Leidensweges für die Betroffenen in der Implantation eines künstlichen Gelenkes enden (Wang et al. 2009). Übergewicht ist ein bedeutender Risikofaktor für die Entstehung einer Arthrose (Doherty 2001). Dabei ist die Pathophysiologie des Übergewichtes und ihr Zusammenhang mit der Entstehung einer Arthrose noch nicht abschließend geklärt. Es werden sowohl mechanische wie auch biochemische Faktoren oder eine Kombination von beiden als Ursachen vermutet (Vasarhelyi und MacDonald 2012).

Mit steigendem Alter nimmt das Risiko, durch einen Sturz eine Fraktur zu erleiden, zu (Järvinen et al. 2008). Der Bruch eines langen Röhrenknochens, wie er bei solchen Stolperstürzen vorkommt, bedeutet für viele Patientinnen schließlich die Aufgabe ihrer bis dato gelebten Selbstständigkeit, was ein einschneidendes Erlebnis für jeden Menschen darstellt (Szulc et al. 2005). Dies ist zu einem bestimmten Grad der Sarkopenie und der Veränderung des Muskelgewebes geschuldet, welche auch in $\mathrm{Zu}$ sammenhang mit der menopausal verursachten Hypoöstrogenität steht (Maltais et al. 2009).

Die Neugierde, ob es pharmakologische Substanzen gibt, die diese physiologischen postmenopausalen Prozesse therapieren könnten, führte letztendlich zur Durchführung dieser Arbeit. Die Grundlagen dieser Dissertation bilden das wissenschaftlich anerkannte, tierexperimentelle Versuchsmodell der ovarektomierten (ovx) Ratte und die Entwicklung der selektiven ER-Agonisten $\alpha$ und $\beta$.

\subsection{Hormone}

Endokrinologie ist die Lehre von der so genannten inneren Sekretion. Unter diesem Begriff, geprägt von Claude Bernard im Jahre 1855, wurde die Sekretion von Substanzen im lebenden Organismus 
verstanden, die über den Blutweg transportiert, an anderen Orangen und Zellen ihre spezifische Wirkung ausüben. Substanzen, die auf diesem Wege biologisch aktiv sind, nennt man Hormone.

\subsection{Die Steroidhormone}

Zur Familie der Steroidhormone zählen insgesamt sechs Mitglieder, die Androgene, Östrogene und Gestagene, die Mineral- und Glukokortikoide und das Vitamin D (Bagchi 2003). Hauptsyntheseorte für die Steroidhormone sind zum einem die Nebennierenrinde, wo Glukokortikoide, Mineralkortikoide und Androgene entstehen, und zum anderen die Gonaden, in welchen die Gestagen-, Androgen- und Östrogensynthese stattfindet (Wuttke 1995).

Zudem sind Gewebe in der Körperperipherie, wie Muskel- und Fettgewebe, auch in der Lage, Steroidhormone zu synthetisieren. Allen Steroidhormonen ist gemein, dass sie aus derselben Muttersubstanz, dem Cholesterol, entstehen. Sie besitzen als Kohlenstoffgerüst alle das Steran des Cholesterin (Leidenberger 1997).

\subsection{Die Sexualhormone}

Unter dem Begriff Sexualsteroide oder Sexualhormone sind Hormone zusammengefasst, die für die Entwicklung und Funktion der Geschlechtsorgane sowie für die Ausbildung der Geschlechtsmerkmale beim Menschen verantwortlich sind. Hierzu zählen die Androgene, Östrogene und Gestagene (Kiechle 2007). In beiden Geschlechtern werden sowohl männliche als auch weibliche Sexualhormone produziert, allerdings in unterschiedlichen Mengen (Wuttke 2007).

\subsection{Die Östrogene}

Die Biosynthese der Östrogene findet in den Graaf-Follikeln, im Gelbkörper (Corpus luteum), in der Plazenta und im Hoden statt (Kiechle 2007). Über die Gonadotropine FSH und LH, welche über die hypothalamische Freisetzung von GnRH gesteuert werden, wird die Hormonproduktion der weiblichen und männlichen Gonaden stimuliert. Die obligaten Prohormone zur Bildung der Östrogene stellen die Androgene dar. Die Umwandlung von Androgenen in Östrogene nennt man Aromatisierung, das hierfür verantwortliche Enzym ist die Aromatase (Leidenberger 1997). Der zur Ovulation herangereifte Tertiärfollikel, auch Graafscher Follikel genannt, besteht aus einer inneren Granulosa- und einer äußeren Thekazellschicht. Die Thekazellen bilden vor allem Androgene wie Androstendion und Testosteron, die dann durch die Aromatisierung in den Granulosazellen zu Östrogenen umgewandelt 
werden. Die wichtigsten natürlichen Östrogene sind Östron $\left(E_{1}\right)$, Östradiol $\left(E_{2}\right)$, und Östriol $\left(E_{3}\right)$ (Teschner und Hinrichsen 2005). Das wichtigste, stärkste Östrogen mit der biologisch höchsten Aktivität ist das 17- $\beta$-Östradiol $\left(E_{2}\right)$. Östrogene wirken in nahezu jeder Zelle jedes weiblichen, aber auch männlichen Organs (Wuttke 2007). Es werden genitale und extragenitale Wirkung von Östrogenen unterschieden. Als extragenitaler Wirkungsort wird z.B das Knochengewebe bezeichnet, bei dem durch den Einfluss von Östrogenen die Osteoblasten-Aktivität stimuliert wird. Genitale Wirkung durch Östrogene sind unter anderem das proliferative Wachstum der Schleimhaut am Uterus oder die Abnahme der Viskosität des Zervixschleims (Teschner und Hinrichsen 2005).

\subsection{Die Steroidhormonrezeptoren}

Die Steroidhormonrezeptoren gehören zu der großen Familie der Transkriptionsfaktoren, die durch spezifische Liganden aktiviert werden (Weigel 2003). Durch die Wechselwirkungen des vom Liganden besetzten Rezeptors mit der DNA der Zielzelle werden bestimmte Gene funktionell an- oder abgeschaltet. Daher werden Steroidhormonrezeptoren als Transkriptionsfaktoren bezeichnet (Kiechle 2007).

Auf Grund ihrer lipophilen Eigenschaft, können Steroidhormone Zellmembranen per Diffusion leicht passieren, um an ihre intrazellulär gelegenen Steroidhormonrezeptoren zu binden. Auf diese Weise wird die biologische Aktivität der Hormone auf die Zielzelle vermittelt.

Die Bindung eines Hormons an einen Steroidhormonrezeptor löst eine Konformationsänderung des Rezeptors aus (Bagchi 2003). Aus den Rezeptoren entstehen Dimere, die sich mit spezifischen Sequenzen der DNA verbinden (Weigel 2003).

Der aktivierte Hormon-Rezeptor-Komplex lagert sich an die DNA im Zellkern an, dies wir als Translokation bezeichnet wird. Die Anschaltung der Transkription für bestimmte Gene kann durch Coaktivatoren begünstigt und durch Corepressoren gehemmt werden (Kiechle 2007). Die Stellen auf der DNA, an welche die Komplexe binden, bezeichnet man als Hormon-Responsive Element (HRE). Bei den Proteinen, deren Expression auf diese Weise beeinflusst wird, handelt es sich meist um Schlüsselenzyme des Stoffwechsels. Die Tatsache, dass die Neusynthese von Proteinen eine gewisse Zeit in Anspruch nimmt, bedeutet, dass lipophile Hormone, wie es die Steroidhormone sind, nicht für kurzfristige Regulationsaufgaben des Stoffwechsels verwendet werden. Viel eher dienen sie der langfristigen Einstellung eines veränderten Stoffwechselzustandes (Horn 2003).

Neben den beschriebenen Steroidhormonrezeptoren existieren zusätzliche rezeptorähnliche Proteine, die sehr große Strukturanalogien mit den bekannten intrazellulären Hormonrezeptoren haben, aber für die noch kein bekanntes Hormon oder eine andere biologisch aktive Substanz identifiziert ist. Man nennt diese Strukturen Waisenrezeptoren (orphan receptors) (Leidenberger 1997). 


\subsection{Die Östrogenrezeptoren (ER)}

Die Östrogenrezeptoren gehören zur Gruppe der Liganden-aktivierten Transkriptionsfaktoren, welche zur großen Familie der nukleären Hormonrezeptoren zählen (Dahlman-Wright et al. 2006).

Die Existenz eines Rezeptors, der $\mathrm{E}_{2}$ binden kann, wurde Anfang der 60er Jahre erstmals von Jensen und Jacobsen beschrieben (1962).

Lange Zeit nach Entdeckung des ersten ER wurde im Jahr 1996 ein zweiter ER im Prostatagewebe der Ratte entdeckt und geklont. Um die beiden Rezeptoren zukünftig voneinander zu differenzieren, wurde der zuletzt entdeckte Rezeptor als ER $\beta$ bezeichnet, während der schon bekannte Rezeptor den Namen ER $\alpha$ bekam (Kuiper et al. 1996). Noch im selben Jahr wurde der neu entdeckte ER $\beta$ auch beim Menschen nachgewiesen (Mosselman et al. 1996).

Die Wirkung von Östrogenen auf die Zielzellen wird über die intrazelluläre Bindung an ER $\alpha$ und ER $\beta$ erzielt. Als den klassischen Signalweg der ERs bezeichnet man die Bindung von Liganden, wodurch der ER aktiviert wird, die anschließende Bildung von Dimeren, die sich darauf mit ihren DBD an den ERE der DNA verankern. Wie andere Steroidhormone fungieren ER als Dimere, um die Transkriptionsrate einer Zelle zu regulieren (Zhao et al. 2008).

Es gibt Gemeinsamkeiten, aber auch einige Unterschiede zwischen den beiden ER-Subtypen.

Die ERs weisen gemeinsame strukturelle Charakteristika mit anderen Mitgliedern der Gruppe von nukleären Hormonrezeptoren auf, nämlich ihre Einteilung in fünf unterschiedliche Domänen, die mit den Buchstaben A/B, C, D, E und F bezeichnet werden (Gronemeyer und Laudet 1995). Die NTerminal liegende A/B-Domäne ist die veränderlichste aller fünf Domänen. Sie weist lediglich eine Übereinstimmung von 20\% der Primärsequenz der Aminosäure beider ER-Subtypen in diesem Bereich auf. Auf ihr ist die AF-1 lokalisiert, welche Liganden unabhängig aktiviert wird und Zell- und Promotor spezifische Wirkung zeigt (Tora et al. 1989).

In der zentralen C-Domäne zeigen ER $\alpha$ und ER $\beta$ eine Aminosäuren Übereinstimmung von 95\%. Die D-Domäne ist eine so genannte flexible Gelenkverbindung, welche die DBD von der LBD, die als EDomäne bezeichnet wird, trennt. Beide Subtypen zeigen eine $59 \%$ - Übereinstimmung der Aminosäuresequenz im Bereich der E-Domäne (Hillisch et al. 2004). Sie beinhaltet zusätzlich noch die Cterminale AF-2, eine Liganden-abhängige Aktivierungseinheit (Tora et al. 1989).

ER $\alpha$ und ER $\beta$ haben eine sehr ähnliche drei dimensionale Struktur ihrer LBD. Jedoch ist die LBD von ER $\beta$ um $20 \%$ kleiner als die von ER $\alpha$. Dies kann Auswirkungen auf die Affinität der Rezeptoren gegenüber verschiedenen Liganden haben (Brzozowski et al. 1997). Das natürliche Östrogen $E_{2}$ bindet an beide Rezeptoren mit der gleich hohen Affinität (Dahlman-Wright et al. 2003). ER $\beta$ zeigt eine schwächere Transkriptionseigenschaft und benötigt etwa zehnfach höhere $E_{2}$ Konzentrationen als ER $\alpha$, um die vollständige Transkriptionskapazität erbringen zu können (Dahlman-Wright et al. 2003, 
Ramsey et al. 2004). Erst durch das Zusammenwirken von ER $\alpha$ und ER $\beta$ wird die gesamte biologische Aktivität von Östrogenen erreicht (Dahlman-Wright et al. 2003).

Beide Rezeptoren zeigen gänzlich unterschiedliche Antworten auf die Bindung der synthetisch hergestellten Antiöstrogene Tamoxifen und Raloxifen. Während diese Liganden für ER $\alpha$ partielle Agonisten darstellen, sind sie gleichzeitig reine Antagonisten am ER $\beta$ (Barkhem et al. 1998). Tamoxifen vermag die Trankskripiton von Genen, die über den klassischen Signalweg über ERE kontrolliert werden, zu verhindern. Jedoch besitzt es zusätzlich die Eigenschaft wie $\mathrm{E}_{2}$, die Transkription von Genen zu aktivieren, welche durch das Activating Protein 1 (AP-1) kontrolliert werden. Die Liganden- induzierte Antwort des AP-1 durch den ER $\beta$ liefert ein Beispiel für die negative transkriptorische Regulation über ein natürliches Hormon und eine positive Regulation anhand eines synthetisch hergestelltes Antiöstrogen (Paech et al. 1997).

Matthews und Gustafsson postulierten 2003, dass bei Coexprimierung der ER-Subtypen in einer Zelle der ER $\beta$ einen inhibitorischen Effekt auf die durch den ER $\alpha$ vermittelte Genexpression ausübt, was ER $\beta$ zu dem dominanten Regulator im Östrogensignalweg macht (Matthews und Gustafsson 2003). Durch ein durchgeführtes In-vivo-Experiment, in dem das Knochen- und Lebergewebe von KnockoutMäusen untersucht wurde, entstand die These einer Ying-Yang-Beziehung zwischen dem ER $\alpha$ und ER $\beta$ (Lindberg et al. 2003). Yin und Yang sind zwei Begriffe aus der chinesischen Philosophie, die gegensätzliche Beziehung zwischen zwei oder mehreren Dingen auszudrücken (Ames 2003). Gleichzeitig wurde in diesem Experiment für Knochen- und Lebergewebe auch festgestellt, dass in der Abwesenheit von ER $\alpha$ (ERKO) die östrogene Wirkung zum Teil durch ER $\beta$ vermittelt wird, wenn auch nicht mit der gleichen Potenz, wie es der ER $\alpha$ vermochte, auf die Transkription von Genen der oben genannten Zellen einzuwirken.

Die Expression der beiden Rezeptorsubtypen umfasst ein breites Spektrum von Geweben. In manchen Organen werden ER $\alpha$ und ER $\beta$ zu gleichen Anteilen exprimiert, indessen ist in anderen Organen der eine oder andere Typ dominanter vertreten (Dahlman-Wright et al. 2006). ER $\alpha$ wird hauptsächlich im Uterus, der Leber, den Nieren und dem Herzen exprimiert, wohingegen die Ovarien, die Prostata, die Lunge, die Blase, der Gastrointestinaltrakt und das ZNS überwiegend die Expression des ER $\beta$ aufweisen (Dahlman-Wright et al. 2003). Für einen umfassenden Überblick über die Expressionsmuster der ER im menschlichen Körper wird auf die Arbeit von A. Taylor verwiesen (Taylor und Al-Azzawi 2000).

\subsection{Die Muskulatur}

Auf Grund von morphologischen und funktionellen Eigenschaften lässt sich das Muskelgewebe der Säugetiere in die Skelettmuskulatur, die Herzmuskulatur und die glatte Muskulatur einteilen. Gegen- 
stand der Untersuchung dieser Arbeit ist die Skelettmuskulatur, die quantitativ die größte Gruppe der drei Gewebetypen darstellt.

Mit einem Anteil von fast 40\% des Gesamtkörpergewichtes des Menschen nimmt die Skelettmuskulatur eine bedeutende Stellung in der Ausstattung der individuellen Körperkomposition ein.

Der einzelne Skelettmuskel besteht aus zahlreichen Muskelfaserbündeln, den so genannten Faszikeln. Jedes Muskelfaserbündel setzt sich aus vielen einzelnen Muskelfasern (Myozyten) zusammen. Die Skelettmuskelfaser ist eine vielkernige, nicht mehr teilungsfähige Zelle (Linke und Pfitzer 2007). Als quergestreifte Muskulatur werden der Skelett- und der Herzmuskel bezeichnet, da die geordnete Struktur ihrer kontraktilen Einheiten im Längsschnitt zu einem im Lichtmikroskop sichtbaren Bandenmuster führt.

Aus der embryonalen Verschmelzung von mehreren hundert einkernigen Myoblasten zu einem Synzytium resultiert die Vielkernigkeit der Skelettmuskelzelle. In den Muskelfasern befinden sich die ovalen Zellkerne am Rand der Zelle, direkt unterhalb der Zellmembran. Die Tatsache, dass ihre Zellkerne zentral liegen, ermöglicht lichtmikroskopisch Skelettmuskelfasern von Herzmuskelfasern oder glatter Muskulatur zu unterscheiden.

Der gesamte Skelettmuskel wird von einer derben Bindegewebshülle umgeben, dem so genannten Epimysium. Von dieser äußeren Hülle ziehen dünne Bindegewebssepten ins Innere des Muskels, die als Perimysium bezeichnet werden und den Muskel in die einzelnen Muskelfaserbündel unterteilen. Die einzelne Muskelfaser wird vom Endomysium umsponnen, welches aus einer Basallamina und retikulären Fasern besteht. Das Endomysium beinhaltet ein dichtes Netzwerk aus Kapillaren, Lymphgefäßen und Nervenfasern.

Das Sakroplasma, wie das Plasmalemm einer Muskelzelle genannt wird, ist fast vollständig von längs angeordneten Myofibrillen ausgefüllt. Eine Myofibrille ergibt sich aus vielen hintereinander geschalteten Sakromeren, den kleinsten Einheiten des kontraktilen Apparates. Der Durchmesser einer menschlichen Myofibrille liegt bei 1-2 $\mu \mathrm{m}$ und enthält mehrere hundert Aktin- und Myosinfilamente (Zanner et al. 2002). Die meisten Muskeln enthalten eine Mischung aus zwei oder mehr Muskelfasertypen, die sich in ihren Myosinisoformen unterscheiden. Man differenziert drei Haupttypen, die langsamen Typ-I-Fasern, die schnellen Typ-IIA-Fasern und die am schnellsten kontrahierenden Typ-IIBFasern. Die drei Fasertypen unterscheiden sich in funktioneller, biochemischer und struktureller Hinsicht. Je nach Muskelfunktion, d.h eher andauernden Haltearbeit oder Ausführung von schnellen Bewegungen, wird die Muskelfaserkomposition bestimmt (Linke und Pfitzer 2007). Bei Geburt sind die Muskeln der Ratte in Bezug auf ihre Fasertypen noch undifferenziert. Eine Differenzierung in die verschiedenen Muskelfasertypen erfolgt erst nach der Geburt in den ersten Lebenswochen (Ishihara und Taguchi 1991). Der Muskelfasertyp beeinflusst die Kontraktionskraft des Muskels, die maximale Kontraktionsgeschwindigkeit und die Ermüdungszeit des Muskels nach stattgehabter Kontraktion (Eng et al. 2008). Der M. soleus der Ratte besteht z.B vornehmlich aus Typ-I-Fasern und einem geringen Anteil aus Typ-IIA-Fasern. Hingegen besteht der M. gastrocnemius zu einem Großteil aus 
Typ-I-und IIA-Fasern mit einem geringen Anteil an Typ IIB-Fasern, so genannten Hybridmuskelfasern, welche aus mehreren Fasertypen, je nach Anforderung, bestehen (Staron et al. 1999).

\subsection{Die Muskelhypertrophie, Muskelatrophie und Muskelregeneration}

Je größer die Summe der Querschnitte der einzelnen Muskelfasern eines Muskels, desto höhere Kräfte können durch ihn entwickelt werden. Muskeltraining kann zur Muskelhypertrophie führen, wobei die Dicke der Muskelfasern zunimmt, während die Anzahl der Fasern im Muskel nicht verändert wird. Ein hypertropher Muskel synthetisiert mehr Proteine in den Myozyten als er abbaut. Übersteigt im umgekehrten Fall der Abbau der Muskeleiweiße deren Protein-Neusynthese über einen längeren Zeitraum, tritt Muskelatrophie ein, eine Abnahme der Muskelmasse infolge einer Verkleinerung des Muskelfaserdurchschnittes. Einer Muskelatrophie können vielerlei Ursachen zu Grunde liegen. Die Hauptgründe sind Ruhigstellung des Muskels, seine Denervierung oder der Alterungsprozess (Linke und Pfitzer 2007). Die Inaktivitätsatrophie, welche durch fehlende physische Belastung entsteht, wie sie z.B bedingt durch Bettlägerigkeit vorkommt, bleibt die Hauptursache der Atrophie (Machida und Booth 2004).

Schon wenige Tage des Nichtverwendens der Muskulatur setzen biochemische und morphologische Veränderungen des Muskels in Gang, die zur Atrophie führen (Diffee et al. 1991).

Der Durchmesser einer Skelettmuskelfaser kann je nach Muskel, Alter, Geschlecht, Ernährungszustand und Training stark variieren (Zanner et al. 2002). Diese genannten Faktoren wurden in dieser Arbeit berücksichtigt, um identische Vorrausetzungen für alle Untersuchungsgruppen zu schaffen.

Nach Verletzungen des Skelettmuskelgewebes werden die adulten Stammzellen des Muskels - einkernige, spindelförmige Satellitenzellen - zur Zellteilung angeregt. Satellitenzellen sind aus der Embryonalentwicklung übrig gebliebene Myoblasten, welche bei Bedarf fusionieren, differenzieren und so vielkernige Muskelfasern bilden können. Im Gegensatz zur Herzmuskulatur ist der Skelettmuskel dadurch noch begrenzt regenerierbar (Linke und Pfitzer 2007).

\subsection{Die Endokrinologie des Skelettmuskels}

Hormone sind die Schlüssel-Regulatoren im Stoffwechsel des Skelettmuskels. Der menschliche Skelettmuskel unterliegt kontinuierlichen Umbauprozessen, die eine empfindliche Balance zwischen der Muskelprotein-Neusynthese und des Protein-Abbaus aufweisen, die in Phasen des Wachstums und des Alterns stattfinden aber auch während Gesundheit und Krankheit (Sheffield-Moore und Urban 2004). Die Homöostase des Muskelstoffwechsels wird durch bestimmte Faktoren wie Fasten (Fryburg et al. 1990), Ernährung (Volpi et al. 2003), Bewegung (Rennie und Tipton 2000), Altern (Volpi et al. 2001) 
und in Zeiten von Krankheit (Lim et al. 2003) beeinträchtigt. Hormone wie Testosteron, Groth Hormon (GH), Insulin, IGF-1 und Glukokortikoide haben beträchtlichen Einfluss auf den Skelettmuskel und sind von großer Bedeutung für die einzelnen Umbauprozesse. Sie sind entscheidend dafür verantwortlich, ob die Gesamtproteinbilanz des Muskels im negativen oder im positiven Maße beeinflusst wird (Sheffield-Moore und Urban 2004). Der anabole Effekt von Testosteron wird durch die Stimulation von Myoblasten und eine Zunahme der Satellitenzellen vermittelt (Brown 2008). Außerdem wird der Muskelprotein-Abbau reduziert und die Muskelstärke vergrößert (Ferrando et al. 2002). Auch für das GH ist eine anabolische Wirkung auf das Skelettmuskelsystem nachgewiesen worden (Weber 2002). Die Expression von IGF-1 ist mit Muskelhypertrophie assoziiert (Musaro et al. 1999). Es gibt viele verschiedene Faktoren, die einen lokalen Anstieg in der Ausprägung von IGF-1 erzielen können. Hierzu zählen unter anderem Androgene (Sheffield-Moore et al. 1999) und Bewegung (Bamman et al. 2001). Dagegen wird die Expression von IGF-1 durch Interleukin-6, welches bei chronischen Entzündungen vermehrt synthetisiert wird, supprimiert (Barbieri et al. 2003).

Neben der tragenden Rolle in der Regulation des Glukose- und des Fettsäurestoffwechsels, ist für Insulin eine eindeutige anabolische Wirkung auf den Stoffwechsel des Skelettmuskels bewiesen worden (Biolo et al. 1995).

Glukokortikoide und Myostatin sind zwei Hormone, die eine katabole Wirkung auf den Stoffwechsel des Skelettmuskels ausüben, was eine Verkleinerung der Muskelmasse bedeutet ( Sheffield-Moore und Urban 2004). Darüberhinaus ist Myostatin in den Prozess der Reparatur von Skelettmuskeln involviert. Nach erlittenen Muskelverletzungen vermindert Myostatin den Regenerationsprozess erheblich indem die Satellitenzell-Aktivierung verhindert wird und die Differenzierung und Transformation von Myoblasten beeinträchtigt (Burks und Cohn 2011). Der Skelettmuskel ist jedoch nicht nur ein Zielorgan sondern auch Ausgangspunkt und Urheber für endokrinologische Prozesse.

Körperliches Training, egal ob aerob oder anaerob, führt zu einer Aufrechterhaltung oder gar Verbesserung der Gesundheit. Der Wirkmechanismus, welcher hinter dieser Verbesserung des körperlichen Zustandes durch Training steckt, wurde erst kürzlich wissenschaftlich erwiesen. Skelettmuskeln synthetisieren verschiedenartige Faktoren und diese vom Muskel ausgehenden Faktoren erzeugen vorteilhafte Effekte an peripheren Organen. Diese vom Muskel ausgehenden bioaktiven Faktoren werden Myokine genannt (Iizuka et al. 2014). Der Skelettmuskel ist ein endokrines Organ, das Myokine produziert und freisetzt, welche dann ähnlich wie Hormone, spezifische endokrine Auswirkungen an anderen Organen erzielen. Myokine wirken jedoch auch parakrin und nehmen so Einfluss auf Stoffwechselvorgänge des Skelettmuskels selbst (Pedersen 2011). 


\subsection{Die ER im Skelettmuskelgewebe}

Die Existenz der beiden ERs ist für das menschliche Muskelgewebe nachgewiesen worden. Nicht nur der ER $\alpha$ (Lemoine et al. 2003), sondern auch der ER $\beta$ werden in der menschlichen Skelettmuskelfaser exprimiert. Die ERs sind sowohl in der Zellmembran, im Sakrolemm als auch im Nukleolus lokalisiert (Brown 2008). Darüber hinaus findet man den ER $\beta$ Subtyp auch im Endothel der Kapillaren, welche den Muskel mit Sauerstoff und Nährstoffen versorgen (Wiik et al. 2005). Beide ER-Subtypen werden im Skelettmuskel ausgeprägt, jedoch ist ein klares Übergewicht in der Expression zugunsten von ER $\alpha$ beschrieben (Lemoine et al. 2003). Mit Hilfe der RT-PCR konnte auch für Nagetiere nachgewiesen werden, dass der ER $\alpha$ der vorherrschende ER im Muskelgewebe ist (Emmen und Korach 2003).

Durch das Wissen, dass beide ERs im Skelettmuskelsystem von Maus, Ratte und Mensch coexprimiert werden, lässt sich ableiten, dass es sich beim Skelettmuskel um ein Östrogen-sensibles Gewebe handelt (Glenmark et al. 2004, Lemoine et al. 2002, Moran et al. 2007).

Es wurde bereits bewiesen, dass in neun verschiedenen Geweben - das Skelettmuskelgewebe nicht mit eingeschlossen - die Ovx bei Ratten einen ER $\alpha$-messenger-RNA (mRNA) Expressionsanstieg auslösen konnte, der bis hin zum dreifachen des normalen Expressionslevels reicht, und dass eine Östrogensubstitution dieser Tiere die vermehrte ER $\alpha$ mRNA Expression wieder rückgängig macht. In einigen Geweben konnte keine Änderung des ER $\alpha$ mRNA Levels festgestellt werden, was die Vermutung erhärtet, dass die Regulation der ERs gewebespezifisch ist.

$E_{2}$ vermag, einen genetischen Einfluss in östrogen sensiblen Zellen auszulösen. Diese genetische Wirkung wird durch die ERs vermittelt, welche nachdem $\mathrm{E}_{2}$ als Ligand eine Bindung mit ihnen eingegangen ist, als Transkriptionsfaktoren wirken. Dass dieser östrogene Wirkmechanismus auch für den Skelettmuskel begründet werden kann, setzt die Erwartung voraus, dass Skelettmuskelzellen auf die Plasmakonzentration von Östrogenen reagieren. Mit anderen Worten, es ist von grundlegender Bedeutung, dass ERs in Skelettmuskelfasern eine typische steroidale Reaktion auslösen. Die wissenschaftliche Hypothese für den Skelettmuskel besteht darin, dass sich Ovx oder altersbedingter Östrogenmangel auf die Quantität der ERs im Skelettmuskel auswirkt, und umgekehrt die Östrogensubstitution diese Auswirkungen wieder rückgängig zu machen vermag (Mohamed und Abdel-Rahmann 2000).

\subsection{Der Einfluss von Östrogenen auf den Skelettmuskel}

Ein Verlust von Muskelkraft tritt bei allen Frauen und Männern als Konsequenz des Älterwerdens ein, aber der Grund, weshalb es Unterschiede zwischen den Geschlechtern in Bezug auf Tempo und Ausmaß dieses Kraftverlustes gibt, ist noch nicht gänzlich wissenschaftlich geklärt. Frauen haben mit dem Rückgang der Östrogen- und Progesteronproduktion um die Menopause einen ausgeprägteren 
Muskelkraftverlust. Der Einsatz von HRT bewahrt jedoch die Muskelkraft, was den Zusammenhang zwischen Sexualhormonen und Muskelkraftverlust zeigt (Lowe et al. 2010). Für die Gruppe der Östrogene ist bekannt, dass sie einen Einfluss auf die Muskelmasse und die Funktion des Skelettmuskels haben. Ihr Mangel kann möglicherweise dazu führen, dass neben Muskelschwäche auch der Verlust von Muskelmasse auftritt (Beckett et al. 2002, Sitnick et al. 2006).

Den vermutlichen Anfang einer Muskelproteinsynthese bildet die Aktivierung des Akt/mTORSignalweges (Glass 2003). Verschiedene Stimuli sind in der Lage, diese Kaskade in Gang zu setzen, etwa die vermehrte mechanische Belastung des Muskels oder endokrine Faktoren wie Insulin und IGF-1 (Bodine et al. 2001, Sitnick et al. 2006).

In verschiedenen Geweben, z.B. dem Herzmuskel, konnte der aktivierende Effekt von Östrogenen auf den Akt/mTOR-Signalweg nachgewiesen werden (Patten et al. 2004). Für das Skelettmuskelsystem ist jedoch noch nicht soviel über den Einfluss von Östrogenen auf die Akt/mTOR-Kaskade bekannt (Sitnick et al. 2006).

Die Wirkung von Östrogenen auf den Skelettmuskel kann in direkte und indirekte Effekte unterteilt werden. $\mathrm{Zu}$ den direkten Auswirkungen von Östrogenen auf das Skelettmuskelsystem zählen die mögliche Erhaltung der Muskelmasse und der Schutz vor Muskelverletzungen bei jungen prämenopausalen Frauen. Auch die möglichen Veränderung der kontraktilen Funktion sowie des Muskelstoffwechsels werden zu direkten östrogenen Wirkungen gezählt (Brown 2008).

Unter indirekten östrogenen Effekten versteht man Zustände, die sich erst sekundär auf die Skelettmuskulatur auswirken. Ein Beispiel hierfür ist die verminderte Aktivität und Bewegung, wie sie beispielsweise bei niedrigen Östrogenspiegeln vorkommt (Eckel et al. 2000). Diese Verhaltensänderung, hervorgerufen durch den Mangel an Östrogenen, bewirkt somit sekundär eine Abnahme der Muskelmasse infolge von Inaktivität (Brown 2008).

Dazu ist bekannt, dass Östrogene für die Regulation von Fettanteil und Fettverteilung verantwortlich sind. Der Mangel an Östrogenen führt zu einem signifikanten Gewichtsanstieg. Diese Tatsache ist nicht Folge einer gesteigerten Nahrungsaufnahme, sondern einer Veränderung der hormonellen Fettgewebsregulation. Die Gewichtszunahme, gekoppelt mit der verminderten Bewegung, führt somit indirekt zur Abnahme der Skelettmuskulatur (Brown 2008).

Der östrogene Einfluss auf das Skelettmuskelsystem mag auch von der Beschaffenheit der verschiedenen Muskelfasertypen eines Muskels abhängen. Der Anteil von ER $\alpha$ ist viel höher auf den schnellen Typ-IIA-Muskelfasern als auf den langsamen Typ-I-Fasern. Dies könnte der Grund dafür sein, dass der Verlust an Typ-IIA-Fasern während des Alterns höher ist und sie mit Beginn der fünften Dekade atrophieren. Typ-I-Fasern behalten für den Großteil des Lebens ihre Fasergröße bei (Brown 2008).

Verschiedene Studien haben gezeigt, dass der Skelettmuskel von jungen, heranwachsenden Nagetieren Östrogen sensibel ist (McCormick et al. 2004). Bei älteren Tieren wurden bisher nur wenige Untersuchungen in diese Richtung unternommen (Moran et al. 2007). 
In der Gesamtbetrachtung zeigen die Studien, die an ovx Nagetieren durchgeführt wurden, kontroverse Ergebnisse, nämlich dass die Muskelstärke zunimmt, sich nicht verändert oder durch die ovx gar abnimmt (Lowe et al. 2010).

In einer durchgeführten Metaanalyse wurde bei sechs der Studien, die an Mäusen mit Östrogenmangel und Östrogenübersättigung durchgeführt wurden, erhärtende Beweise für den hormonellen Einfluss auf die Muskelstärke beschrieben, jedoch zeigten die drei Studien an Ratten, dass keine bedeutende Veränderung festgestellt werden konnte. Die gemeinsamen Ergebnisse der Untersuchungen an postmenopausalen Frauen und ovx Nagetieren unterstützen jedoch die Behauptung, dass $E_{2}$ einen vorteilhaften Effekt auf die Muskelstärke hat. Die Nachweise deuten darauf hin, dass $E_{2}$ dies nicht über einen Einfluss auf die Muskelgröße erreicht, sondern eher über eine Verbesserung der intrinsischen Qualität der Skelettmuskelfasern, wodurch diese mehr Kraft erbringen können. Diese Ergebnisse zeigen in ihrer Auswertung, dass der Skelettmuskel sehr wohl ein östrogen sensibles Gewebe ist und zeigt einen plausiblen Wirkungsweg der Östrogene im Skelettmuskel via ERs. Wie genau hierdurch Myosin und die Muskelstärke beeinflusst werden, ist noch nicht endgültig erforscht und geklärt (Lowe et al. 2010).

\subsection{Die Sarkopenie}

Der Begriff Sarkopenie wurde erstmals 1989 von Rosenberg geprägt (Rosenberg 1989), der damit den fortschreitenden Verlust von Muskelmasse während des Alterns beschrieb. Die griechische Bedeutung lautet übersetzt „Mangel an Fleisch“. Eine gegenwärtige, genauere Definition beschreibt Sarkopenie als eine Reduktion von Muskelstärke, Masse und Qualität (Rolland et al. 2008).

Die Ursachen der Entstehung von Sarkopenie sind vielschichtig in der Literatur diskutiert. Als Gründe werden unter anderem aufgeführt, eine metabolische Dysregulation, die zu einem Rückgang der Insulinsensitivität führt (Dela und Kjaer 2006) oder die Verminderung an zirkulierenden anabolischen Hormonen wie Testosteron, DHEA und GH. Weitere diskutierte Faktoren der Entstehung von Sarkopenie sind Inaktivität und Ernährung (van den Beld und Lamberts 2002) sowie endokrine Einflüsse wie die Höhe des Katecholaminspiegels und parakrine / autokrine Systeme wie beispielsweise IGF-1 (Solomon und Bouloux 2006).

Der Verlust von Muskelstärke und Muskelmasse während des physiologischen Alterungsprozesses ist die Folge von fortschreitender Muskelatrophie und einer Verringerung der Muskelfaserzahl (McNeil et al. 2005). Zusätzlich entsteht eine Verschlechterung der Muskelqualität durch die Infiltration von Fett und anderem nicht-kontraktionsfähigen Material wie z.B. Bindegewebe (Cree et al. 2004, Ryall et al. 2008).

Neben allen bedeutenden körperlichen Veränderungen, die mit dem Älterwerden assoziiert sind, ist die Sarkopenie eines der Hauptcharakteristika, die für die Gebrechlichkeit im Alter verantwortlich sind 
(Rolland et al. 2008). Sie kann bei älteren Menschen dazu führen, dass betroffene Individuen ihre körperliche Unabhängigkeit verlieren und dass ihr Risiko zu stürzen und sich dabei Frakturen zu zuziehen, steigt (Ryall et al. 2008, Szulc et al. 2005). Menschen, die im Alter an Sarkopenie leiden, haben auch einen niedrigeren BMD-Wert und ein erhöhtes Sturzrisiko (Janssen et al. 2002). In der Gruppe der postmenopausalen Frauen leiden 25\% der osteopenischen und etwa 50\% der osteoporotischen Frauen unter Sarkopenie, welches einen engen Zusammenhang zwischen Muskeln und Knochen als funktionelle Einheit aufzeigt. Eine Verbindung zwischen Sarkopenie und niedrigen BMD-Werten ist in zahlreichen Studien beschrieben worden (Gentil et al. 2007, Szulc et al. 2005, Rolland et al. 2008). Menschen, die durch Sarkopenie motorische Defizite oder Schwächen aufweisen, wie etwa das Aufstehen aus einem Stuhl und das längere Stehen, haben ein erhöhtes Fraktur-Risiko (Rolland et al. 2008). Als Studienmodell werden Ratten für die Erforschung der Sarkopenie verwendet. Carter et al. verwenden einen Rattenstamm (F344BN), der durch seine Gemeinsamkeiten zum Menschen in Bezug auf Lebensphasen, altersbedingte Veränderung der Körperkonstitution und nachlassender körperlicher Tätigkeit ein exzellentes Modell darstellt, um die Verbindungen zwischen Alter, Adipositas, Muskelqualität und körperlicher Aktivität zu untersuchen (Carter et al. 2012).

\subsection{Die Peri- und Postmenopause}

Als Menopause wird das Sistieren der Menstruation beschrieben, welche durch den Verlust der Ovarialfunktion hervorgerufen wird. Die Perimenopause beschreibt die Zeit direkt vor der Menopause, wenn die endokrinologischen, biologischen und klinischen Merkmale der sich nahenden Menopause eintreten sowie das erste Jahr nach der Menopause (Burger 1999). Der Zeitpunkt der Menopause wird retrospektiv nach einem Jahr der Amenorrhö festgelegt (Practice Committee of American Society for Reproductive Medicine 2008). Die Postmenopause wird als der Zeitraum beschrieben, dessen Beginn zwölf Monate nach der letzten Regelblutung eintritt und schließlich bis zum Tod andauert.

Zum Zeitpunkt der Geburt ist das weibliche Geschlecht mit einer begrenzten Anzahl an Oozyten ausgestattet. Im Laufe des Lebens nimmt diese Zahl individuell durch Atresie bzw. Ovulationen stetig ab (Practice Committee of American Society for Reproductive Medicine 2008). Zum Zeitpunkt der Menopause befinden sich nur wenige, wenn überhaupt noch, Follikel in den Ovarien (Burger 1999). Damit verbunden ist ein Erliegen der Östradiol- und Inhibinproduktion, welches ein Ausbleiben der Proliferation des Endometriums bedeutet. Letztendlich resultiert dies in einem Ausbleiben der Menses. (Breckwoldt 2001).

Ein dualer negativer Feedback-Mechanismus ermöglicht im Alter mit Beginn der Prämenopause die Aufrechterhaltung einer fortwährenden Östradiolsekretion trotz sinkender Follikelanzahl im Ovar. Inhibin B wird durch diesen zahlenmäßigen Rückgang vermindert produziert und sekretiert, was wiederum eine selektive erhöhte Ausschüttung von FSH nach sich zieht. Durch diesen Umstand wird 
trotz sinkender Follikelzahl für eine gesteigerte Produktion an Östradiol gesorgt (Burger et al. 2007). Viele Studien belegen, dass erhöhte FSH Spiegel bei Frauen im fortgeschrittenen biologischen Alter mit normalen bis zuweilen erhöhten $E_{2}$ Werten einhergehen (Burger et al. 2002). Dieser Kompensationsmechanismus des Körpers, der mit regelmäßigen Zyklen jedoch wiederholt Anovulationen aufweist, ist mit Annäherung an die Menopause zunehmend erschöpft. Die Östrogenbildung fällt schließlich merklich ab und es kommt zu einer deutlichen Zunahme der Gonadotropinausschüttung (Teschner und Hinrichsen 2005). Postmenopausal gibt es einen 10-15fachen Anstieg des FSH Serumlevels, einen 4-5fachen Anstieg des LH-Levels und einen mehr als $90 \%$ Rückgang des biologischen aktiven Östradiol (Burger 1999). Selbst nach dem Untergang der gonadalen Östrogenproduktion werden durch die extragonadale Östrogenproduktion noch messbare Östrogenspiegel auf einem konstanten niedrigen Level nachgewiesen (Sluijmer et al. 1995). Letztendlich sind alle Zielorgane der Östrogene durch den Mangel der gonadalen Östrogenproduktion im Klimakterium betroffen.

Die Mehrzahl an Informationen, auf denen wir unsere Erkenntnisse und Zusammenhänge bezüglich der Rolle des Gehirns im Alterungsprozess des Fortpflanzungssystems begründen, ist auf die Forschung an Nagetieren zurückzuführen (Downs und Wise 2009).

Es gibt auffallend viele Parallelen zwischen alternden weiblichen Ratten und prä- und perimenopausalen Frauen, was die Funktion des Hypothalamus, der Hypophyse und der Ovarien in der PostFortpflanzungsphase betrifft (Wise et al. 2002). Weibliche Ratten erreichen die Menopause im Alter zwischen 15 und 20 Monaten (600 Tagen) (Durbin et al. 1966). Dieser postmenopausale Zustand wird in der wissenschaftlichen Forschung auch künstlich durch die Ovx einer Ratte erzeugt.

Die erste Gemeinsamkeit zwischen weiblicher Ratte und Mensch ist zugleich auch das frühste Anzeichen der bevorstehenden Abnahme der reproduktiven Funktion, was sich in einer Erhöhung des FSH, besonders zum Zeitpunkt der Ovulation feststellen lässt (Klein et al. 1996). Die zweite Analogie betrifft das Intervall zwischen den Pulsen der LH Freisetzung sowie die eigentliche Pulsdauer von LH, die bei älteren Frauen mit regelhaften Zyklus verlängert ist (Matt et al. 1998), was parallel bei Ratten mittleren Alters ebenso der Fall ist (Scarbrough und Wise 1990). Als dritte Übereinstimmung variiert mit zunehmenden Alter die Zykluslänge (Fitzgerald et al. 1994). Die vierte Gemeinsamkeit bildet die Tatsache, dass prä- und perimenopausale Frauen normale oder gar erhöhte $\mathrm{E}_{2}$ Plasmakonzentrationen haben (Klein et al. 1996), so wie es vergleichend weibliche Ratten mittleren Alters haben, welche sich im Übergang zu unregelmäßigen Sexualzyklen befinden (Lu 1983). Außerdem ist die Fähigkeit von $\mathrm{E}_{2} \mathrm{GnRH} / \mathrm{LH}$ Anstiege auszulösen bei Ratte und Frau vermindert (Weiss et al. 2004).

Neben all diesen aufgezählten Gemeinsamkeiten, welche die Phase des Erlöschens der Fortpflanzungsfähigkeit bei Säugetieren betreffen, gibt es zwischen Ratte und Mensch jedoch auch Unterschiede.

Der negative Feedback-Mechanismus von $\mathrm{E}_{2}$ auf die Gonadotropine stellt eine dieser Ungleichheiten dar. Während bei postmenopausalen Frauen die Plasmalevel von $\mathrm{E}_{2}$ rapide fallen, das von den Ovarien 
nur noch rudimentär freigesetzt wird, werden LH und FSH uneingeschränkt freigesetzt und führen zu deutlich erhöhten Plasmakonzentrationen (Yen 1999). Konträr dazu bleibt die LH Plasmakonzentration relativ normal bei gealterten, azyklischen und wiederholt pseudoschwangeren Ratten (Lu 1983).

Eine weitere Diskrepanz zwischen Ratte und Mensch besteht in der Anzahl der Follikel am Ende der Fortpflanzungsfähigkeit. Während Frauen das mittlere Alter erreichen, nimmt der Abbau der Follikelanzahl im Ovar stetig zu, so dass am Ende der reproduktiven Phase der Frauen sich nahezu keine Follikel mehr in den Ovarien befinden (Richardson et al. 1987). Dahingegen konnte man bei alten, azyklischen Ratten noch Follikel in den Ovarien feststellen (Lu et al. 1979).

\subsection{Das metabolische Syndrom}

Frauen in ihrer Menopause erfahren einen Anstieg des Körpergewichtes und mit diesem verbunden eine Zunahme des prozentualen Fettanteils (Sowers et al. 2007). Die Definition, ob es sich bei einer Gewichtszunahme um Übergewicht oder Adipositas handelt, ist vom BMI abhängig. Ein BMI zwischen 25 und 29,9 beschreibt ein Übergewicht, wohingegen Werte von 30 oder größer einen Menschen beschreiben, der an Adipositas leidet (World Health Organization 2013).

Das Metabolische Syndrom ist laut der World Health Organization (WHO) dadurch charakterisiert, dass drei der folgenden fünf Faktoren gleichzeitig vorliegen: Adipositas, Diabetes mellitus Typ 2 mit Insulinresistenz, arterieller Bluthochdruck, Dyslipidämie und schließlich die koronare Herzerkrankung (Ford et al. 2002).

Bis ins Detail sind die vielfältigen, komplexen pathophysiologischen Mechanismen die zur Entstehung eines Metabolischen Syndroms führen noch nicht gänzlich erforscht (Miranda et al. 2005). Die Fettleibigkeit nimmt jedoch eine zentrale Rolle in der Pathophysiologie ein, welche schließlich zur Entwicklung der anderen Faktoren des Metabolischen Syndroms führt.

Der inflammatorische Zustand und die Dyslipidämie, die durch Adipositas erzeugt wird, erklärt die meisten Manifestationsformen des Metabolischen Syndroms, was die Fettleibigkeit zur wichtigsten verkettenden Komponente dieses Krankheitsbildes macht, obwohl diese Rolle ursprünglich dem Diabetes mellitus Typ 2 zugeschrieben wurde (Redinger 2008). Adipositas ist zudem der Hauptrisikofaktor für Morbidität und Mortalität und wird als vierthäufigste Todesursache weltweit aufgeführt (James et al 2004).

Eine der Ursachen für Adipositas im Alter bei Frauen ist bedingt durch die postmenopausal bestehende Hypoöstrogenität. Aus diesem Hang zur Fettleibigkeit entwickelt sich dann häufig ein Metabolisches Syndrom (Villa et al. 2008). Das Risiko ein Metabolisches Syndrom zu entwickeln, ist um 60\% erhöht (Carr 2003). Postmenopausale Frauen, egal welchen ethnischen Ursprungs, haben allesamt auch ein erhöhtes Risiko an Bluthochdruck und Kardiovaskulären Krankheiten zu erkranken (Reckelhoff und Fortepiani 2004). 
Die oben beschreibenden Komorbiditäten des Metabolischen Syndroms erhöhen zudem das Kardiovaskuläre Risiko und treten besonders bei peri- und postmenopausalen Frauen auf (Perez-Lopez et al. 2009). Die koronare Herzerkrankung ist immer noch die Haupttodesursache bei Männer und Frauen in Industrie- und Entwicklungsländern (Stevenson 2007), was die Bedeutung der Prävention einer Entstehung des Metabolischen Syndroms bei postmenopausalen Frauen unterstreicht.

Ovx Ratten entwickeln eine Hyperphagie und nehmen an Gewicht zu, wodurch sie eine positive Gesamtenergiebilanz auf Grund einer vermehrten Energieaufnahme erreichen (Latour et al. 1985).

Durch die ovx bedingte Gewichtszunahme (Adipositas), eine Zunahme des viszeralen Fettgewebes und eine entstehende Dyslipidämie durch Erhöhung der Plasmalevel von Triglyzerid und LDL (Saengsirisuwan et al. 2009) sind bereits zwei Hauptcharakteristika des Metabolischen Syndroms erfüllt. Ob die ovx bei Ratten zu einer gestörten Glukosetoleranz führt, wird kontrovers diskutiert. Es gibt Untersuchungen, die eine gestörte Glukosetoleranz nach Ovx nachgewiesen haben (Kumagai et al 1993), andere Forschungen stellten hingegen keine Änderung des Glukosestoffwechsel durch Ovx fest (Latour et al. 1985).

Auch in Bezug auf die Entwicklung von Bluthochdruck, ausgelöst durch ovx, besteht wissenschaftlich keine einheitliche Meinung. Einige Autoren sind der Ansicht, dass Östrogenmangel Bluthochdruck fördern könnte (Flues et al. 2010), wohingegen andere Autoren keine Verbindung zwischen Östrogenmangel und Bluthochdruck in ihren Ovx-Untersuchungen feststellen konnten (Tezini et al. 2013).

\subsection{Die Veränderungen des Fettgewebes durch die Menopause}

Durch den Rückgang der gonadalen Östrogenproduktion während der Menopause wird der Fettstoffwechsel der betreffenden Frauen negativ verändert. Die Plasmakonzentration des Gesamtcholesterol steigt an (Stevenson et al. 1993), der Anteil der Low Density Lipoprotein (LDL) und der Triglyzeride (TG) erhöht sich, während es zu einer Senkung des Anteils der High Density Lipoprotein (HDL) kommt (Kuh et al. 2005). Es wird kontrovers diskutiert, ob diese Verschiebung des Fettmetabolismus langfristig mit einem erhöhten Risiko für eine koronare Herzkrankheit (KHK) assoziiert ist (Expert Panel on Detection and Treatment of High Blood Cholesterol in Adults 2001). In Zusammenhang mit den einhergehenden beschriebenen Veränderungen des Fettstoffwechsels sei auch das Hormon Leptin erwähnt, welchem eine zentrale Rolle bei der Kontrolle des Körperenergiehaushaltes zukommt. Leptin wird durch das Fettgewebe sezerniert. Dabei ist die ausgeschüttete Menge in etwa proportional zur Menge des Fettgewebes. Leptin übermittelt somit den Sättigungsgrad der peripheren Energiespeicher ins Gehirn, wodurch das Verlangen nach Essen unterdrückt und ein gesteigerter Energieverbrauch gefördert wird (Villanueva und Myers 2008). Somit ist Leptin im entscheidenden Maße an der Regulation des Körpergewichtes beteiligt (Cammisotto et al. 2010). In der Abwesenheit von Leptin kommt es beim Menschen und beim Versuchstier Ratte zu einem unersättlichen Essverhalten, wobei der 
Energieverbrauch reduziert und die Speicherung der Energiereserven vorangetrieben wird (Montague et al. 1997, Villanueva und Myers 2008). Dem entgegen wirkt $E_{2}$ das durch seinen lipolytischen Effekt und die östrogenbedingte verminderte Nahrungsaufnahme ein sinkendes Körpergewicht und einen erniedrigten BMI zur Folge hat. Hieraus resultiert ein Abfall des Serumleptin-Levels (SeidlovàWuttke et al. 2003 a). Durch Erliegen der gonadalen Östrogenproduktion während der Menopause sinkt im Umkehrschluss der lipolytische Effekt und es resultiert ein Anstieg des BMI.

Untersuchungen haben auch an Nagetieren gezeigt, dass eine Ovx die Lipolyse im Fettgewebe verringert, und dass die Behandlung mit Östrogenen diesem Effekt entgegen wirkt, indem die Fettsäuresynthese verringert und die Lipolyse erhöht werden (Hansen et al. 1980). Dies ist ein weiterer Hinweis auf den direkten Einfluss von Östrogenen auf Adipozyten (Abeles et al. 2012).

Es ist wissenschaftlich belegt, dass die Ovx von Ratten zu einer gesteigerten Nahrungsaufnahme und einer Gewichtszunahme führen. Die Behandlung mit $\mathrm{E}_{2}$ hebt diese Auswirkungen wieder auf (Laudenslager et al. 1980).

Östrogene regulieren Adipozyten, dazu gehören die Adipozyten von Nagetieren wie auch die von Menschen, welche beide nachweislich ERs exprimieren (Dieudonne et al. 2004, Pedersen et al. 2001). Die Aufhebung des östrogenen Einflusses durch Ovx verursacht Fettleibigkeit (Christoffel et al. 2006, Seidlovà-Wuttke et al. 2003 b). Dieser Effekt ist ER $\alpha$-vermittelt, da Untersuchungen an weiblichen $\alpha$ ERKO Mäusen nachweisen konnten, dass es zu einer Vergrößerung der Fettspeicher kommt, ähnlich den Veränderungen, wie sie bei ovx Versuchstieren beobachtet werden können. Sexuell ausgereifte BERKO-Mäuse beider Geschlechter wiesen keine signifikanten Unterschiede in puncto Körpergewicht und intraabdominale Verteilung des Fettgewebes auf. $\alpha$ ERKO und nicht BERKO-Mäuse sind adipös (Korach et al. 1996). Daraus lässt sich schließen, dass die östrogene Wirkung auf die Stoffwechselvorgänge des Fettgewebes durch den ER $\alpha$ vermittelt wird (Couse und Korach 1999).

Die Substitution von ER $\alpha$ Agonisten verhindert die Entwicklung von Fettleibigkeit bei ovx Ratten, wohingegen ER $\beta$ Agonisten keine präventive Wirkung zeigen (Harris et al. 2002).

\subsection{Hormonersatztherapie}

Die Hormonersatztherapie (HRT) ist ein allgemeiner Begriff, der die Applikation von verschiedenen Sexualhormonen beinhaltet, vornehmlich Östrogene und Progesteron allein oder in Kombination sowie deren mögliche unterschiedliche Applikationsformen. Sie wird bei Frauen mit klimakterischen Beschwerden eingesetzt und soll deren Symptome lindern und die Lebensqualität verbessern (Stevenson 2004). Im Laufe der 90er Jahre wurde aufgrund erster positiver klinischer Erfahrung z.B die Steigerung des Wohlbefindens und Leistungsvermögens, das Erreichen der völligen Symptomfreiheit sowie das Erzielen von kosmetischen Effekten an der Haut, die Indikation zur HRT mit Östroge- 
nen und Gestagenen in der Perimenopause relativ großzügig gestellt (Teschner und Hinrichsen 2005). Über Jahrzehnte war die HRT die Therapie der Wahl, wenn es um die Behandlung von menopausalen Beschwerden sowie um die Langzeitprävention von postmenopausaler Osteoporose ging (Palacios 2008). Zu einem Umdenken in der HRT Behandlung kam es schließlich durch die Ergebnisse der „Women Health Initiative (WHI)“ (Rossouw et al. 2002) und der „Million Women Study“ (Beral 2003). Das Risiko-Nutzen-Verhältnis verschob sich, da durch die Studien ein erhöhtes Risiko für Brustkrebs, Schlaganfälle und venöse Thromboembolien bei Frauen unter langfristiger Hormonersatztherapie nachgewiesen wurden. Demgegenüber wurde ein vermindertes Risiko von osteoporotischen Frakturen und Colonkrebs festgestellt. Für den klinischen Alltag bedeutete dieses Wissen eine deutlich strengere Indikationsstellung für HRT. Die potentiellen Vorteile einer Hormonersatztherapie müssen immer gegen die möglichen Risiken dieser Therapie für jede einzelne Frau individuell abgewogen werden (Martin und Manson 2008). Schlüsselkriterien für die richtige HRT sind die Dosis der verabreichten Hormone (Crandall 2003) und der Zeitpunkt des Beginns der Therapie sowie deren Dauer. Bei Frauen, die sich in der Prämenopause befinden, kann eine HRT das Risiko für eine koronare Herzerkrankung senken, wohingegen dieselbe Therapie bei einer Frau in der Postmenopause das Risiko erhöhen würde. Die Effektivität von HRT in Bezug auf die Verbesserung der vasomotorischen Symptome postmenopausaler Frauen steht trotz des Rückgangs dieser Therapieform in den letzten Jahren nicht zur Diskussion. Es gibt kein Argument gegen die Wirksamkeit und Überlegenheit von Östrogenpräparaten bei der Behandlung von menopausalen Symptomen (Palacios 2008). Unter anderem mildert die HRT die Folgen des Östrogenmangels in Bezug auf Hypercholesterinämie (Zengura et al. 2006), koronare Herzerkrankung (Collins et al. 2006) und senkt das Risiko, Typ II-Diabetes mellitus zu entwickeln (Skouby et al. 2005).

\subsection{SERM (Selective Estrogen Receptor Modulator)}

Über die letzten Jahrzehnte wurde nach einer Lösung für den unter Östrogenwirkung entstehenden Brustkrebs gesucht, denn die Mehrheit der Brustkrebstumore sind ER-positiv und reagieren positiv auf Antagonismus von Östrogenen (Wakeling und Valcaccia 1983). Ergebnis dieser Forschung waren die Pharmazeutika Tamoxifen und Raloxifen, die der östrogenen Wirkung an der Brust entgegenwirken (Draper und Chin 2003). Ursprünglich noch als „Antiöstrogene“ bezeichnet, wurden sie später im Verlauf als SERM definiert, denn die beiden Agenzien lösen nicht nur antiöstrogene Effekte an der Brust und im ZNS aus, sondern auch östrogenartige Wirkungen am Knochen, der Leber und im HerzKreislaufsystem. Als SERM bezeichnet man somit eine chemische Verbindung, welche nicht dem chemischen Grundgerüst von Östrogenen gleicht, die jedoch eine hohe Affinität und Selektivität gegenüber ER zeigen, ohne eine signifikante Bindungsaktivität zu einem anderen nukleären Rezeptor aufzuweisen. SERM erzeugen durch ihre Verbindung mit einem ER selektiv östrogenartige Effekte in 
manchen Geweben des Körpers, jedoch führen sie zu antiöstrogenen Wirkungen in anderen Geweben (Shelly et al. 2008). Charakteristisch für SERM ist somit, gleichzeitig Agonist und Antagonist für ER zu sein, abhängig vom Zielgewebe. SERM haben ihren Nutzen in der Behandlung oder der Prävention von Brustkrebs in der Vergangenheit unter Beweis gestellt (Cauley et al. 2001). Trotz der Leistungsfähigkeit in Bezug auf die Blockierung der Östrogenwirkung auf die Brust ist der bedeutende Nachteil, dass durch östrogene Wirkung am Uterus durch z.B Tamoxifen es zu einer Proliferation des Endometriums kommt und damit das Risiko für die Entstehung von Krebs in einer anderen Körperregion erhöht wird (Katzenellenbogen und Katzenellenbogen 2002). Somit ist Tamoxifen zwar für die präventive Therapie gegen Brustkrebs zugelassen, jedoch darf es nur über einen begrenzten Zeitraum appliziert werden, da mit zunehmender Therapiedauer das Risiko, an Endometrium-Krebs zu erkranken, signifikant erhöht ist (Gal et al. 1994).

Der Unterschied zwischen SERM und den in unserer Untersuchung verwendeten rezeptorspezifischen Agonisten ER $\alpha 16 \alpha-\mathrm{LE}_{2}$ (3,17-dihydroxy-19-nor-17 $\alpha$-pregna-1,3,5(10)-triene-21,16 $\alpha$-lacton) und ER $\beta$ 8 $\beta$-VES (8-vinylestra-1,3,5(10)-triene-3,17 $\beta$-diol) ist, dass diese unabhängig vom Gewebetyp ihre agonistischen Auswirkung an ihrem spezifischen ER auslösen.

\subsection{Die verwendeten Testsubstanzen}

Im Hinblick auf die große Vielfalt von menopausalen Symptomen und postmenopausalen Beschwerden sind Informationen über die verschiedenen gewebespezifischen Wirkungen, welche von Östrogenen über ER $\alpha$ und ER $\beta$ vermittelt werden, noch sehr begrenzt. Neben den Daten, die durch Untersuchungen an Knockout-Mäusen gewonnen wurden, bietet der Einsatz von isotypischen-selektiven ERLiganden eine Alternative, um die biologische Funktion von ERs zu untersuchen (Hertrampf et al. 2008). Über die Anwendung von selektiven ER-Liganden an Versuchstieren lassen sich weitere Erkenntnisse über die pharmakologischen Auswirkungen gewinnen. Im Gegensatz zu Knockout Versuchstieren, bei denen die spezifische Rezeptorfunktion gänzlich verhindert wird, besteht durch die Anwendung von potenten isotypischen steroidalen ER Liganden die Möglichkeit, Liganden-abhängige Funktionen der beiden ERs und vor allem ihre Interaktion zu untersuchen (Hillisch et al. 2004). Östrogenrezeptoren sind aus drei Hauptdomänen aufgebaut (siehe 1.7): der A/B-Domäne, der DNABindungsdomäne und die LBD. Verschiedene Merkmale unterscheiden sich bei ER $\alpha$ und ER $\beta$, welche bedeutend für die Entwicklung von spezifischen, isotypischen ER-Agonisten sind. 


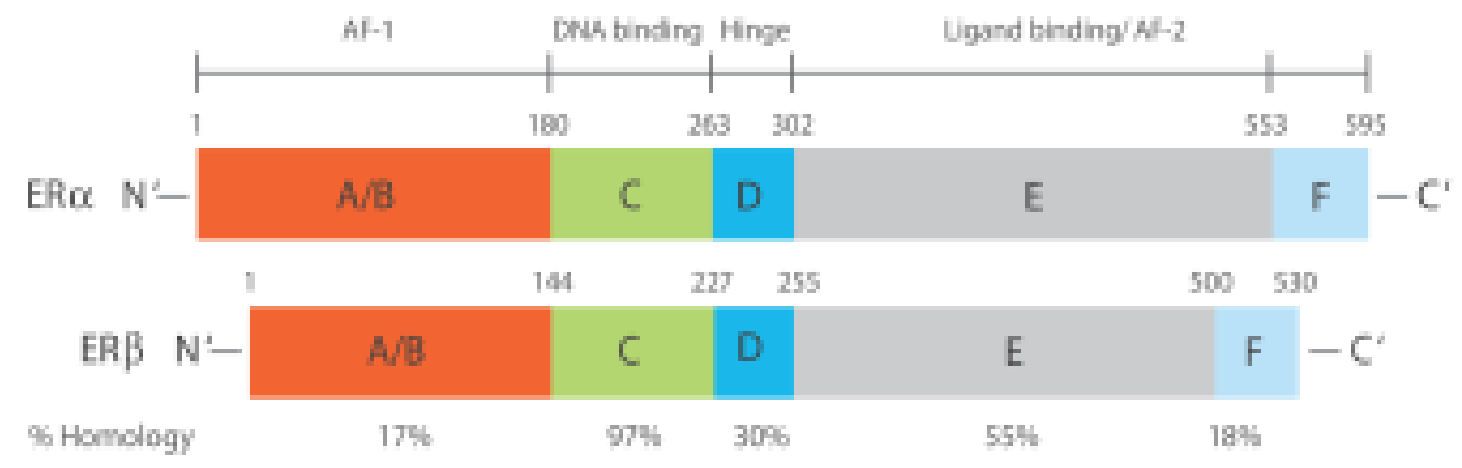

\begin{abstract}
Abb. 1.1 Vergleich zwischen der Struktur und Homologie von ER $\alpha$ und ER $\beta$. Menschlicher ER $\alpha$ enthält 595 Aminosäuren wohingegen ER $\beta 530$ Aminosäuren enthält. Die DNA-Bindungsdomäne ist annähernd identisch, wohingegen die A/B-Domäne und die LBD, welche AF-1 und AF-2 enthalten, die wenigste Homologie aufweisen (Litman et al. 2010)
\end{abstract}

Einen Ansatzpunkt bieten die Aktivierungsfunktionen (AF-1 und AF-2), welche für die Regulation der Gentranskription verantwortlich sind und sich im Vergleich der beiden ERs in den am wenigsten homologen Regionen befinden. Die A/B-Domäne hat nur eine 17\% - Übereinstimmung wohingegen die LBD, die AF-2 beinhaltet, eine im Verglich noch höhere Homologie bietet (siehe Abb. 1.1).

Ein weiterer Ansatzpunkt ist die Größe der Bindungstasche zwischen ER $\alpha$ und ER $\beta$ für Liganden. Diese ist unterschiedlich, was die strukturelle Grundlage bietet, spezielle Liganden zu entwickeln, die auf diese Weise selektiv an einem der ER binden können. Die Bindungstasche von ER $\beta$ hat ein kleineres Volumen als die von ER $\alpha$ und weist zudem noch kleinere Unterschiede bezüglich der Form auf. Die jedoch noch immer hohe Ähnlichkeit der Bindungstasche zwischen ER $\alpha$ und ER $\beta$ in Bezug auf Aminosäuresequenz, Größe und Form macht die Entwicklung von spezifischen Liganden zu einer Herausforderung (Leitman et al. 2010).

Die Arbeitsgruppe um Hillisch et al. entwickelte auf Basis der Proteinstruktur der LBD des ER $\alpha$ in Verbindung mit $\mathrm{E}_{2}$ ein homologes Modell für ER $\beta$. Im Vergleich der Abfolge der Aminosäuresequenz der LBD zwischen ER $\alpha$ und ER $\beta$ wird eine 59\% - Übereinstimmung mit nur zwei gelöschten Aminosäuren in der „Loop Region“ von ER $\beta$ festgestellt. Für das Homologie-Modell von ER $\beta$ wurden die beiden nicht identischen Aminosäuren ersetzt und die Proteinstruktur im Bereich der Deletionen modifiziert. Im nächsten Schritt wurde auf Basis des Homologie-Modells $\mathrm{E}_{2}$ für den ER $\alpha$ Agonisten an Position $16 \alpha$ und $17 \alpha$ durch chemische Synthese verändert. Durch diese Modifizie- 
rung wurde ein selektiver Substituent für die LBD des ER $\alpha$ geschaffen. Analog dazu wurde ebenfalls auf Basis der chemischen Strukturformel des $\mathrm{E}_{2}$ die Position $8 \beta$ durch chemische Synthese erweitert (siehe Abb. 1.2).

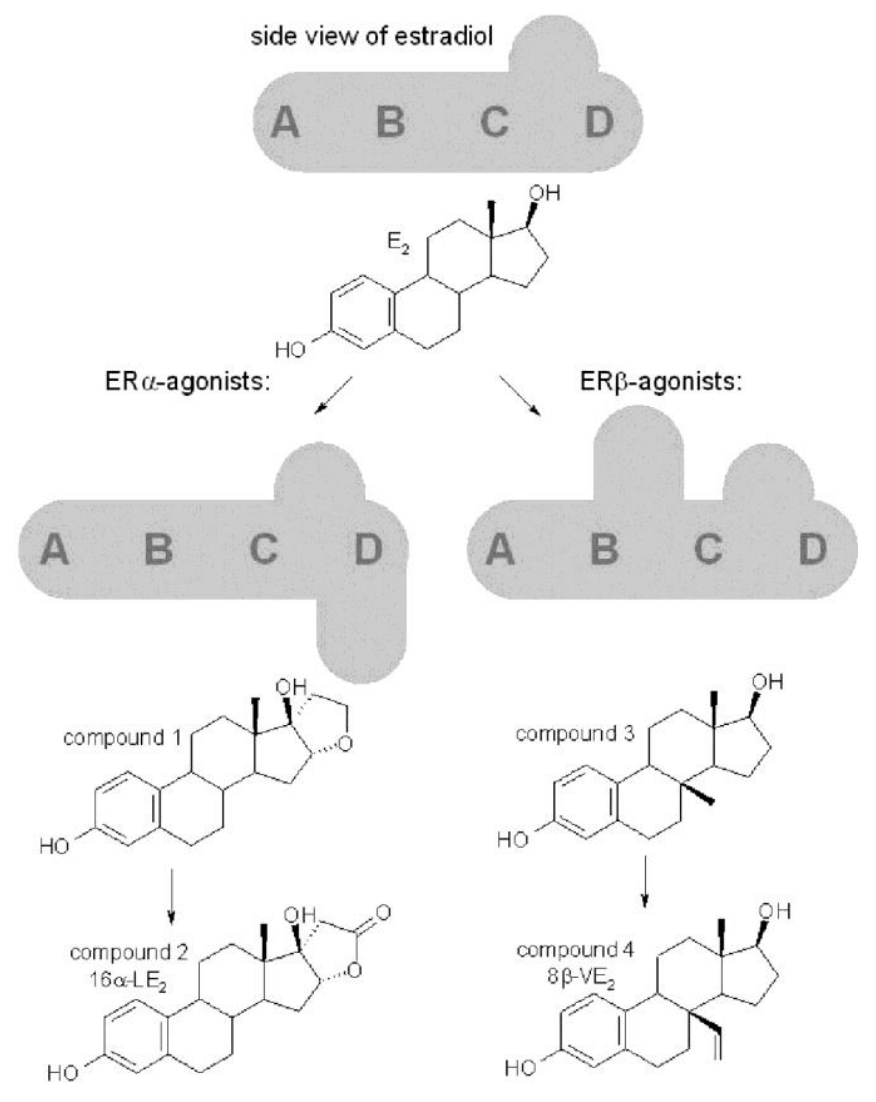

\begin{abstract}
Abb. 1.2 Synthesestrategie für die Identifikation von ER-Isotyp-Selektiven Agonisten. Eine schematische Darstellung der Seitansicht von Steroiden mit der dazugehörigen Nummerierung der Steroidringe. Das Volumen oberhalb des C- und D-Ringes korrespondiert mit der 18-Methyl-Gruppe von E2. Große Substitutionen unterhalb des D-Ringes richten sich zu einem ER $\alpha$-Agonisten wohingegen die lipophile Substitution oberhalb des B- und C-Ringes einen ER $\beta$-Agonisten entstehen lässt (Hillisch et al. 2004).
\end{abstract}

Durch diesen zusätzlich geschaffenen lipophilen Platz werden die geringen Unterschiede der Bindungstaschen des ER $\alpha$ und $\beta$ zu Gunsten des ER $\beta$ ausgenutzt. Für die genaue chemische Synthese und Modifikation von $\mathrm{E}_{2} \mathrm{zu}$ den beiden ER-Agonisten wird auf die Arbeiten von Peters et al. 2000 und Fritzemeier et al. 2000 verwiesen.

Die für unsere Untersuchung verwendeten isotypisch-selektiven steroidalen ER-Agonisten ER $\alpha 16 \alpha-$ $\mathrm{LE}_{2}$ und ER $\beta$ 8 $\beta$-VES stimulieren nach Applikation mit einer vergleichsweisen hohen Selektivität jeweils direkt ihren ER Subtyp mit der gleichen Potenz, wie es $E_{2}$ vermag und sind somit exzellent 
dafür geeignet, Untersuchungen über die Funktion von ER $\alpha$ und $\beta$ durchzuführen. Weiter sind beide ER-Agonisten, begründet durch ihre Synthese, sehr enge chemische, steroidale Analoga von $\mathrm{E}_{2}$ (nur zwei bis vier zusätzliche Kohlenstoff- / Sauerstoff-Atome) und verringern durch diese strukturelle chemische Ähnlichkeit zu $\mathrm{E}_{2}$ die Wahrscheinlichkeit einer komplett anderweitigen biologischen Wirkung an einem anderen Rezeptor oder Enzym.

Aufbauend auf dem Wissen, dass ER $\alpha$ der dominante ER im Uterusgewebe ist und der ER $\beta$ hohe Expressionslevel im Prostatagewebe aufweist, wurden Rezeptor-Bindungs-Untersuchungen mit den spezifischen ER Agonisten $\alpha$ und $\beta$ in diesen Geweben unternommen. Die in vivo Untersuchungen mit den isotypischen-selektiven steroidalen ER Agonisten ER $\alpha 16 \alpha-\mathrm{LE}_{2}$ und ER $\beta$ 8 $\beta$-VES stehen in Übereinstimmung mit den Erwartungen, welche auf Grund der gewebsspezifischen Verteilung von ER $\alpha$ und $\beta$ beziehungsweise zu den ER Knockout Phänotypen bestanden. Organe, welche vornehmlich ER $\alpha$ exprimieren wie Uterus, Hypophyse und Leber konnten mit $E_{2}$ und ER $\alpha$-Agonisten stimuliert werden, hingegen nicht (oder nur in sehr hoher Dosis) mit ER $\beta$-Agonisten. Bei einer solch hohen verwendeten Dosis wird vermutlich die residuale ER $\alpha$ Aktivität vom ER $\beta$-Agonisten für die entstandenen Effekte verantwortlich gemacht.

Die In-vitro- und In-vivo-Studien der ER-Agonisten ER $\alpha 16 \alpha-\mathrm{LE}_{2}$ und ER $\beta$ 8 $\beta$-VES zeigten korrelierende Ergebnisse bezüglich der ER Affinität und Agonisten Wirkung. Zudem wurde durch Transaktivierungsassays eine 250fache ER $\alpha$ Selektivität für den ER $\alpha 16 \alpha-\mathrm{LE}_{2}$ Agonisten und eine 183fache Selektivität für ER $\beta$ 8 $\beta$-VES Agonisten zu seinem ER $\beta$ nachgewiesen (Hillisch et al. 2004).

\subsection{Das Tiermodell}

Das Versuchstier Ratte ist ein unvermeidlicher und heutzutage notwendiger Teil der medizinischen Forschung. Sie nimmt die Stelle des Menschen als Versuchsobjekt in der wissenschaftlichen Forschung ein. Es ist schwierig zu schätzen, wie viele Tiere jedes Jahr für wissenschaftliche Zwecke benutzt werden. Schätzungen gehen davon aus, dass es im Jahr mehrere Millionen Tiere weltweit sind. Allein in den USA sollen es jährlich 15 Millionen, in Europa 11 Millionen und in Japan 5 Millionen Tiere sein. $80 \%$ dieser Tiere sind Nagetiere. Wistar- und Sprague-Dawley-Ratten sind die am meisten verwendeten Versuchstiere weltweit. Besondere Sorgfalt besteht bei dem Unterfangen, die Lebensphasen einer weiblichen Ratte, zeitlich mit den Lebensphasen des Menschen zu vergleichen. Wie viele Tage im Leben einer Ratte entsprechen einem menschlichen Jahr?

Dies ist davon abhängig, in welcher Lebensphase sich eine Ratte befindet. Im Durchschnitt haben Ratten eine Gesamtlebenszeit von 3 Jahren, was auf ein Menschenleben von durchschnittlich 80 Jahren Lebenszeit berechnet bedeutet, dass 13,8 Tage einer Ratte einem menschlichen Jahr gleichzusetzen sind. Die Menopause erreichen weibliche Ratten im Alter von 15-20 Monaten. Verglichen mit der 
Zeitspanne des Menschen bis zum Eintreten der Menopause entspricht ein Menschenjahr 11,8 Rattentagen. Ratten leben durchschnittlich noch 485 Tage nach Erreichen der Menopause. Das bedeutet auf die Lebenszeit des Menschen übertragen, dass 17,1 Tage im Leben einer Ratte einem menschlichen Jahr nach der Menopause gleichzusetzen sind (Sengupta 2013).

Ovarektomierte Versuchstiere wie die ovx Ratte stellen ein in der Wissenschaft häufig verwendetes Modell zur Untersuchung von Fragestellungen in Bezug auf Östrogenmangel dar (Saengsirisuwan et al. 2009). Durch die Entfernung der Ovarien entsprechen die Versuchstiere in ihrem klinischen Erscheinungsbild, dem von Frauen in bzw. nach der Menopause (Sitnick et al. 2006). Das physiologische Erlöschen der Ovarialfunktion im Alter der Frau wird somit künstlich chirurgisch durch die Ovarektomie (Ovx) bei der Ratte herbeigefügt. Die ovx Ratte stellt ein exzellentes wissenschaftliches Tiermodell dar, welches die klinischen Funktionen und phänotypischen Merkmale eines Östrogenerschöpften Organismus nachahmt und seine Reaktion auf pharmakologische Therapeutika widerspiegeln kann (Torricelli et al. 2004). Durch die Tatsache, dass dieses Tiermodel schon seit vielen Jahren in der wissenschaftlichen Forschung Verwendung findet, sind die Stoffwechselvorgänge und die mit ihr eintretenden morphologischen Veränderung der Tiere, bereits genau erforscht. Es ist wissenschaftlich erwiesen, dass die Ovx einen Anstieg des täglichen Energieverbrauches, der Körper- und Fettmasse verursacht (Saengsirisuwan et al. 2009). Die Substitution der ovx Tiere mit Östrogenen verringert die Zunahme des Fettgewebes und verbessert das Fettstoffwechsel Profil (Shinoda et al. 2002).

\subsection{Der Versuchsablauf}

102 Versuchstiere wurden in 9 Gruppen aufgeteilt und über einen Versuchszeitraum von 4 Wochen therapiert (siehe 2.7). Die Applikation der Substanzen erfolgte nach einem genau festgelegten Schema (siehe Tabelle 2.1) in isolierter, kontinuierlicher simultaner und zeitversetzter simultaner Gabe der ERAgonisten und $\mathrm{E}_{2}$. Den physiologischen Vergleich bildete eine intakte sham-ovx Gruppe, welche nur eine Schein-OP und regelmäßige Placebo Injektionen erfuhr. Weitere Kontrollgruppen bildeten die durchgehend mit $\mathrm{E}_{2}$ therapierten Tiere und die ovx Tiere ohne jegliche Therapie während des gesamten Versuchszeitraums.

Die quantitative Auswertung des Fett- und Muskelgewebes erfolgte mittels pqCT. Hierfür wurden CT-Schnitte des Abdomens in Höhe von LWK 4 / 5 vor ovx und nach Beendigung der vierwöchigen Therapie durchgeführt.

Der Skelettmuskel wurde zusätzlich histomorphometrisch aufgearbeitet und untersucht. Darüber hinaus wurden die Serumparameter Cholesterin, HDL, LDL, Triglyzeride, IGF und Glukose ausgewertet. 


\subsection{Ziel der Arbeit}

Ein viel verwendetes Mittel zur Bekämpfung der durch den Östrogenrückgang hervorgerufenen klimakterischen Symptome stellt die pharmakologische hormonelle Substitution von Sexualhormonen dar (HRT). Durch den Nachweis, dass mit dieser Form der Therapie auf Dauer das Risiko für die Patientinnen, an Brustkrebs, Schlaganfällen und Thromboembolien zu erkranken, steigt, wurde der Wunsch nach alternativen, sicheren Therapieoptionen geboren. Die Entdeckung der Selektiven Estrogen Receptor Modulator (SERM) ermöglichte zwar die östrogene Wirkung in spezifischen Zielorganen zu erreichen, jedoch wurden damit gleichzeitig antiöstrogene Wirkungen in einem anderen Gewebe des Körpers in Kauf genommen. Die Entdeckung, dass Östrogene ihre Wirkung an Zielorganen über zwei verschiedene ER auslösen, nämlich ER $\alpha$ und $\beta$, eröffnete der Wissenschaft die Möglichkeit, gezielt künstliche, selektive Agonisten für diese beiden Rezeptoren zu entwickeln, um so zu erforschen, welcher Rezeptor in welchem Gewebe für die östrogenen Wirkungen Verantwortung trägt. Das Ziel, nur die positiven Eigenschaften einer Östrogen-Therapie zu erreichen, aber gleichzeitig die negativen Aspekte in anderen Geweben vermeiden zu können ist bis dato noch nicht erreicht.

Der Nachweis, dass die beiden Östrogen Rezeptoren Subtypen ER $\alpha$ und ER $\beta$ im Fettgewebe (Pedersen et al. 2001) und im Skelettmuskel (Lemoine et al. 2003; Wiik et al. 2003) von Menschen exprimiert werden, eröffnete gleichzeitig die Frage, inwieweit die Substitution von $E_{2}$, ER $\alpha$ und ER $\beta$-Agonisten Einfluss auf diese Gewebetypen nehmen würde.

In der hier vorliegenden Arbeit wurde durch einen In-vivo Versuch mit ovx Ratten untersucht, ob die Verwendung der beiden spezifischen ER $\alpha 16 \alpha-\mathrm{LE}_{2}$ und ER $\beta$ 8 $\beta$-VES-Agonisten Auswirkungen auf das Skelettmuskel- und Fettgewebe sowie bestimmte Serumparameter hat. Inwieweit können Veränderungen der Gewebe durch die isolierte Gabe eines ER Agonisten im Vergleich zu $\mathrm{E}_{2}$ erreicht werden? Wie wirkt sich die Kombination des ER $\alpha$ und ER $\beta$-Agonisten in Kombination auf die untersuchten Gewebetypen der ovx Ratte aus? Besteht ein Unterschied in der simultanen und der zeitversetzten Applikation der ER Agonisten?

Ist der ER $\beta$-Agonisten ein Inhibitor für die Wirkung des ER $\alpha$-Agonisten in Bezug auf das Fett- und Muskelgewebe der ovx Ratte? Beeinflusst die alleinige Vorbehandlung mit dem ER $\alpha$-Agonisten oder $\mathrm{E}_{2}$ die Wirkung des ER $\beta$-Agonisten? Besteht eine Ying-Yang Beziehung zwischen beiden ERAgonisten? 


\section{Material und Methoden}

\subsection{Die Versuchstiere und ihre Haltung}

Von der Bezirksregierung Braunschweig lag für alle durchgeführten Tierexperimente - gemäß der gesetzlichen Bestimmung - eine Genehmigung vor: Az 509.42502-01-36.03 (13.10.200331.10.2006).

Alle Versuche wurden unter der Anleitung und Aufsicht von PD Dr. D. Seidlovà-Wuttke in der Tierexperimentellen Abteilung des Klinikums der Georg-August-Universität in Göttingen durchgeführt.

Die Versuchstiere bestanden aus 102 adulten, weiblichen Sprague-Dawley Ratten (Firma Winkelmann, Borchen) im Alter von 3 Monaten, die im Tierstall des Universitätsklinikums Göttingen untergebracht wurden.

Ihre Haltung erfolgte zu je 6 Tieren pro Käfig (Makrolonkäfig Typ 4, Firma Tecniplast Deutschland $\mathrm{GmbH}$ ). In dem für sie separaten Aufbewahrungsraum herrschte eine konstante Raumtemperatur von $20-22^{\circ} \mathrm{C}$. Die Luftfeuchtigkeit der Räumlichkeiten befand sich zwischen 60-85\% und wurde über ein Thermo-Hydrometer stetig kontrolliert. Per Zeitschaltuhr gesteuert fand eine tägliche Beleuchtung von 12 Stunden statt, die einen regelmäßigen Hell-Dunkel-Rhythmus der Versuchstiere garantierte. Ein fest bestimmter Personenkreis war mit der Aufgabe der Betreuung und Versorgung der Tiere während des Versuchszeitraumes betraut worden, und nur diesen Personen war der Zutritt zum Aufbewahrungsraum gestattet.

Das Ziel all dieser Vorkehrungen war es, so viele Stressfaktoren wie möglich von den Versuchstieren fernzuhalten.

\subsection{Die Nahrung}

Alle Tiere bekamen sojafreies Pelletfutter (ssniff® R-Z phytoöstrogenarm, V 1355, Soest, Germany). Die Fütterung erfolgte über die Raufen der Käfige, welche regelmäßig aufgefüllt wurden und so den Sprague-Dawley Ratten ad libitum zur Verfügung standen. Die ständige Versorgung mit Trinkwasser wurde den Tieren über die Wasserspender der Käfige ermöglicht.

\subsection{Die Identifizierung der Versuchstiere}

Damit es während des Versuchsablaufes zu keinen Verwechslungen zwischen einzelnen Tieren kommen konnte, wurden alle 102 Versuchstiere während der ersten Narkose mit einem Transponderchip versehen. Dieser Chip - mit einer Länge von $12 \mathrm{~mm}$ - wurde subkutan in die Nackenhaut eines jeden 
Tieres implantiert (Transponder-UNO MICRO-ID-System mit ISO-Transponder (Uno-Roesvastaal BV, Zevenaar, Holland).

Die individuelle Chip-Identifikationsnummer wurde mit Hilfe eines externen Lesegerätes ermittelt (Gesreader II Ge S008: ISO kompatibler Taschenleser).

Dadurch war eine zweifelsfreie Identifizierung der Versuchstiere zu jedem Zeitpunkt gewährleistet und Verwechslungen gänzlich ausgeschlossen.

\subsection{Die Narkose}

Zum Zwecke der Implantation der Identifikationschips, der Ovx sowie der optimalen Durchführung der diagnostischen Computertomographie wurden die Versuchstiere zu Beginn und zum Abschluss der Studie jeweils einer Inhalationsnarkose mittels Isofluran Gas (Forene ${ }^{\circledR}$, Firma Abbott) unterzogen. Hierzu wurde ein Kleintiernarkosegerät in Kombination mit einem Flow-Meter (Firma UNO, Zevenaar/Holland) verwendet. Die volatile Narkose wurde mit Hilfe einer Mund-Nasen-Maske induziert, die sich während des gesamten Narkosezeitraums über den Atmungsöffnungen der Ratte befand. Durch Kontrolle des Flow-Meters sowie der beigemischten Sauerstoffkonzentration konnte für jedes Tier eine individuell angepasste Narkosetiefe erreicht werden.

\subsection{Die Gewichtsbestimmung}

Die erste Gewichtsbestimmung der Versuchstiere erfolgte nach einer Akklimatisierungsphase von 7 Tagen. Das durchschnittliche Gewicht lag zu diesem Zeitpunkt bei 239 +/- 0,99 Gramm (g). Weitere Gewichtsbestimmungen wurden zum Zeitpunkt der Ovx sowie jeweils in Woche 1, Woche 3 und zum Abschluss der Studie durchgeführt (Waage basis lite BL3, Sartorius).

\subsection{Die Ovarektomie (Ovx)}

Um bei den Versuchstieren den Zustand einer künstlichen Menopause herzustellen, wurden die Ratten der Gruppen 1-8 (siehe Tabelle 2.1) unter den in 2.4 beschriebenen Narkosebedingungen ovarektomiert, was gleichzeitig den Start der Studie (Tag 1) bedeutete. Bei diesem chirurgischen Eingriff erfolgte eine Hautinzision von $2 \mathrm{~cm}$ Länge entlang des distalen Abschnittes des Rippenbogens, die Durchtrennung der darunter liegenden Fett- und Muskelschichten sowie die Inzision des Peritoneums mit Eröffnung des Cavum abdominis. Nach einer Inspektion des Situs mit Lokalisation des Ovars, der anliegenden Tube und des Uterus wurde die Tube mit resorbierbarem Nahtmaterial legiert und das Ovar mit einem Skalpell exzidiert. Derselbe Eingriff wurde dann für die kontralaterale Seite durchge- 
führt. Während des gesamten Zeitraums der OP wurde fortwährend auf eventuelle Blutungsquellen geachtet. Nach Ausschluss von Blutungen wurde das Peritoneum, die durchtrennten Muskelschichten und abschließend die Haut mit sterilem Nahtmaterial verschlossen. Zur zusätzlichen Sicherung erfolgte eine zusätzliche Klammerung der Hautinzision. Während der postoperativen Aufwachphase standen die operierten Tiere unter ständiger Beobachtung. Die Ovx wurde von PD Dr. D. SeidlovàWuttke und weiteren erfahrenen wissenschaftlichen Mitarbeitern der Abteilung durchgeführt.

\subsection{Gruppeneinteilung und Injektionsplan}

Die 102 Sprague-Dawley Ratten wurden nach der Akklimatisierungsphase von 7 Tagen in 8 Gruppen zu je 12 Tieren und 1 Gruppe mit 6 Tieren aufgeteilt. Die 96 Tiere der Gruppen à 12 Tiere wurden an Tag 1 der Studie unter Isofluran Narkose ovx und auf der Basis des Körpergewichtes randomisiert. Parallel dazu wurde eine Gruppe sham operiert (sham-ovx), die somit die physiologische Vergleichsgruppe bildete. Alle Tiere erhielten ab Tag 2 für die Dauer von 4 Wochen, je nach Gruppeneinteilung ein bestimmtes Substrat bzw. eine bestimmte Kombination von Substraten in einem durchgehenden oder in einem additiven Rhythmus, täglich 0,2 ml/Tier subkutan appliziert. Die Tabelle 2.1 gibt eine Übersicht der Gruppeneinteilung und der für jede Gruppe spezifischen Applikation der Testsubstanzen, ihrer unterschiedlichen Kombinationen und der wechselnden Applikationsrhythmen wieder. 
Tab. 2.1. Gruppeneinteilung und Injektionsplan

\begin{tabular}{|c|c|c|c|c|}
\hline Gruppe & Substanz & Konzentration & $\begin{array}{c}\text { Injektions- } \\
\text { art + Intervall }\end{array}$ & Zeitraum \\
\hline 1 & $\mathrm{ovx}+\mathrm{SF}$ & 0,2 ml/Tier Benzylbenzoat/Rizinusöl,1/4 & s.c. täglich & $4 \mathrm{Wo}$ \\
\hline 2 & $o v x+E_{2}$ & $\begin{array}{l}1 \mu \mathrm{g} \mathrm{E}_{2} / \text { Tier in } 0,2 \mathrm{ml} \\
\text { gelöst in Benzylbenzoat/Rizinusöl,1/4 }\end{array}$ & s.c. täglich & $4 \mathrm{Wo}$ \\
\hline 3 & ovx + ER $\alpha$ & $\begin{array}{l}10 \mu \mathrm{g} \text { ER } \alpha / \text { Tier in } 0,2 \mathrm{ml} \text { gelöst in } \\
\text { Benzylbenzoat/Rizinusöl, } 1 / 4\end{array}$ & s.c. täglich & $4 \mathrm{Wo}$ \\
\hline 4 & ovx + ER $\beta$ & $\begin{array}{l}50 \mu \mathrm{g} \text { ER } \beta / \text { Tier in } 0,2 \mathrm{ml} \text { gelöst in } \\
\text { Benzylbenzoat/Rizinusöl, } 1 / 4\end{array}$ & s.c. täglich & $4 \mathrm{Wo}$ \\
\hline 5 & $\begin{array}{r}\text { ovx }+E_{2} \\
\quad+E R \beta \\
4 \text { Wochen }\end{array}$ & $\begin{array}{l}1 \mu \mathrm{g} \mathrm{E}_{2} / \text { Tier }+50 \mu \mathrm{g} \text { ER } \beta / \text { Tier in } 0,2 \mathrm{ml} \\
\text { gelöst in Benzylbenzoat/Rizinusöl, } 1 / 4\end{array}$ & s.c. täglich & $4 \mathrm{Wo}$ \\
\hline 6 & $\begin{array}{r}\text { ovx }+ \text { ER } \alpha \\
+ \text { ER } \beta \\
4 \text { Wochen }\end{array}$ & $\begin{array}{l}10 \mu \mathrm{g} \mathrm{E} \alpha / \text { Tier }+50 \mu \mathrm{g} \text { ER } \beta / \text { Tier in } 0,2 \mathrm{ml} \\
\text { gelöst in Benzylbenzoat/Rizinusöl, } 1 / 4\end{array}$ & s.c. täglich & $4 \mathrm{Wo}$ \\
\hline 7 & $\begin{array}{l}\text { ovx }+\mathrm{E}_{2} \\
\text { nach } 14 \text { Tagen } \\
\quad+\text { ER } \beta\end{array}$ & $\begin{array}{l}1 \mu \mathrm{g} \mathrm{E}_{2} / \text { Tier in } 0,2 \mathrm{ml} \text { (gelöst in Benzylben- } \\
\text { zoat/Rizinusöl,1/4) } \\
\text { dann } \\
1 \mu \mathrm{g} \mathrm{E} \mathrm{E}_{2} / \text { Tier }+50 \mu \mathrm{g} \text { ER } \beta / \text { Tier in } 0,2 \mathrm{ml} \\
\text { gelöst in Benzylbenzoat/Rizinusöl, } 1 / 4\end{array}$ & s.c. täglich & $4 \mathrm{Wo}$ \\
\hline 8 & $\begin{array}{l}\text { ovx }+ \text { ER } \alpha \\
\text { nach } 14 \text { Tagen } \\
\quad+\text { ER } \beta\end{array}$ & $\begin{array}{l}10 \mu \mathrm{g} \text { ER } \alpha / \text { Tier in } 0,2 \mathrm{ml} \text { gelöst in } \\
\text { Benzylbenzoat/Rizinusöl,1/4 } \\
\text { dann } \\
10 \mu \mathrm{g} \text { ER } \alpha / \text { Tier }+50 \mu \mathrm{g} \text { ER } \beta / \text { Tier in } 0,2 \\
\mathrm{ml} \text { gelöst in Benzylbenzoat/Rizinusöl,1/4 }\end{array}$ & s.c. täglich & $4 \mathrm{Wo}$ \\
\hline 9 & Sham ovx & 0,2 ml/Tier Benzylbenzoat/Rizinusöl,1/4 & s.c. täglich & $4 \mathrm{Wo}$ \\
\hline
\end{tabular}




\subsection{Die Injektionstherapie}

Den Beginn der 28 Tage dauernden Injektionstherapie bildete Tag 2 der Studie, welcher der Tag nach der Ovarektomie der einzelnen Versuchstiere war. Während des Versuchszeitraums wurden den Tieren täglich die für ihre Gruppe spezifischen Substanzen, welche der Tabelle $2.1 \mathrm{zu}$ entnehmen sind, appliziert. Die subkutane Applikation nach dem Injektionsplan erfolgte bei den Ratten wechselnd nucheal oder in die Flanken (siehe Abb. 2.1).

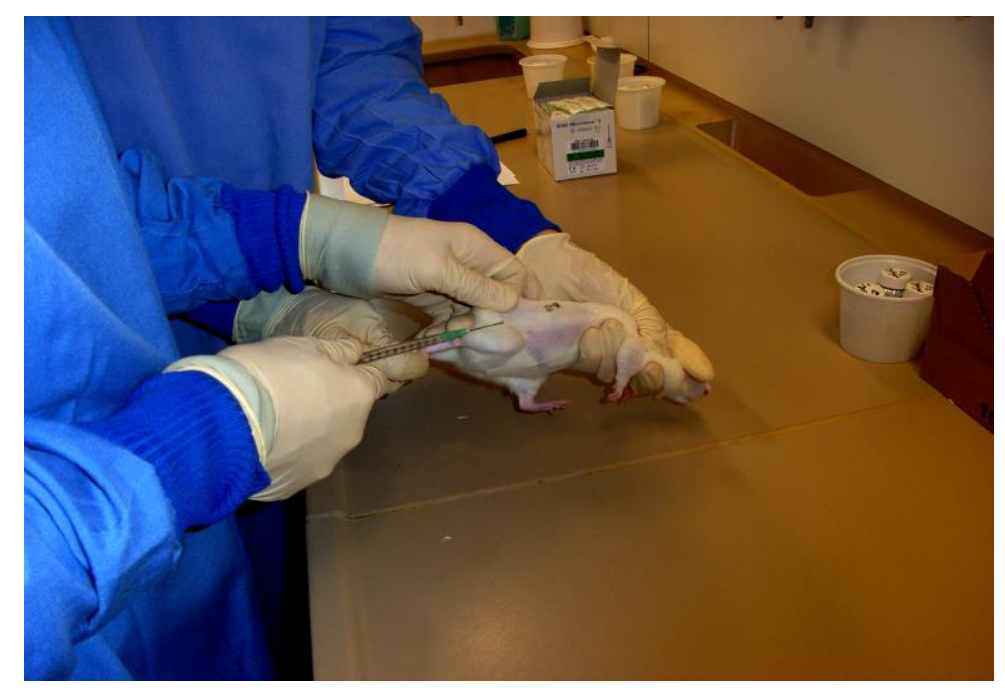

Abb. 2.1 s.c Injektion in die linke Flanke Foto Abteilung Experimentelle Endokrinologie Göttingen

Das subkutane Depot der applizierten Substanzen sorgte für eine konstante Metabolisierung der Injektionslösung. Unter Verwendung von neuen, sterilen Utensilien für jedes einzelne Versuchstier wurden die Applikationen immer von einem festen Personenkreis, zu dem ich persönlich nicht gehörte, durchgeführt. Dieser Personenkreis bestand aus A. Giffhorn, M. Börris, J. Götze, J. Mahlouji, A. Mench und M. Vormfeld, welche die Ergebnisse dieses In-vivo-Versuches selbst für ihre Dissertationsarbeiten nutzten. Beaufsichtigt und geleitet wurde die Versuchsdurchführung stets von PD Dr. med. D. Seidlovà-Wuttke.

\subsection{Die verwendeten Substanzen der Injektionstherapie}

Die Injektionslösungen, die die Versuchstiere in der 28 Tage dauernden Versuchsreihe täglich appliziert bekamen, waren spezifisch für jede einzelne Gruppe. 
Jede Injektionslösung setzte sich aus den für die Gruppe spezifischen Komponenten (siehe Tab.2.1) und einem für alle Gruppen verwendeten Lösungsmittelgemisch, bestehend aus Benzylbenzoat (Firma Sigma) und Rizinusöl, welches in einem Mischungsverhältnis von 1:4 verwendet wurde, zusammen.

Die mit ZK281471 bezeichneten Substanzen stehen für die rezeptorspezifischen Agonisten ER $\alpha 16 \alpha-$ $\mathrm{LE}_{2}$ (3,17-dihydroxy-19-nor-17 $\alpha$-pregna-1,3,5(10)-triene-21, 16 $\alpha$-lacton) und ZK 281738 ER $\beta$ 8 $\beta$ VES (8-vinylestra-1,3,5(10)-triene-3,17 $\beta$-diol), die entweder einzeln oder in Kombination in den Gruppen 3-9 verwendet wurden.

Die Gruppen 1 und 9 waren die jeweiligen Kontrolltiergruppen und ihnen wurde das reine Lösungsmittelgemisch aus Benzylbenzoat und Rizinusöl (1:4) appliziert

\subsection{Die Organ- und Probengewinnung}

Im Anschluss an die 4-wöchige Injektionstherapie wurden die Versuchstiere einer zweiten Narkose (siehe 2.4) unterzogen. Die narkotisierten Tiere wurden im Verlauf dekapitiert und das Dekapitationsblut für spätere Serumanalysen gesichert. Für die vorliegende Arbeit erfolgte unter anderem die Präparatgewinnung durch die Exzision des Caput laterale des Musculus gastrocnemius des linken Hinterlaufs bei jedem Versuchstier. Über eine Längsinzision der Haut und anschließender Präparation bis auf das Muskelgewebe wurde der Musculus gastrocnemius mit seinem medialen und lateralen Kopf und dem dazwischen lokalisierten Musculus plantaris in seinem Verlauf identifiziert und offen gelegt. Das Caput laterale wurde vorsichtig an seinem Ursprung dem Epicondylus lateralis femoris und seinem Ansatz an der Tendo calcaneus mit einem Skalpell abgetrennt und umgehend in eine 4\% Formalinlösung gegeben. Das Muskelpräparat war somit für spätere Untersuchungen konserviert. Diese chirurgische Probeentnahme des Muskels wurde von Frau PD Dr. D. Seidlovà-Wuttke und weiteren erfahrenen wissenschaftlichen Mitarbeitern der Abteilung durchgeführt.

\subsection{Die Organhistologie}

Die histologischen Organschnitte, die Gegenstand der Untersuchung und Vermessung waren, wurden aus den in Formalin aufbewahrten Muskelpräparaten hergestellt. Für die weiterführenden Untersuchungen der Präparate mussten diese zunächst noch entwässert und fixiert werden. Eine aufsteigende Alkoholreihe diente der Entwässerung, die Verwendung verschiedener Xylol- und Paraffinlösungen der Fixierung der Muskelpräparate (siehe Anhang Tab. 2.2). Diese Arbeitsschritte wurden mit der Zitadelle (Leica TP 1020, V 2,0, Ordernummer: 070430101, Herstellung 03/98) durchgeführt. 
Die endgültig im Paraffinblock fixierten Präparate wurden dann schockgefroren im Tiefkühlschrank aufbewahrt. Für die eben beschriebenen Arbeitsschritte der Entwässerung und Fixierung der Muskelpräparate war ausschließlich die leitende MTA Frau H. Brüggemann-Meyer zuständig.

Mit Hilfe eines Mikrotoms (Leica Model RM 2135 Fabriknummer: 2794/10.2000, Kat.Nr.: 050029802) wurden die paraffinfixierten, eingefrorenen Muskelpräparate dann durch mich in Schichten à $3 \mu \mathrm{m}$ Dicke geschnitten und auf einen Objektträger (SuperFrostPlus, Menzel GmbH, Braunschweig) aufgebracht. Es wurden 3 Tiere pro Gruppe als Referenz zufällig ausgewählt und pro Tier schließlich 10 Schnitte angefertigt. Bei 9 Gruppen zu je 3 Tieren wurden also 270 Präparate angefertigt. Die $3 \mu \mathrm{m}$ dicken Muskelschichten wurden auf Objektträger aufgetragen und einer HE-Färbung unterzogen, welche ich eigenverantwortlich durchführte. Diese bestand aus einer absteigenden Alkoholreihe, der eigentlichen Färbung der Präparate und einer aufsteigenden Alkoholreihe (siehe Anhang Tab. 2.3).

\subsection{Die Auswertung}

Zur Auswertung wurden die HE-gefärbten Präparate dann durch mich mit einem Zeiss AxiophotMikroskop betrachtet, das an eine digitale Fotokamera und ein Rechnersystem angeschlossen war. So konnten über den mit dem System vernetzten Computerbildschirm und durch Gebrauch des Softwareprogrammes analySIS (Soft imaging System GmbH, Olympus Münster) die einzelnen histologischen Präparate beurteilt, ausgemessen und evaluiert werden. Jedes Muskelpräparat wurde in 4 Quadranten eingeteilt und pro Quadrant erfolgte die Vermessung von 10 unterschiedlichen Muskelfasern, so dass schließlich 40 Muskelfasern pro Tier in die Evaluierung mit einbezogen wurden. Bei 3 Tieren pro Gruppe machte dies 120 Muskelfaservermessungen pro Versuchsgruppe, d.h bei 9 Gruppen 1080 Muskelfaservermessungen insgesamt. Das Softwareprogramm ermöglichte die Quantifizierung der Zirkumferenz der einzelnen Muskelzelle und darüber schließlich die Kalkulation der Muskelfaserfläche in $\mu \mathrm{m}^{2}$. 


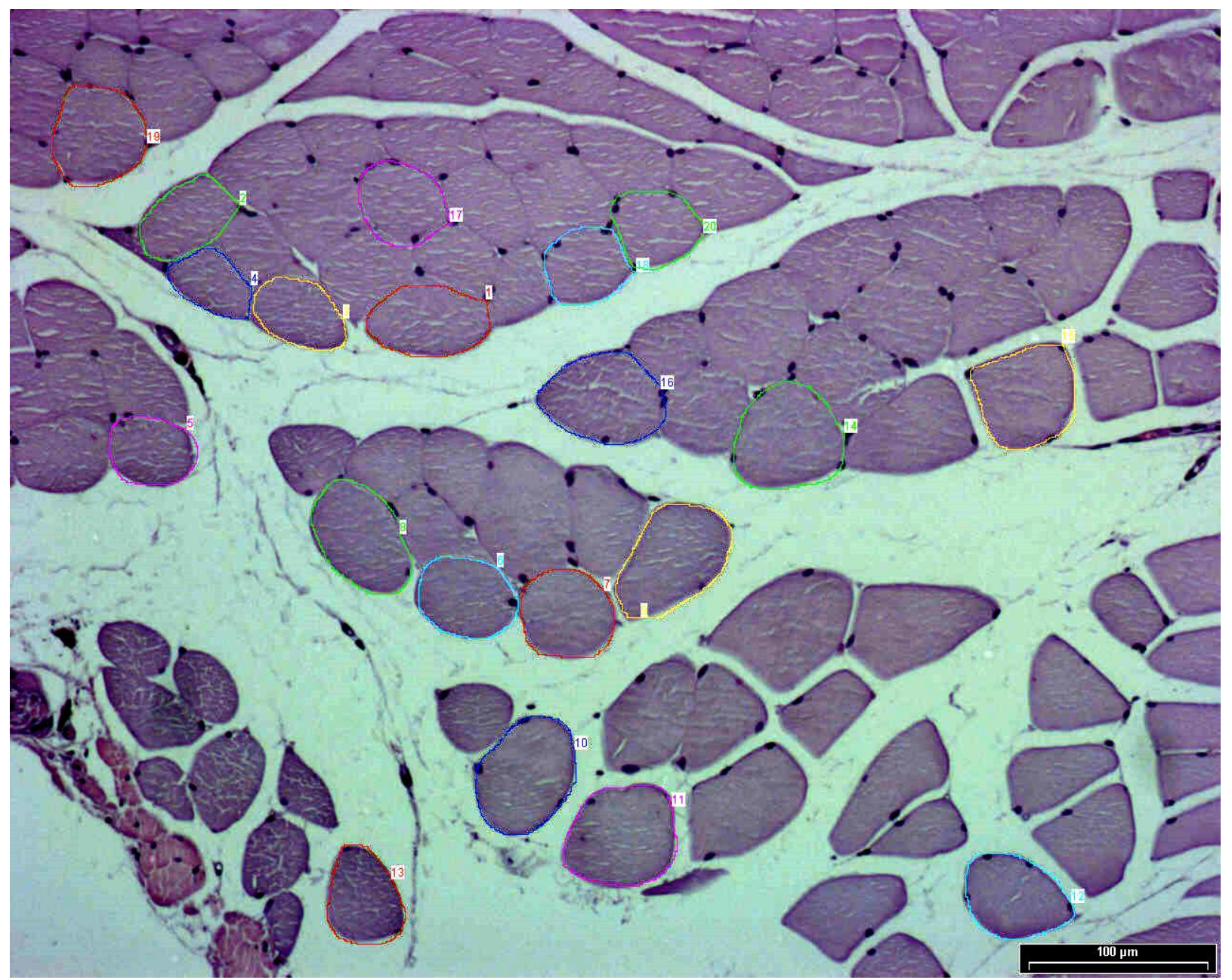

Abb. 2.2 Histomorphometrische Untersuchung eines Muskelpräparates

\subsection{Die Serumanalyse}

Die Messung der verschiedenen Serumparameter erfolgte über das Dekapitationsblut, welches am Versuchsende bei jedem einzelnen Versuchstier gewonnen wurde.

$\mathrm{Zu}$ Versuchsbeginn wurde kein Blut von den Tieren entnommen. Alle gemessenen Serumwerte der verschiedenen Versuchsgruppen wurden mit den Werten der Vergleichsgruppe (Gruppe 9, Tab. 2.1) in Bezug gesetzt, da deren Ergebnisse die physiologischen Parameter adulter Ratten widerspiegeln. Die Bestimmung der Werte für Cholesterol, Triglyzeride und Glukose erfolgte mittels enzymatischer flurometrischer Methodik mit dem Hitachi-Autoanalyser (Roche Diagnostics, Mannheim). IGF wurden mit kommerziell erhältlichen RIAs (Radio Immuno Assays) ermittelt.

(E $E_{2}$ : Estradiol ${ }^{3 r d}$ Generation, Sinsheim, Germany, IGF: DSL-2900, Diagnostic Systems Laboratories Inc. , Webster, Texas, USA). Die praktische Durchführung dieser Analyse unternahm erneut die leitende MTA Frau H. Brüggemann-Meyer. 


\subsection{Der periphere quantitative Computertomograph (pqCT)}

Nach einer Eingewöhnungsphase von einer Woche wurde mit Hilfe eines CT-Gerätes (pqCT mit XT Research Bone Scanner, Stratec Medizintechnik, Pforzheim, Germany) jedes einzelne Versuchstier zu Beginn und Ende der Injektionstherapie unter Isofluran Narkose (siehe Abb. 2.3) vermessen.

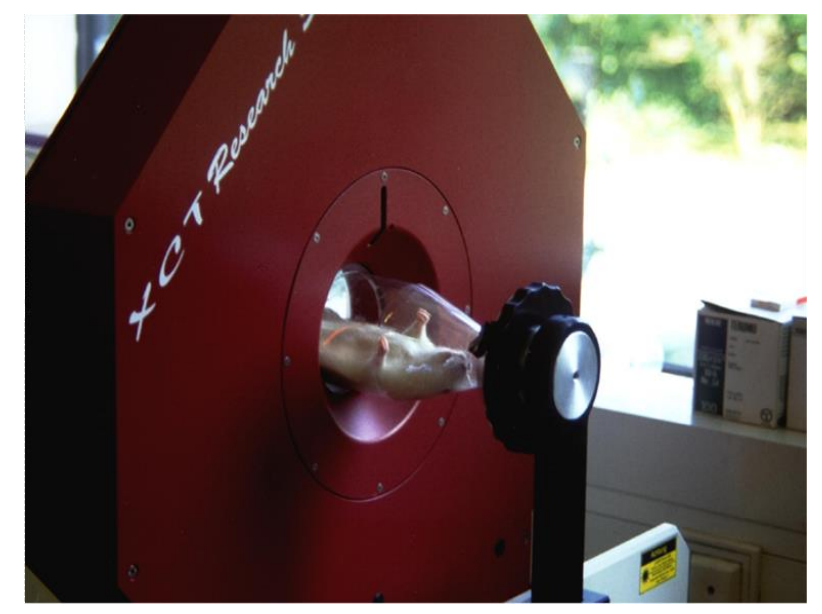
Abb. 2.3 pqCT-Vermessung der unter volatiler Narkose befindlichen Ratte in Höhe LWK 4 / 5 (siehe
Lasermarkierung)

Dies wurde durch die in Punkt 2.8 genannten Personen durchgeführt, zu denen ich persönlich nicht gehörte. Das CT-Gerät ist in seiner Größe speziell an die Anforderung zur Vermessung von Kleintieren angepasst und in der Wissenschaft ein anerkannt eingesetztes Diagnostik-Instrument (Helterbrand et al. 1997). Bei der peripheren quantitativen Computertomographie rotiert die Röntgenröhre um das zu untersuchende Objekt. Das pqCT ist mit einem PC verbunden, wodurch die gemessenen Strukturen sowohl graphisch als auch numerisch dargestellt werden konnten. Durch diese spezifische Messung anhand der Dichteunterschiede der einzelnen Gewebe, konnte zwischen Knochen-, Fett- und Muskelgewebe differenziert werden.

Die Diagnostik zur Bestimmung der Knochendichte (BMD) fand für jedes Tier immer an den gleichen spezifisch festgelegten Stellen statt, einmal im Bereich der Tibia und zum anderen im Bereich zwischen den Lendenwirbelkörpern 4 und 5. Exemplarisch wird die Vermessung am Beispiel der Tibia erläutert. Hierzu wurde der Scanner auf die Epiphyse der Tibia ausgerichtet und ein Koronarschnitt (Testbild) durchgeführt. Auf Grundlage des Testbildes wurde die Position des Scanners dem Untersuchungsobjekt angepasst. Zwei CT-Schnittbilder wurden mit einem Abstand von 3,75 und 4,25 mm distal der zuvor bestimmten Referenzlinie zur Untersuchung der Knochenparameter durchgeführt. Anschließend erfolgte die Durchführung eines dritten Schnittbildes $15 \mathrm{~mm}$ distal der Referenzlinie zur Messung der Kortikalen Parameter. 
Die Bilderfassung, ihre Verarbeitung und die Kalkulation der Ergebnisse wurden mit Hilfe des Software-Package XCT 5.40 (STRATEC INC) ausgeführt (Seidlovà-Wuttke et al. 2008). Die Rohdaten der im CT-ermittelten Werte nutzte ich zur weiteren Bearbeitung zur Verifizierung der Muskel- und Fettgewebsflächen für den abdominalen Bereich (siehe Abb. 2.4).

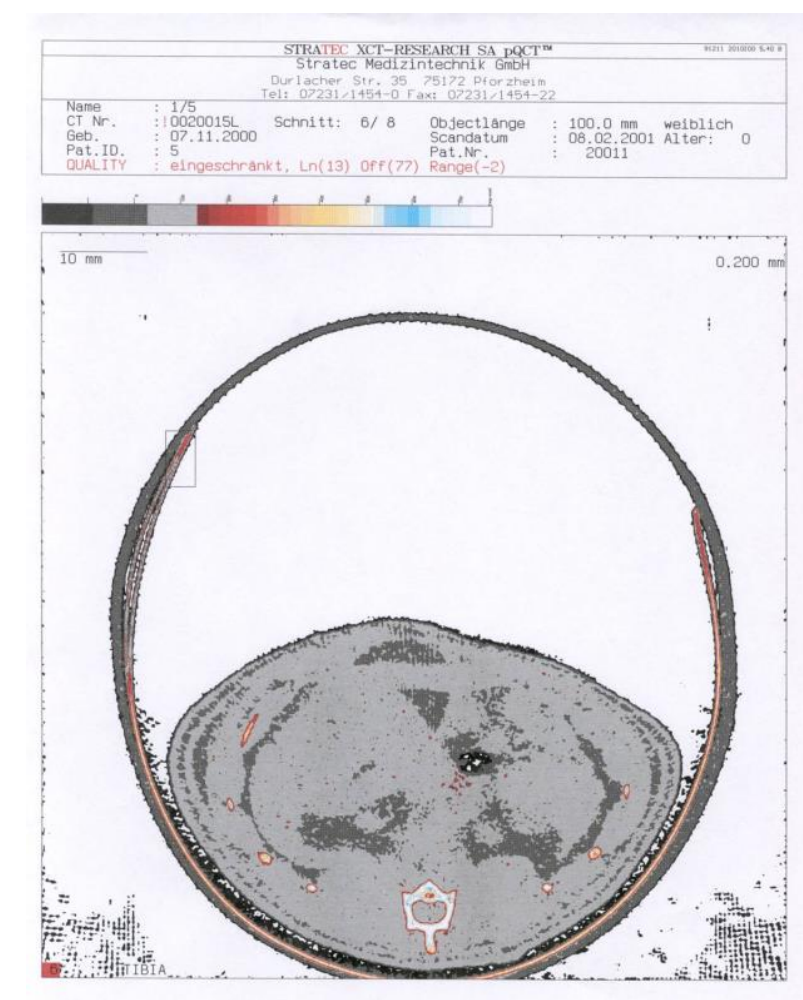

Abb. 2.4 CT-Bild Höhe LWK 4 / 5 mit den farblich abgestuften Dichtegraden der unterschiedlichen Gewebetypen

\subsection{Die Statistische Methode}

Die Werte für die Statistik wurden mit dem Computerprogramm Graph Pad Prism $4^{\circledR}$ berechnet. Das Signifikanzniveau im Vergleich zu den unbehandelten ovx Versuchstieren (Gruppe 1) wurde auf ${ }^{*} \mathrm{p}<0,05$ und beim Vergleich zu den sham-ovx Versuchstieren (physiologische Vergleichsgruppe, Gruppe 9) wurde das Signifikanzniveau auf ${ }^{\#} \mathrm{p}<0,05$ festgelegt. Die statistische Auswertung erfolgte durch Anwendung einer Varianzanalyse für wiederholte Messungen eines Faktors (ANOVA) und anschließenden multiplen Tests nach Dunett und wurde ausschließlich durch mich durchgeführt. 


\section{Ergebnisse}

\subsection{Körpergewicht}

In der Abb. 3.1 wird der Einfluss der unterschiedlichen Substanzen und Applikationsschemen auf die Gewichtsentwicklung der ovarektomierten Ratte am Ende des 4-wöchigen Versuchszeitraums dargestellt.

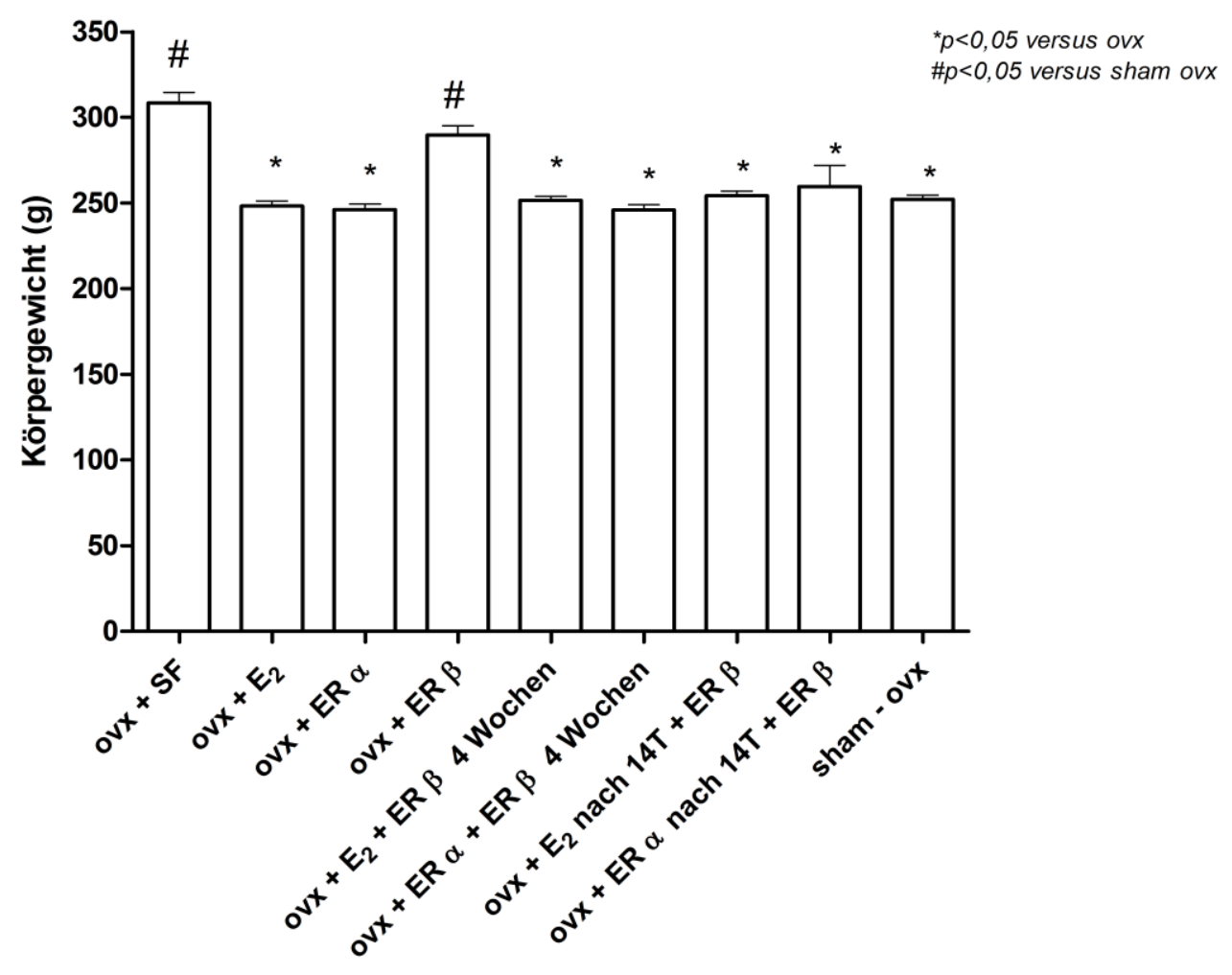

Abb. 3.1 Durchschnittliches Körpergewicht der ovarektomierten Ratte nach 4-wöchiger s.c. Substitutionstherapie unter dem jeweiligen Applikationsschema mit E2, dem ER $\alpha$ - und ER $\beta$-Agonisten 


\begin{tabular}{|c|c|c|c|c|c|c|c|c|c|}
\hline $\begin{array}{l}\text { Applikations- } \\
\text { schema }\end{array}$ & $\begin{array}{l}\text { ovx }+ \\
\text { SF }\end{array}$ & $\begin{array}{l}\mathrm{ovx}+ \\
\mathrm{E}_{2}\end{array}$ & $\begin{array}{l}\text { ovx }+ \\
\text { ER } \alpha\end{array}$ & $\begin{array}{l}\text { ovx }+ \\
\text { ER } \beta\end{array}$ & $\begin{array}{l}\text { ovx }+ \\
E_{2}+E R \\
\beta \\
4 \text { Wo- } \\
\text { chen }\end{array}$ & $\begin{array}{l}\text { ovx }+ \\
\text { ER } \alpha+ \\
\text { ER } \beta \\
4 \text { Wo- } \\
\text { chen }\end{array}$ & $\begin{array}{l}\text { ovx + } \\
E_{2} \\
\text { nach } \\
14 T+ \\
\text { ER } \beta\end{array}$ & $\begin{array}{l}\text { ovx }+ \\
\text { ER } \alpha \\
\text { nach } \\
14 T+ \\
\text { ER } \beta\end{array}$ & $\begin{array}{l}\text { sham - } \\
\text { ovx }\end{array}$ \\
\hline $\begin{array}{l}\varnothing \text { Gewicht } \\
\text { in } g\end{array}$ & 308,5 & 248,2 & 246,2 & 289,7 & 251,6 & 245,9 & 254,3 & 259,8 & 252,2 \\
\hline
\end{tabular}

Die tägliche alleinige Substitution von $\mathrm{E}_{2}$ und dem ER $\alpha$-Agonisten führte zu einer signifikanten Reduzierung der Gewichtszunahme im Vergleich zu den unbehandelten Kontrolltieren der ovx-SF Gruppe. Auch die Kombinationsapplikationen von $\mathrm{E}_{2}$ und dem ER $\beta$-Agonist sowie die Kombination von ER $\alpha$ und ER $\beta$-Agonisten über jeweils 4 Wochen oder als zwei Stufen-Schema zeigten eine signifikante geringere Gewichtszunahme im Vergleich zu den Kontrolltieren. Da es bei der alleinigen 4wöchigen Applikation mit dem ER $\beta$-Agonisten zu einem deutlichen Gewichtsanstieg der Tiere kam, ist hier im Vergleich zu allen anderen Gruppen kein signifikanter Unterschied zu der ovx + SF-Gruppe feststellbar.

Im Vergleich zu den sham-ovx Tieren, welche die physiologische Vergleichsgruppe in dieser Untersuchung bildeten, zeigte sich eine signifikante Gewichtszunahme in Bezug auf die Tiere der ovx $+\mathrm{SF}$ und der ovx-ER $\beta$ Gruppe. 


\subsection{CT-Auswertung}

Durch die Anwendung des pqCT konnten einzelne Gewebetypen abhängig von ihrem Dichtegrad voneinander differenziert werden. Der prozentuale Anteil eines spezifischen Gewebes konnte somit ins Verhältnis zur gemessenen Gesamtfläche gesetzt werden. Die Applikation von $\mathrm{E}_{2}$ und dem ER $\alpha$ und ER $\beta$-Agonisten zeigte dabei verschiedene Auswirkung auf die unterschiedlichen Gewebetypen wie Fett-, Knochen- und Muskelgewebe. Gegenstand dieser Arbeit sind das Fett- und Muskelgewebe.

\subsubsection{Fettanteil im abdominalen Bereich LWK 4/5}

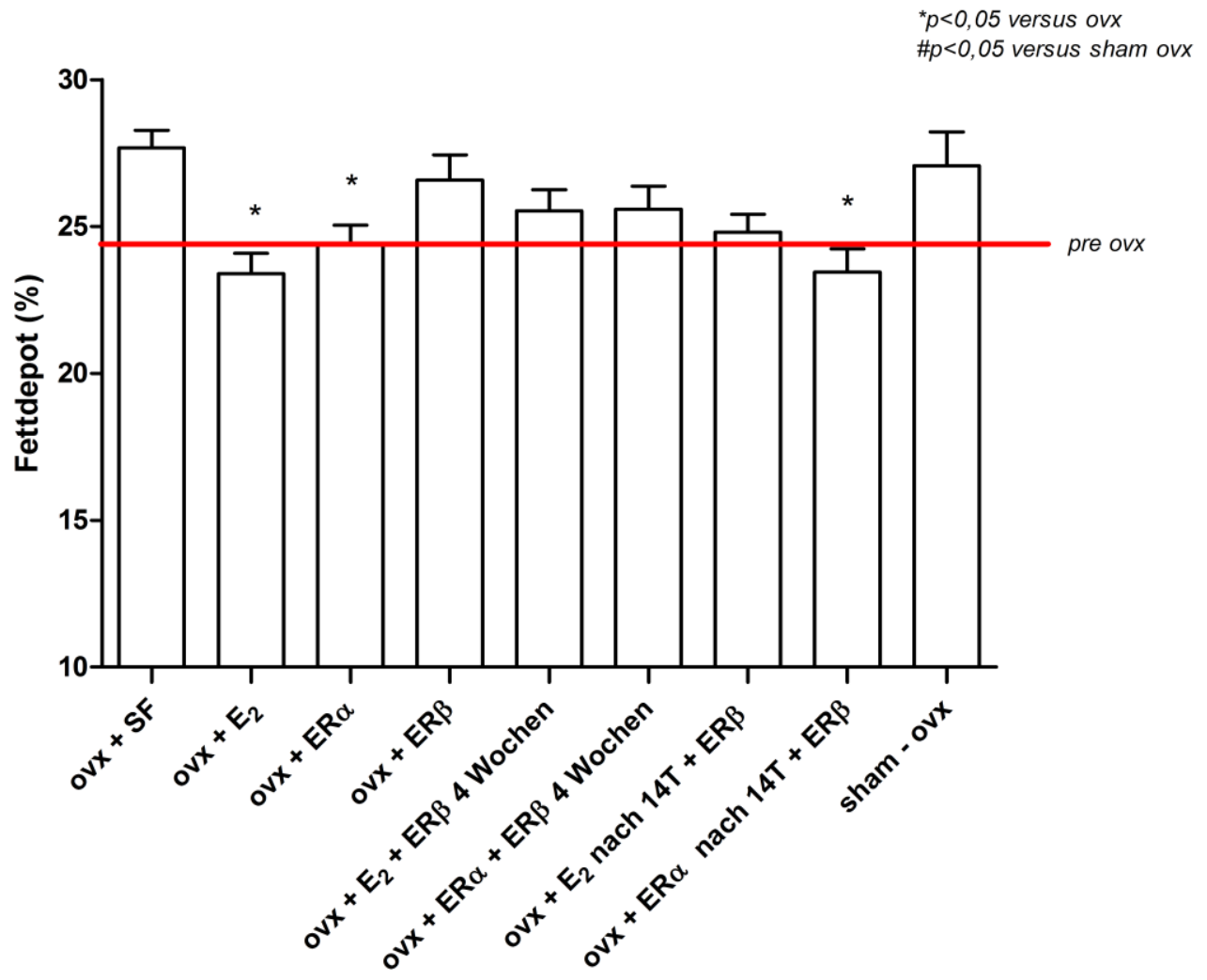

Abb. 3.2.1 Durchschnittlicher Prozentanteil des Fettgewebes im Bereich LWK 4/5 der ovarektomierten Ratte nach 4-wöchiger s.c. Substitutionstherapie unter dem jeweiligen Applikationsschema mit $E_{2}$, dem ER $\alpha$ - und ER $\beta$-Agonisten 


\begin{tabular}{|c|c|c|c|c|c|c|c|c|c|c|}
\hline $\begin{array}{c}\text { Applikations- } \\
\text { schema }\end{array}$ & $\begin{array}{l}\text { ovx } \\
+ \text { SF }\end{array}$ & $\begin{array}{l}\text { ovx } \\
+E_{2}\end{array}$ & $\begin{array}{c}\text { ovx } \\
+\mathrm{ER} \\
\alpha\end{array}$ & $\begin{array}{l}\text { ovx } \\
+ \text { ER } \\
\beta\end{array}$ & $\begin{array}{c}\text { ovx }+ \\
E_{2}+\text { ER } \beta \\
4 \text { Wochen }\end{array}$ & $\begin{array}{l}\text { ovx }+ \\
\text { ER } \alpha+ \\
\text { ER } \beta \\
4 \text { Wo- } \\
\text { chen }\end{array}$ & $\begin{array}{c}\text { ovx } \\
+\mathrm{E}_{2} \\
\text { nach } \\
14 \mathrm{~T} \\
+\mathrm{ER} \\
\beta\end{array}$ & $\begin{array}{c}\text { ovx }+ \\
\text { ER } \alpha \\
\text { nach } \\
14 T+ \\
\text { ER } \beta\end{array}$ & $\begin{array}{l}\text { sham } \\
\text { - ovx }\end{array}$ & $\begin{array}{l}\text { pre - } \\
\text { Ovx }\end{array}$ \\
\hline $\begin{array}{l}\% \text { Anteil des } \\
\text { Fettgewebes }\end{array}$ & 27,7 & 23,4 & 24,4 & 26,6 & 25,5 & 25,6 & 24,8 & 23,4 & 27,1 & 24,5 \\
\hline
\end{tabular}

Mit „pre-Ovx“ wird der durchschnittliche Fettanteil aller Tiere bezeichnet, welcher während der ersten CT-Untersuchung vor Versuchsbeginn ermittelt wurde.

Eine signifikante Reduzierung des Fettgewebeanteils im abdominalen Bereich zeigte die alleinige Applikation von $\mathrm{E}_{2}$ und des $\mathrm{ER} \alpha$-Agonisten. Zudem führten die Kombinationen des ER $\alpha$-Agonisten und ER $\beta$-Agonisten in der Stufenapplikation ebenfalls zu einem signifikant niedrigeren Wert als die Gruppe der ovx-Kontrolltiere.

Die alleinige Behandlung der Tiere mittels ER $\beta$-Agonisten hatte keinen Einfluss auf die Reduzierung des Fettgewebeanteils. Im Vergleich zur physiologischen Vergleichsgruppe zeigte keine Versuchsgruppe einen bedeutenden Unterschied. Die physiologische Vergleichsgruppe und die ovxKontrolltiere waren die Gruppen mit dem am höchsten gemessenen Fettgewebsanteil im Abdomen. 


\subsubsection{Fläche des Muskelgewebes im abdominalen Bereich LWK 4/5}

Die hier als Muskelgewebe bezeichnete Fläche setzt sich aus der im pqCT gemessenen abdominalen Gesamtfläche des Versuchstieres zusammen, von der dann über die Dichtebestimmung der einzelnen Gewebe der Fettgewebsanteil und der Knochengewebsanteil subtrahiert wurden. Als Ergebnis erhält man eine Fläche in $\mathrm{mm}^{2}$, die vom Fett- und Knochengewebe befreit ist und vornehmlich dem Muskelgewebe entspricht.

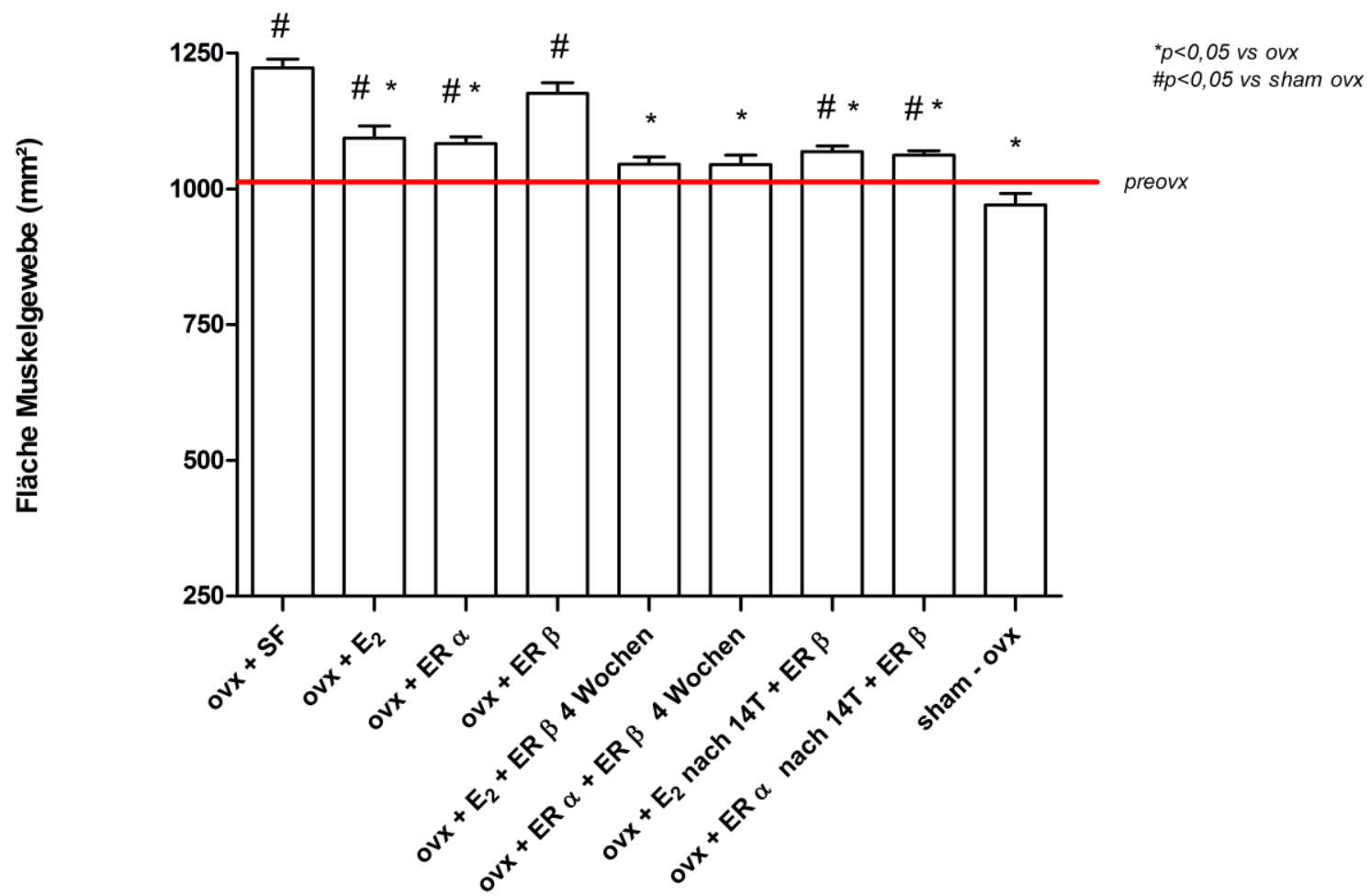

Abb. 3.2.2 Durchschnittlicher Anteil der Fläche des Muskelgewebes im Bereich LWK 4/5 der ovarektomierten Ratte nach 4-wöchiger s.c. Substitutionstherapie unter dem jeweiligen Applikationsschema mit $\mathrm{E}_{2}$, dem ER $\alpha$ - und ER $\beta$-Agonisten

\begin{tabular}{|c|c|c|c|c|c|c|c|c|c|c|}
\hline $\begin{array}{c}\text { Applikations- } \\
\text { schema }\end{array}$ & $\begin{array}{c}\text { ovx }+ \\
\text { SF }\end{array}$ & $\begin{array}{c}\text { ovx }+ \\
E_{2}\end{array}$ & $\begin{array}{l}\text { ovx }+ \\
\text { ER } \alpha\end{array}$ & $\begin{array}{l}\text { ovx }+ \\
\text { ER } \beta\end{array}$ & $\begin{array}{c}\text { ovx }+ \\
\mathrm{E}_{2}+\mathrm{ER} \\
\beta \\
4 \mathrm{Wo-} \\
\text { chen }\end{array}$ & $\begin{array}{c}\text { ovx }+ \\
\text { ER } \alpha+ \\
\text { ER } \beta \\
4 \text { Wo- } \\
\text { chen } \\
\end{array}$ & $\begin{array}{c}\text { ovx }+ \\
\mathrm{E}_{2} \text { nach } \\
14 \mathrm{~T}+ \\
\text { ER } \beta\end{array}$ & $\begin{array}{c}\text { ovx }+ \\
\text { ER } \alpha \\
\text { nach } \\
14 \mathrm{~T}+ \\
\mathrm{ER} \beta\end{array}$ & $\begin{array}{l}\text { sham } \\
\text { - ovx }\end{array}$ & $\begin{array}{l}\text { pre - } \\
\text { Ovx }\end{array}$ \\
\hline $\begin{array}{c}\text { Muskelfläche } \\
\qquad\left(\mathrm{mm}^{2)}\right.\end{array}$ & 1222,7 & 1093,7 & 1083,4 & 1175,9 & 1045,5 & 1044,7 & 1068,6 & 1062,5 & 954,1 & 1016,1 \\
\hline
\end{tabular}

Alle angewandten Substitutionsschemen, ausgenommen die reine Applikation des ER $\beta$-Agonisten, zeigen eine signifikante Reduktion der Fläche des Muskelgewebes im Vergleich zu den ovx- 
Kontrolltieren. Alle Applikationsschemen - bis auf die Kombinationstherapien über 4 Wochen erreichen eine signifikante Erhöhung der Fläche des Muskelgewebes im Vergleich zur physiologischen Vergleichsgruppe, welche die geringste abdominale Muskelgewebefläche aller untersuchten Tiere aufweist. 


\subsection{Histometrische Ergebnisse}

Es wurden die Auswirkungen der eingesetzten Substanzen und Applikationsschemen auf die Querschnittsgröße der einzelnen Muskelfaser des linken Caput laterale des M. gastrocnemius getestet.

\subsubsection{Durchschnittliche Muskelfasergröße}

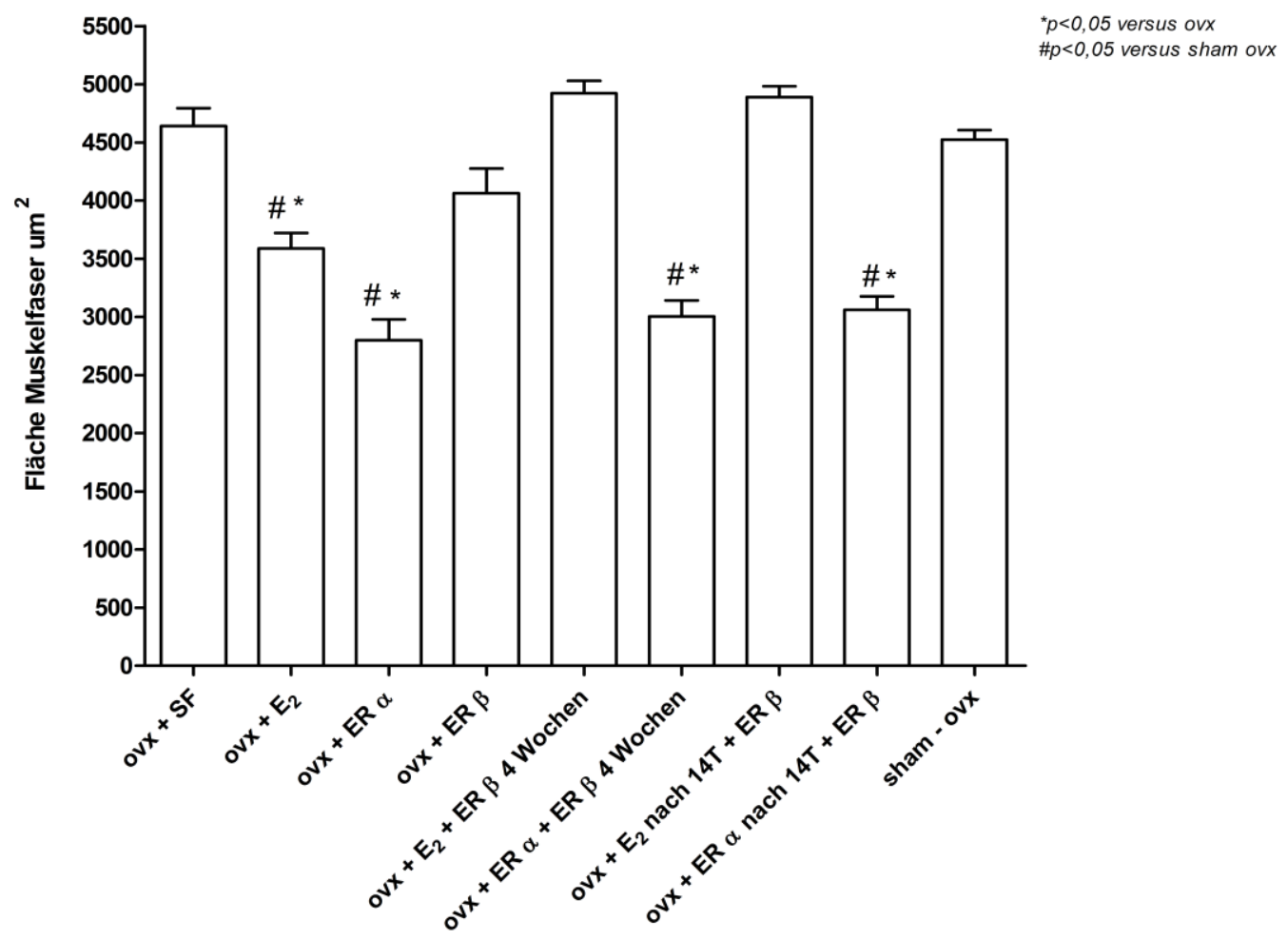

Abb. 3.3.1 Durchschnittliche Muskelfasergröße des M. gastrocnemius der ovarektomierten Ratte nach 4-wöchiger s.c. Substitutionstherapie unter dem jeweiligen Applikationsschema mit $E_{2}$, dem ER $\alpha$ - und ER $\beta$-Agonisten 


\begin{tabular}{|c|c|c|c|c|c|c|c|c|c|}
\hline $\begin{array}{l}\text { Applikations- } \\
\text { schema }\end{array}$ & $\begin{array}{c}\text { ovx }+ \\
\text { SF }\end{array}$ & $\begin{array}{c}\mathrm{ovx}+ \\
\mathrm{E}_{2}\end{array}$ & $\begin{array}{l}\text { ovx }+ \\
\text { ER } \alpha\end{array}$ & $\begin{array}{c}\text { Ovx }+ \\
\text { ER } \beta\end{array}$ & $\begin{array}{c}\mathrm{ovx}+ \\
\mathrm{E}_{2}+\mathrm{ER} \\
\beta \\
4 \mathrm{Wo-} \\
\text { chen } \\
\end{array}$ & $\begin{array}{c}\text { ovx }+ \\
\text { ER } \alpha+ \\
\text { ER } \beta \\
4 \text { Wo- } \\
\text { chen }\end{array}$ & $\begin{array}{c}\text { ovx + } \\
E_{2} \\
\text { nach } \\
14 T+ \\
\text { ER } \beta\end{array}$ & $\begin{array}{c}\text { ovx }+ \\
\text { ER } \alpha \\
\text { nach } \\
14 T+ \\
\text { ER } \beta\end{array}$ & $\begin{array}{c}\text { sham - } \\
\text { ovx }\end{array}$ \\
\hline$\varnothing$ Größe & & & & & & & & & \\
\hline $\begin{array}{l}\text { Muskelfaser } \\
\text { in } \mu \mathrm{m}^{2}\end{array}$ & 4640,7 & 3588,2 & 2800,0 & 4062,99 & 4922,58 & 3005,4 & 4891,8 & 3058,8 & 4524,1 \\
\hline
\end{tabular}

Die einzeln verabreichten Substanzen $\mathrm{E}_{2}$ und der ER $\alpha$-Agonist sowie die durchgehende und die Stufen-Kombination mit dem ER $\alpha$ - und ER $\beta$-Agonisten zeigten gegenüber der ovx-Kontrollgruppe und der physiologischen Vergleichsgruppe eine signifikante Verkleinerung der Durchschnittsgröße einer Muskelfaser im Querschnitt. Die mit dem ER $\beta$-Agonisten behandelten Tiere zeigten eine Abnahme der Muskelfaserquerschnittsgröße in Relation zur Gruppe der ovx-Kontrolltiere. Ein gegenteiliger Effekt wurde in den Gruppen beobachtet, die mit den Substanzen $E_{2}$ und ER $\beta$-Agonisten in Kombination therapiert wurden. Sowohl in der 4-wöchigen durchgehenden Substitution als auch die Applikation im Stufenschema zeigten eine signifikante Vergrößerung des Muskelfaserquerschnittes im Vergleich zur physiologischen Vergleichsgruppe. In diesen beiden Gruppen wurden die größten Muskelfaserquerschnitte gemessen. 


\subsection{Serum-Auswertung}

Es wurde der Einfluss der eingesetzten Substanzen sowie Applikationsschemen auf verschiedene Serumwerte getestet.

\subsubsection{Serum - Cholesterin}

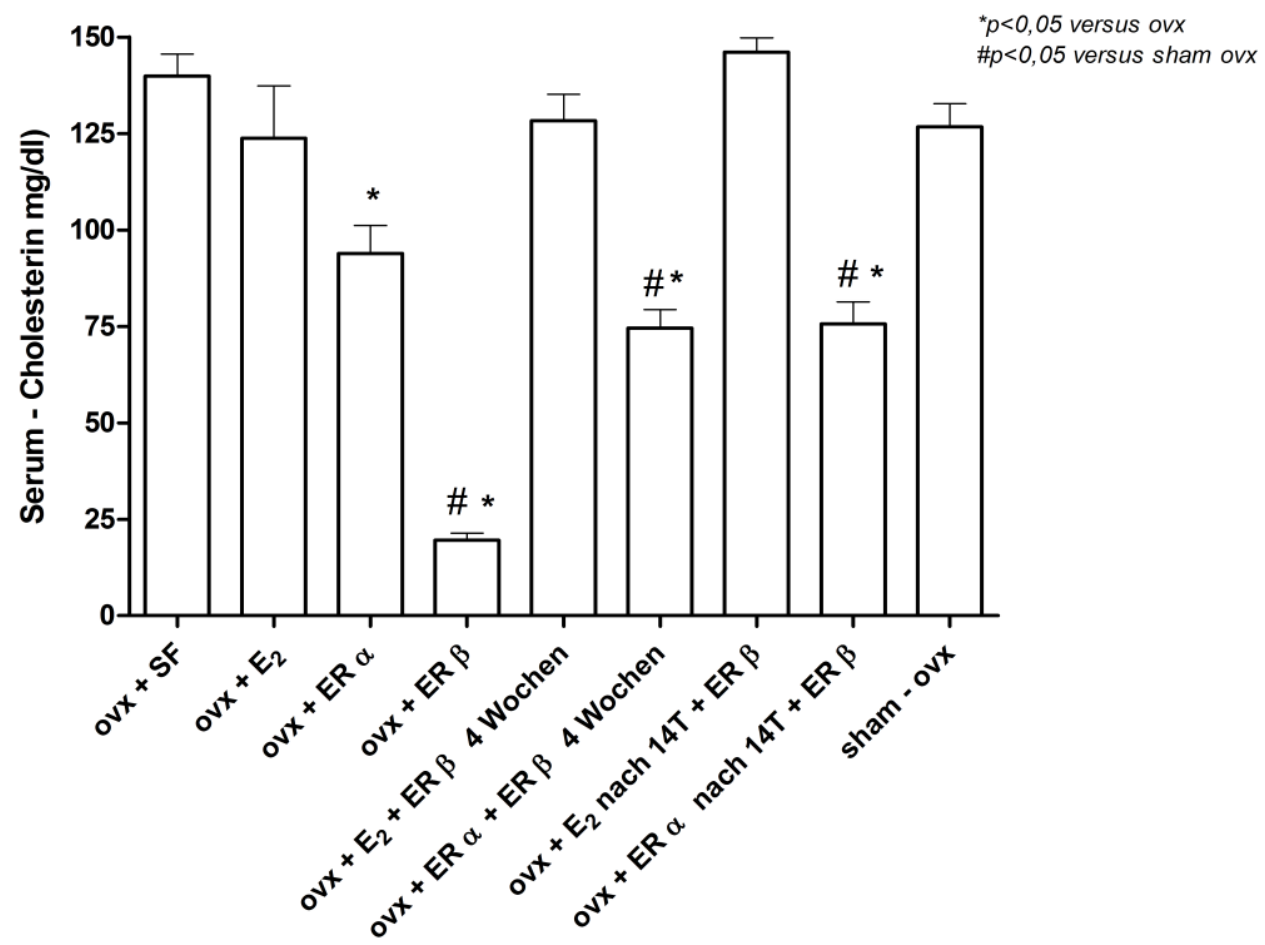

Abb. 3.4.1 Durchschnittlicher Serum-Cholesterinwert der ovarektomierten Ratte nach 4wöchiger s.c. Substitutionstherapie unter dem jeweiligen Applikationsschema mit $E_{2}$, dem ER $\alpha$ - und ER $\beta$-Agonisten

\begin{tabular}{|c|c|c|c|c|c|c|c|c|c|}
\hline $\begin{array}{c}\text { Applikations- } \\
\text { schema }\end{array}$ & $\begin{array}{c}\text { ovx }+ \\
\text { SF }\end{array}$ & $\begin{array}{c}\text { ovx + } \\
\mathrm{E}_{2}\end{array}$ & $\begin{array}{l}\text { ovx }+ \\
\text { ER } \alpha\end{array}$ & $\begin{array}{c}\text { ovx }+ \\
\text { ER } \beta\end{array}$ & $\begin{array}{c}\text { ovx }+ \\
\mathrm{E}_{2}+\mathrm{ER} \\
\beta \\
4 \mathrm{Wo}- \\
\text { chen }\end{array}$ & $\begin{array}{c}\text { ovx }+ \\
\text { ER } \alpha+ \\
\text { ER } \beta \\
4 \text { Wo- } \\
\text { chen }\end{array}$ & $\begin{array}{c}\text { ovx }+ \\
\mathrm{E}_{2} \\
\text { nach } \\
14 \mathrm{~T}+ \\
\text { ER } \beta\end{array}$ & $\begin{array}{c}\text { ovx }+ \\
\text { ER } \alpha \\
\text { nach } \\
14 T+ \\
\text { ER } \beta\end{array}$ & $\begin{array}{c}\text { sham - } \\
\text { ovx }\end{array}$ \\
\hline Ø Serum- & & & & & & & & & \\
\hline $\begin{array}{l}\text { Cholesterinwert } \\
\text { in } \mathrm{mg} / \mathrm{dl}\end{array}$ & 139,8 & 123,7 & 93,9 & 19,5 & 128,3 & 74,5 & 146,0 & 75,6 & 126,6 \\
\hline
\end{tabular}


Der ER $\beta$-Agonist sowie die gleichzeitige Substitution oder als Stufenkombination mit dem ER $\alpha$ Agonisten zeigte eine signifikante Senkung des Serum-Cholesterolwertes im Vergleich zu den Kontrolltieren und der physiologischen Vergleichsgruppe. Die isolierte Applikation des ER $\alpha$-Agonisten führte zu einer bedeutenden Reduzierung des Cholesterolwertes im Vergleich zur ovx -Gruppe, jedoch nicht zur physiologischen Vergleichsgruppe.

\subsubsection{HDL}

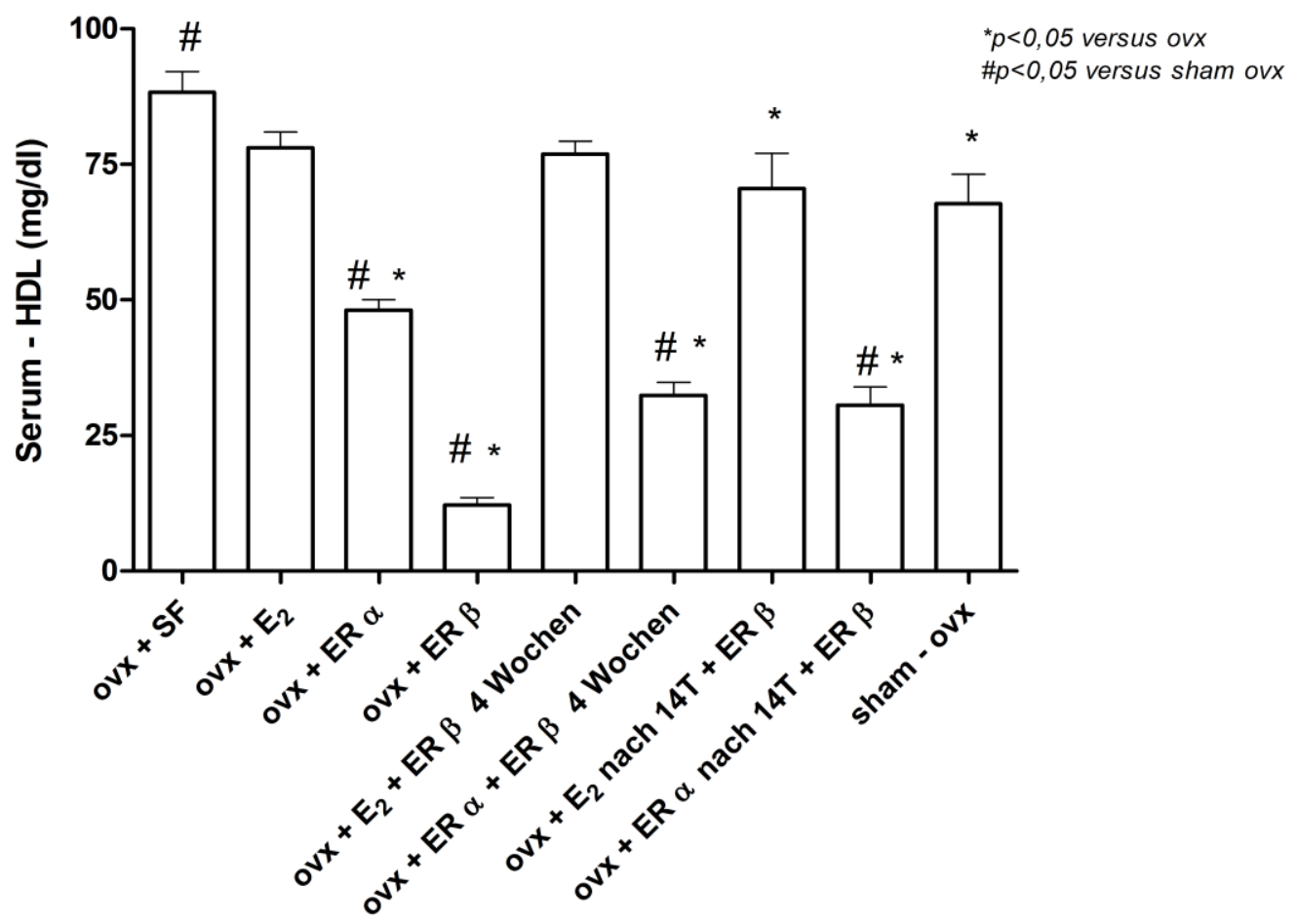

Abb. 3.4.2 Durchschnittlicher HDL-Serumwert der ovarektomierten Ratte nach 4-wöchiger s.c. Substitutionstherapie unter dem jeweiligen Applikationsschema mit $\mathbf{E}_{2}$, dem ER $\alpha$ - und ER $\beta$-Agonisten

\begin{tabular}{|c|c|c|c|c|c|c|c|c|c|}
\hline $\begin{array}{c}\text { Applikations- } \\
\text { schema }\end{array}$ & $\begin{array}{c}\text { ovx }+ \\
\text { SF }\end{array}$ & $\begin{array}{c}\mathrm{ovx}+ \\
\mathrm{E}_{2}\end{array}$ & $\begin{array}{l}\text { ovx }+ \\
\text { ER } \alpha\end{array}$ & $\begin{array}{l}\text { ovx }+ \\
\text { ER } \beta\end{array}$ & $\begin{array}{c}\mathrm{OVX}+ \\
\mathrm{E}_{2}+\mathrm{ER} \\
\beta \\
4 \mathrm{Wo-} \\
\text { chen }\end{array}$ & $\begin{array}{c}\text { ovx }+ \\
\text { ER } \alpha+ \\
\text { ER } \beta \\
4 \text { Wo- } \\
\text { chen }\end{array}$ & $\begin{array}{c}\text { ovx }+ \\
E_{2} \\
\text { nach } \\
14 T+ \\
\text { ER } \beta\end{array}$ & $\begin{array}{c}\text { ovx + } \\
\text { ER } \alpha \\
\text { nach } \\
14 \mathrm{~T}+ \\
\text { ER } \beta\end{array}$ & $\begin{array}{c}\text { sham } \\
\text { ovx }\end{array}$ \\
\hline $\begin{array}{c}\text { Ø HDL Wert } \\
\text { mg/dl }\end{array}$ & 88,3 & 78,1 & 48,2 & 12,2 & 76,9 & 32,5 & 70,6 & 30,6 & 67,8 \\
\hline
\end{tabular}


Die alleinige Applikation des ER $\alpha$ - und ER $\beta$-Agonisten sowie die gleichzeitige Substitution und die Stufenkombination beider Agonisten, zeigte eine signifikante Senkung des Serum-HDL-Wertes im Vergleich zu den Kontrolltieren und der physiologischen Vergleichsgruppe. Zudem führte die Stufen - Applikation von $\mathrm{E}_{2}$ mit dem ER $\beta$-Agonisten zu einer bedeutenden Reduzierung des HDL-Wertes im Vergleich zur ovx-Gruppe, jedoch nicht zur physiologischen Vergleichsgruppe. Im Vergleich zu den ovx Kontrolltieren zeigte die physiologische Kontrollgruppe eine signifikante Reduzierung des HDLWertes.

\subsubsection{LDL}

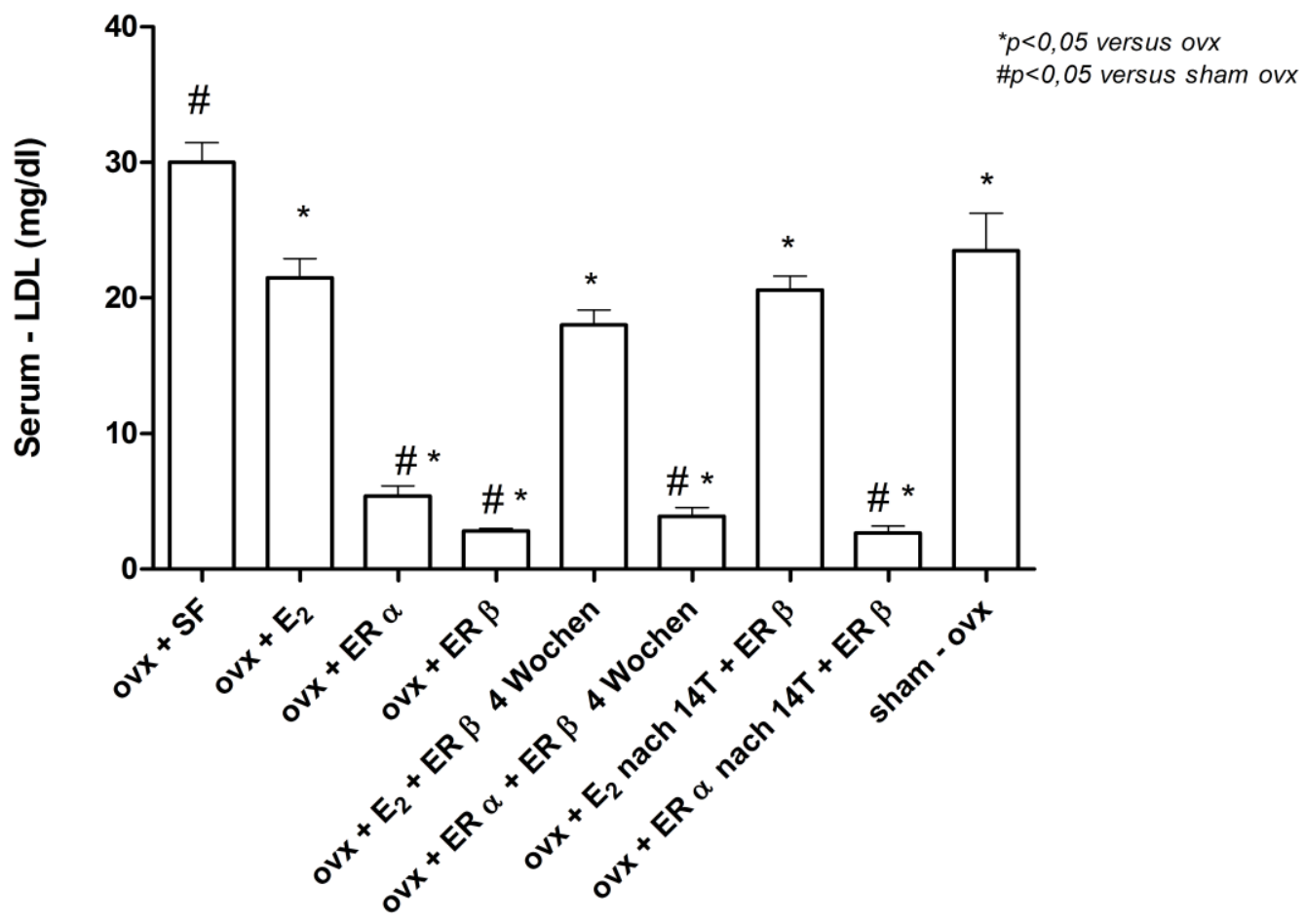

Abb. 3.4.3 Durchschnittlicher LDL-Serumwert der ovarektomierten Ratte nach 4-wöchiger s.c. Substitutionstherapie unter dem jeweiligen Applikationsschema mit $E_{2}$, dem ER $\alpha$ - und ER $\beta$-Agonisten

\begin{tabular}{|c|c|c|c|c|c|c|c|c|c|}
\hline $\begin{array}{l}\text { Applikations- } \\
\text { schema }\end{array}$ & $\begin{array}{c}\text { ovx }+ \\
\text { SF }\end{array}$ & $\begin{array}{c}\mathrm{ovx}+ \\
\mathrm{E}_{2}\end{array}$ & $\begin{array}{l}\text { ovx }+ \\
\text { ER } \alpha\end{array}$ & $\begin{array}{l}\text { ovx }+ \\
\text { ER } \beta\end{array}$ & $\begin{array}{c}\text { ovx }+ \\
\mathrm{E}_{2}+\mathrm{ER} \\
\beta \\
4 \mathrm{Wo-} \\
\text { chen }\end{array}$ & $\begin{array}{c}\text { ovx }+ \\
\text { ER } \alpha+ \\
\text { ER } \beta \\
4 \text { Wo- } \\
\text { chen }\end{array}$ & $\begin{array}{c}\text { ovx }+ \\
E_{2} \\
\text { nach } \\
14 T+ \\
\text { ER } \beta\end{array}$ & $\begin{array}{c}\text { ovx }+ \\
\text { ER } \alpha \\
\text { nach } \\
14 \mathrm{~T}+ \\
\text { ER } \beta\end{array}$ & $\begin{array}{c}\text { sham - } \\
\text { ovx }\end{array}$ \\
\hline $\begin{array}{c}\text { Ø LDL Wert } \\
\mathrm{mg} / \mathrm{dl}\end{array}$ & 30,0 & 21,5 & 5,4 & 2,8 & 18,0 & 3,9 & 20,6 & 2,6 & 23,5 \\
\hline
\end{tabular}


Alle untersuchten Gruppen zeigten im Vergleich zur ovx-Kontrollgruppe eine signifikante Reduzierung des LDL-Serumwertes. Die deutlichsten Unterschiede wurden hier bei den Tieren der Gruppen festgestellt, welche die alleinige Applikation des ER $\alpha$ - und ER $\beta$-Agonisten bekamen, sowie die gleichzeitige Substitution und die Stufenkombination beider Agonisten. Die Ergebnisse dieser Gruppen waren auch im Vergleich zur physiologischen Vergleichsgruppe signifikant niedrig in ihrem gemessenen LDL-Serumwert.

\subsubsection{LDL / HDL ratio}

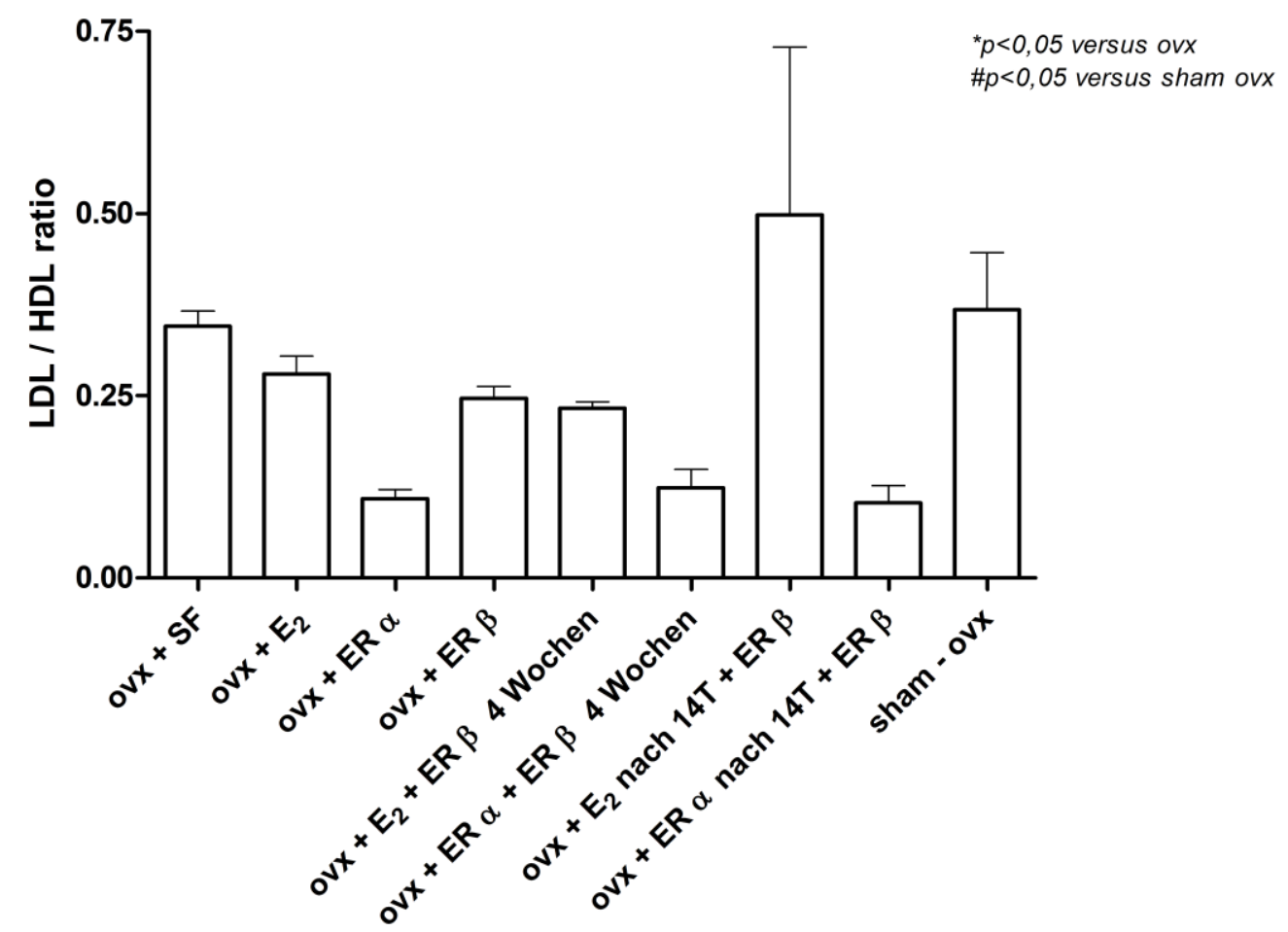

Abb. 3.4.4 LDL / HDL ratio der ovarektomierten Ratte nach 4-wöchiger s.c. Substitutionstherapie unter dem jeweiligen Applikationsschema mit $E_{2}$, dem ER $\alpha$ - und ER $\beta$ Agonisten

\begin{tabular}{|c|c|c|c|c|c|c|c|c|c|}
\hline $\begin{array}{c}\text { Applikations- } \\
\text { schema }\end{array}$ & $\begin{array}{c}\text { ovx }+ \\
\text { SF }\end{array}$ & $\begin{array}{c}\text { ovx + } \\
\mathrm{E}_{2}\end{array}$ & $\begin{array}{l}\text { ovx }+ \\
\text { ER } \alpha\end{array}$ & $\begin{array}{l}\text { ovx }+ \\
\text { ER } \beta\end{array}$ & $\begin{array}{c}\text { ovx }+ \\
\mathrm{E}_{2}+\mathrm{ER} \\
\beta \\
4 \mathrm{Wo}- \\
\text { chen }\end{array}$ & $\begin{array}{c}\text { ovx }+ \\
\text { ER } \alpha+ \\
\text { ER } \beta \\
4 \text { Wo- } \\
\text { chen }\end{array}$ & $\begin{array}{c}\text { ovx }+ \\
E_{2} \\
\text { nach } \\
14 T+ \\
\text { ER } \beta\end{array}$ & $\begin{array}{c}\text { ovx }+ \\
\text { ER } \alpha \\
\text { nach } \\
14 \mathrm{~T}+ \\
\text { ER } \beta\end{array}$ & $\begin{array}{c}\text { sham - } \\
\text { ovx }\end{array}$ \\
\hline $\begin{array}{l}\text { LDL / HDL } \\
\text { ratio }\end{array}$ & 0,34 & 0,28 & 0,11 & 0,25 & 0,23 & 0,12 & 0,50 & 0,10 & 0,37 \\
\hline
\end{tabular}


Die aus den LDL- und HDL-Werten errechnete ratio ergab in der statistischen Auswertung keine Signifikanz für eine der untersuchten Gruppen. Anzumerken bleibt, dass die mit ER $\alpha$-Agonist behandelten Tiere, egal ob isoliert und in Kombination mit dem ER $\beta$-Agonisten, niedrigere Werte aufwiesen als die übrigen Versuchsgruppen.

\subsubsection{Triglyzeride}

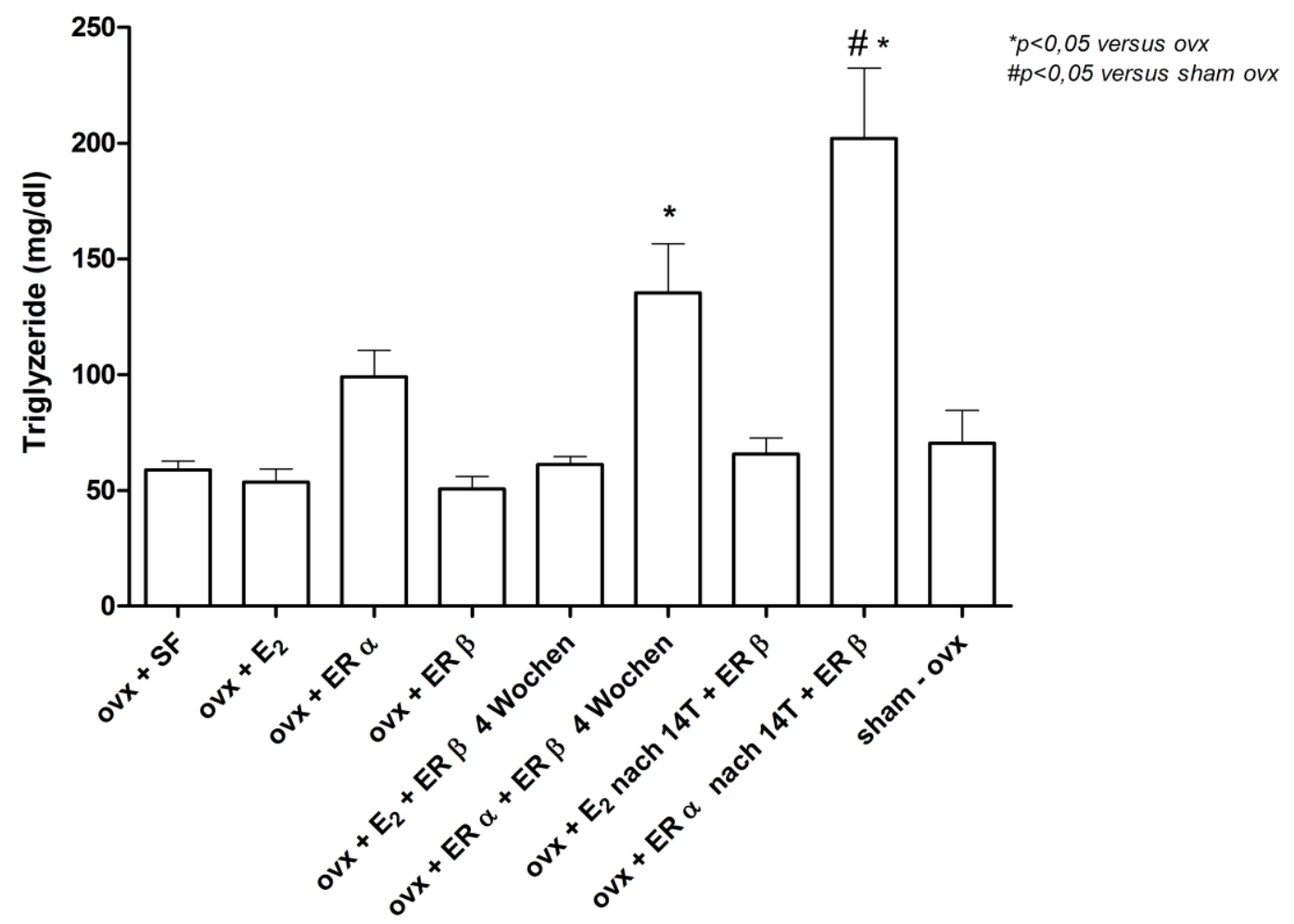

Abb. 3.4.5 Durchschnittlicher Triglyzerid-Serumwert der ovarektomierten Ratte
nach 4-wöchiger s.c. Substitutionstherapie unter dem
jeweiligen Applikationsschema mit $E_{2}$, dem ER $\alpha$ - und ER $\beta$-Agonisten

\begin{tabular}{|c|c|c|c|c|c|c|c|c|c|}
\hline $\begin{array}{c}\text { Applikations- } \\
\text { schema }\end{array}$ & $\begin{array}{c}\text { ovx }+ \\
\text { SF }\end{array}$ & $\begin{array}{c}\text { ovx }+ \\
E_{2}\end{array}$ & $\begin{array}{l}\text { ovx }+ \\
\text { ER } \alpha\end{array}$ & $\begin{array}{c}\text { ovx }+ \\
\text { ER } \beta\end{array}$ & $\begin{array}{c}\mathrm{OVx}+ \\
\mathrm{E}_{2}+\mathrm{ER} \\
\beta \\
4 \mathrm{Wo}- \\
\text { chen }\end{array}$ & $\begin{array}{c}\text { ovx }+ \\
\text { ER } \alpha+ \\
\text { ER } \beta \\
4 \text { Wo- } \\
\text { chen }\end{array}$ & $\begin{array}{c}\text { ovx }+ \\
E_{2} \\
\text { nach } \\
14 T+ \\
\text { ER } \beta\end{array}$ & $\begin{array}{c}\text { ovx }+ \\
\text { ER } \alpha \\
\text { nach } \\
14 T+ \\
\text { ER } \beta\end{array}$ & $\begin{array}{c}\text { sham - } \\
\text { ovx }\end{array}$ \\
\hline $\begin{array}{l}\varnothing \text { Triglyzerid- } \\
\text { wert in } \mathrm{mg} / \mathrm{dl}\end{array}$ & 59,0 & 53,7 & 99,0 & 50,6 & 61,2 & 135,3 & 65,7 & 202,1 & 70,5 \\
\hline
\end{tabular}


Eine signifikante Steigerung des Triglyzeridspiegels im Serum der ovarektomierten Ratte wurde durch die Behandlung der Tiere durch die durchgehende Kombination des ER $\alpha$-Agonisten mit dem ER $\beta$ Agonisten sowie die Stufentherapie beider Substanzen erreicht. Die Stufenapplikation beider ERAgonisten zeigte zudem eine signifikante Erhöhung gegenüber der physiologischen Vergleichsgruppe. Die alleinige Gabe des ER $\alpha$-Agonisten führte zwar zu einer deutlichen Erhöhung des Triglyzeridwertes, welche jedoch als nicht signifikant gewertet wurde.

\subsubsection{Triglyzerid / HDL-ratio}

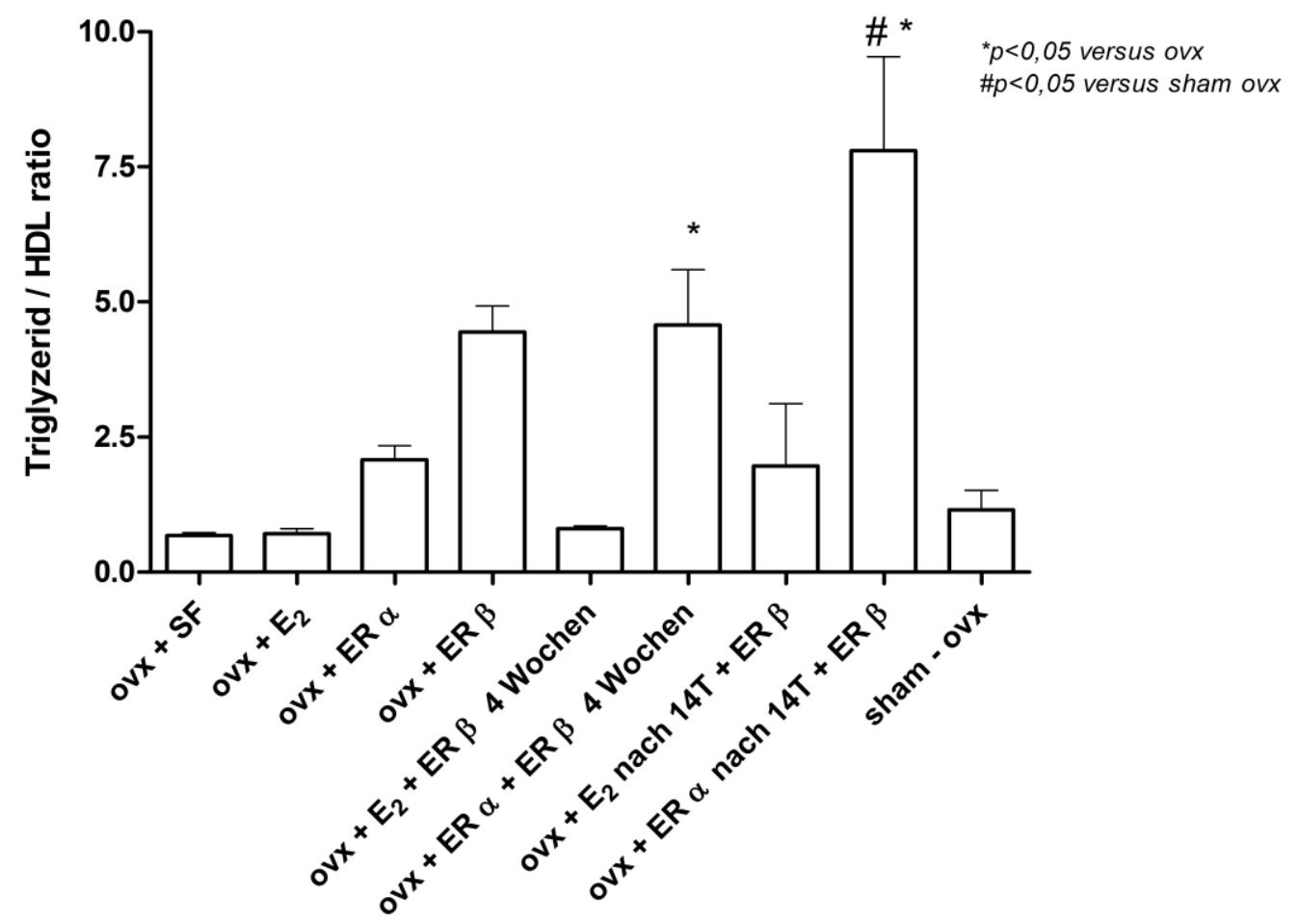

Abb. 3.4.6 Triglyzerid / HDL-ratio der ovarektomierten Ratte nach 4-wöchiger s.c. Substitutionstherapie unter dem jeweiligen Applikationsschema mit $E_{2}$, dem ER $\alpha$ - und ER ß-Agonisten

\begin{tabular}{|c|c|c|c|c|c|c|c|c|c|}
\hline $\begin{array}{l}\text { Applikations- } \\
\text { schema }\end{array}$ & $\begin{array}{c}\text { ovx }+ \\
\text { SF }\end{array}$ & $\begin{array}{c}\mathrm{ovx}+ \\
\mathrm{E}_{2}\end{array}$ & $\begin{array}{l}\text { ovx }+ \\
\text { ER } \alpha\end{array}$ & $\begin{array}{l}\text { ovx }+ \\
\text { ER } \beta\end{array}$ & $\begin{array}{c}\text { ovx }+ \\
\mathrm{E}_{2}+\mathrm{ER} \\
\beta \\
4 \mathrm{Wo-} \\
\text { chen }\end{array}$ & $\begin{array}{c}\text { ovx }+ \\
\text { ER } \alpha+ \\
\text { ER } \beta \\
4 \text { Wo- } \\
\text { chen }\end{array}$ & $\begin{array}{c}\text { ovx }+ \\
\mathrm{E}_{2} \\
\text { nach } \\
14 \mathrm{~T}+ \\
\text { ER } \beta\end{array}$ & $\begin{array}{c}\text { ovx + } \\
\text { ER } \alpha \\
\text { nach } \\
14 \mathrm{~T}+ \\
\mathrm{ER} \beta\end{array}$ & $\begin{array}{c}\text { sham - } \\
\text { ovx }\end{array}$ \\
\hline Triglyzeride / & & & & & & & & & \\
\hline $\begin{array}{l}\text { HDL } \\
\text { ratio }\end{array}$ & 0,68 & 0,71 & 2,09 & 4,44 & 0,80 & 4,58 & 1,97 & 7,80 & 1,16 \\
\hline
\end{tabular}


Eine signifikante Steigerung des Triglyzerid-HDL-Index der ovarektomierten Ratte wurde durch die Behandlung der Tiere, durch die durchgehende Kombination des ER $\alpha$-Agonisten mit dem ER $\beta$ Agonisten sowie die Stufentherapie beider Substanzen erreicht. Die Stufenapplikation beider ERAgonisten zeigte zudem eine signifikante Erhöhung gegenüber der physiologischen Vergleichsgruppe. Die alleinige Gabe des ER $\alpha$-Agonisten führte zwar zu einer deutlichen Erhöhung des Triglyzeridwertes, welche jedoch als nicht signifikant ausgewertet wurde. Dieses Ergebnis deckt sich mit der Auswertung für Triglyzerid im Serum unter Punkt 3.4.5.

\subsubsection{IGF}

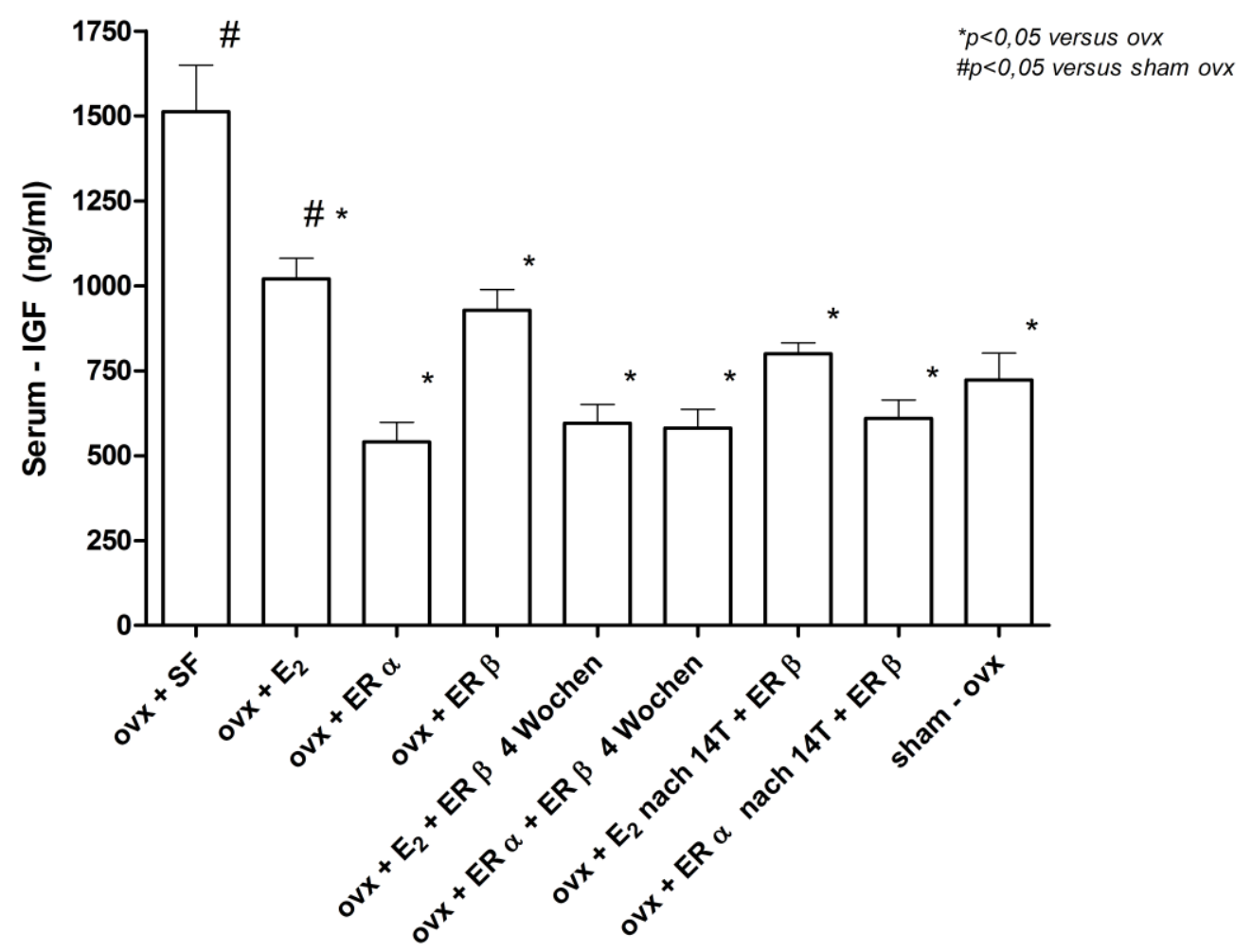

Abb. 3.4.7 Durchschnittlicher IGF-Serumwert der ovarektomierten Ratte nach 4-wöchiger s.c. Substitutionstherapie unter dem jeweiligen Applikationsschema mit $\mathbf{E}_{2}$, dem ER $\alpha$ - und ER $\beta$-Agonisten

\begin{tabular}{|c|c|c|c|c|c|c|c|c|c|}
\hline $\begin{array}{c}\text { Applikations- } \\
\text { schema }\end{array}$ & $\begin{array}{c}\text { ovx }+ \\
\text { SF }\end{array}$ & $\begin{array}{c}\mathrm{ovx}+ \\
\mathrm{E}_{2}\end{array}$ & $\begin{array}{l}\text { ovx }+ \\
\text { ER } \alpha\end{array}$ & $\begin{array}{l}\text { ovx }+ \\
\text { ER } \beta\end{array}$ & $\begin{array}{c}\text { ovx }+ \\
\mathrm{E}_{2}+\mathrm{ER} \\
\beta \\
4 \mathrm{Wo-} \\
\text { chen }\end{array}$ & $\begin{array}{c}\text { ovx }+ \\
\text { ER } \alpha+ \\
\text { ER } \beta \\
4 \text { Wo- } \\
\text { chen }\end{array}$ & $\begin{array}{c}\text { ovx }+ \\
E_{2} \\
\text { nach } \\
14 \mathrm{~T}+ \\
\text { ER } \beta\end{array}$ & $\begin{array}{c}\text { ovx }+ \\
\text { ER } \alpha \\
\text { nach } \\
14 T+ \\
\text { ER } \beta\end{array}$ & $\begin{array}{c}\text { sham - } \\
\text { ovx }\end{array}$ \\
\hline $\begin{array}{l}\text { Ø IGF Wert } \\
\text { in } \mathrm{ng} / \mathrm{ml}\end{array}$ & 1513,7 & 1020,5 & 540,5 & 928,3 & 596,1 & 581,5 & 799,9 & 609,6 & 722,8 \\
\hline
\end{tabular}


Alle verabreichten Substanzen in Reindosis sowie in Kombination in verschiedenen Applikationsschemen erzielten eine signifikante Erniedrigung des Serumwertes für IGF im Vergleich zu den Tieren der Kontrollgruppe. Die einfache Verabreichung von $\mathrm{E}_{2}$ hatte hierbei noch die geringste Senkung des Wertes zur Folge. Gegenüber den sham-ovx Tieren war der IGF-Wert unter der reinen $\mathrm{E}_{2}$ Therapie sogar signifikant erhöht.

\subsubsection{IGF-Index}

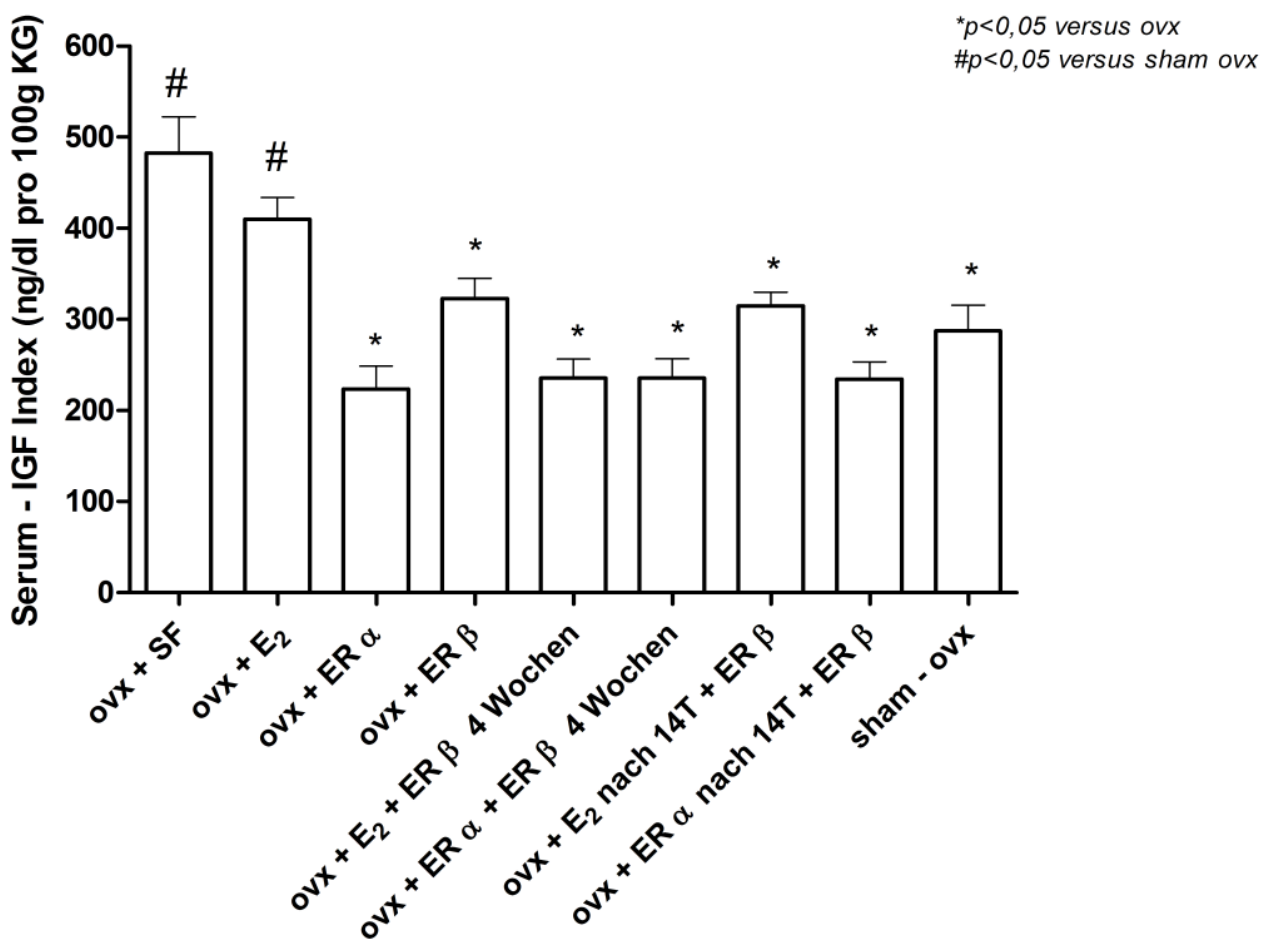

Abb. 3.4.8 Serum-IGF-Index auf 100g Körpergewicht der ovarektomierten Ratte nach 4wöchiger s.c. Substitutionstherapie unter dem jeweiligen Applikationsschema mit $E_{2}$, dem ER $\alpha$ - und ER $\beta$-Agonisten

\begin{tabular}{|c|c|c|c|c|c|c|c|c|c|}
\hline $\begin{array}{c}\text { Applikations- } \\
\text { schema }\end{array}$ & $\begin{array}{c}\text { ovx }+ \\
\text { SF }\end{array}$ & $\begin{array}{c}\text { ovx + } \\
\mathrm{E}_{2}\end{array}$ & $\begin{array}{l}\text { ovx }+ \\
\text { ER } \alpha\end{array}$ & $\begin{array}{l}\text { ovx }+ \\
\text { ER } \beta\end{array}$ & $\begin{array}{c}\mathrm{ovx}+ \\
\mathrm{E}_{2}+\mathrm{ER} \\
\beta \\
4 \mathrm{Wo-} \\
\text { chen }\end{array}$ & $\begin{array}{c}\text { ovx }+ \\
\text { ER } \alpha+ \\
\text { ER } \beta \\
4 \text { Wo- } \\
\text { chen }\end{array}$ & $\begin{array}{c}\text { ovx }+ \\
\mathrm{E}_{2} \\
\text { nach } \\
14 \mathrm{~T}+ \\
\text { ER } \beta\end{array}$ & $\begin{array}{l}\text { ovx }+ \\
\text { ER } \alpha \\
\text { nach } \\
14 \mathrm{~T}+ \\
\text { ER } \beta\end{array}$ & $\begin{array}{c}\text { sham - } \\
\text { ovx }\end{array}$ \\
\hline $\begin{array}{c}\varnothing \mathrm{IGF}- \\
\text { Wert auf } \\
100 \mathrm{~g} \mathrm{KG}\end{array}$ & 482,6 & 382,5 & 223,6 & 286,9 & 201,2 & 204,0 & 314,9 & 196,0 & 335,5 \\
\hline
\end{tabular}


Durch die Umrechnung der IGF-Werte im Verhältnis zum Körpergewicht konnte gezeigt werden, dass alle Gruppen bis auf die Tiere, welche allein mit $\mathrm{E}_{2}$ therapiert wurden, eine Signifikanz in Bezug auf den gemessenen IGF-Serumwert im Verhältnis zur ovx-Kontrollgruppe besteht. Einzig die $\mathrm{E}_{2}$ therapierte Tiere wiesen eine signifikante Erhöhung des IGF-Wertes in Bezug auf das Körpergewicht auf.

\subsubsection{Glukose}

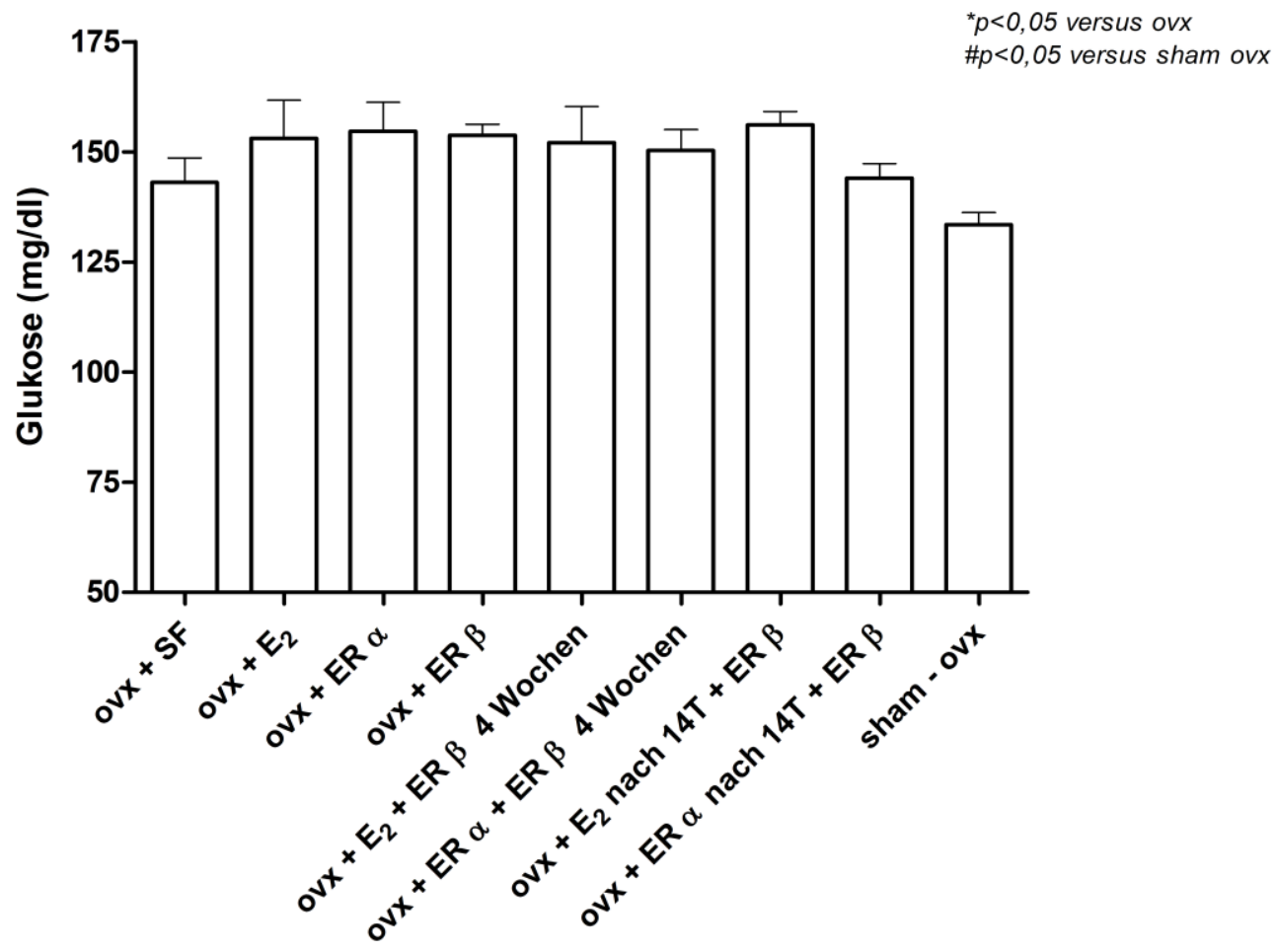

Abb. 3.4.9 Durchschnittlicher Glukose-Serumwert der ovarektomierten Ratte nach 4wöchiger s.c. Substitutionstherapie unter dem jeweiligen Applikationsschema mit $E_{2}$, dem ER $\alpha$ - und ER $\beta$-Agonisten 


\begin{tabular}{|c|c|c|c|c|c|c|c|c|c|}
\hline $\begin{array}{l}\text { Applikations- } \\
\text { schema }\end{array}$ & $\begin{array}{c}\text { ovx }+ \\
\text { SF }\end{array}$ & $\begin{array}{c}\mathrm{ovx}+ \\
\mathrm{E}_{2}\end{array}$ & $\begin{array}{l}\text { ovx }+ \\
\text { ER } \alpha\end{array}$ & $\begin{array}{l}\text { ovx }+ \\
\text { ER } \beta\end{array}$ & $\begin{array}{c}\mathrm{Ovx}+ \\
\mathrm{E}_{2}+\mathrm{ER} \\
\beta \\
4 \mathrm{Wo-} \\
\text { chen } \\
\end{array}$ & $\begin{array}{c}\text { ovx }+ \\
\text { ER } \alpha+ \\
\text { ER } \beta \\
4 \text { Wo- } \\
\text { chen } \\
\end{array}$ & $\begin{array}{c}\text { ovx + } \\
E_{2} \\
\text { nach } \\
14 T+ \\
\text { ER } \beta\end{array}$ & $\begin{array}{c}\text { ovx + } \\
\text { ER } \alpha \\
\text { nach } \\
14 \mathrm{~T}+ \\
\mathrm{ER} \beta\end{array}$ & $\begin{array}{c}\text { sham - } \\
\text { ovx }\end{array}$ \\
\hline $\begin{array}{l}\varnothing \quad \text { Glukose- } \\
\text { wert in } \mathrm{mg} / \mathrm{dl}\end{array}$ & 143 & 153 & 155 & 154 & 152 & 150 & 156 & 144 & 134 \\
\hline
\end{tabular}

In Bezug auf den Serum-Glukosewert wurde festgestellt, dass es zu keiner signifikanten Erhöhung oder Reduzierung der Glukosekonzentration der Versuchsgruppen im Vergleich zur Kontrollgruppe oder physiologischen Vergleichsgruppe kam. Die physiologische Vergleichsgruppe sham-ovx zeigte den niedrigsten gemessenen Glukosespiegel im Vergleich zu allen untersuchten Gruppen. 


\section{Diskussion}

Vor dem Hintergrund, dass durch die demographische Entwicklung immer mehr Frauen einen längeren Zeitraum ihres Lebens in einem postmenopausalen Zustand verbringen, ist die Erforschung von Pharmazeutika, welche speziell auf die Bedürfnisse und Beschwerden dieser Patientenklientel ausgerichtet sind, von großer Bedeutung. In der Vergangenheit wurden durch die Studien „Women Health Initiative (WHI)“ (Rossouw et al. 2002) und der „Million Women Study“ (Beral 2003) die bedrohlichen Nebenwirkungen einer langjährigen HRT festgestellt. Über die Entwicklung von hochselektiven potenten ER-Agonisten eröffnete sich die Möglichkeit, gezielt zu erforschen, welcher ER in welchem Gewebe des Körpers eine bestimmte östrogene Wirkung vermittelt. Das langfristige Ziel der Forschung wird es sein, ein Therapeutikum zu entwickeln, welches in der Lage ist, eine östrogene Wirkung an einem spezifischen Organ auszulösen ohne zu Nebenwirkungen an anderen östrogensensiblen Geweben zu führen. Die Basis hierfür ist jedoch ein genaues Verständnis der gewebsspezifischen Wirkungsweise der ER $\alpha$ und $\beta$ und ihrer Interaktion untereinander.

Ziel dieser Arbeit war es, am Versuchsmodell der ovx Ratte die therapeutischen Auswirkung des Einsatzes von $\mathrm{E}_{2}$ und der selektiven ER-Agonisten $\alpha$ und $\beta$ in Kombination bei simultaner gleichzeitiger und simultaner zeitversetzter Substitution über einen Versuchszeitraum von 4 Wochen zu untersuchen. Im Fokus der Untersuchung standen das Skelettmuskel- und Fettgewebe sowie verschiedene mit ihnen assoziierte Serumparameter (Cholesterol, Triglyzeride, Glukose und IGF).

Es wurde besonders darauf geachtet, ob es durch den gleichzeitigen oder zeitversetzten Einsatz des ER $\beta$-Agonisten zu einem hemmenden oder fördernden Einfluss auf die Wirkung des ER $\alpha$-Agonisten oder $\mathrm{E}_{2}$ kommt. Besteht eine Ying-Yang Beziehung der beiden ERs zueinander oder ist diese durch Gustafsson erhobene Theorie für das Skelettmuskel- und Fettgewebe nicht zu treffend?

Grundlage für diese experimentelle in vivo Untersuchung bildete das wissenschaftlich anerkannte Versuchsmodell der ovarektomierten Ratte (Lelovas et al. 2008), dass einen hormonellen menopausalen Zustand der Versuchstiere durch die chirurgische Entfernung der Ovarien produziert. Eine physiologische Vergleichsgruppe zu den ovx Tieren bildete eine intakte sham-ovx Gruppe, welche nur eine Schein-OP und regelmäßige Placebo Injektionen erfuhr. Eine weitere Kontrollgruppe wurde durchgehend mit $\mathrm{E}_{2}$ therapiert.

Ovx Ratten wurde in der Vergangenheit schon oft zur Erforschung von Therapeutika verwendet, welche östrogene Wirkungen vermitteln sollten. Die Zielgewebe dieser Untersuchungen waren vornehmlich die Geschlechtsorgane und das Knochengewebe. Das Skelettmuskel-und das Fettgewebe sind bisher noch nicht häufig im Fokus der Forschung bei der Substitutionstherapie mit ER-Agonisten und $\mathrm{E}_{2}$ gewesen. 


\subsection{Körpergewicht}

Der durch die Ovx hervorgerufene hypoöstrogene Zustand der Versuchstiere ist gleichzeitig mit einem Aktivitätsrückgang, einer Zunahme der Nahrungsaufnahme und des Körpergewichtes sowie einer Veränderung der Körperkomposition der Tiere verbunden, welche durch die Substitutionsgabe von $\mathrm{E}_{2}$ rückgängig gemacht werden kann (Asarian und Geary 2002; Roepke et al. 2010).

Dies bedeutet, dass eine Verringerung des Gewichtes der Versuchstiere durch eine reduzierte Nahrungsaufnahme, eine Steigerung der Bewegungsaktivität sowie den lipolytischen Effekt des $\mathrm{E}_{2}$ und des ER $\alpha$-Agonisten geschieht (Seidlovà-Wuttke et al. 2008; Lobo et al. 1993).

Wir konnten in unserer Untersuchung nachweisen, dass die ovx Tiere, welche keine Substitutionsbehandlung erfahren haben, den größten und signifikantesten Anstieg des Körpergewichtes im Vergleich zu nahezu allen Vergleichsgruppen (bis auf ovx + ER $\beta$ ) zu verzeichnen hatten. Die mit dem ER $\alpha$ Agonisten therapierten Tiere zeigten das geringste Körpergewicht am Ende des Versuches. In der Gegenüberstellung zur physiologischen Vergleichsgruppe (sham-ovx), welche lediglich eine Placebobehandlung erfuhr, zeigten außer dem isoliert applizierten ER $\alpha$-Agonisten drei weitere Gruppen $\left(\mathrm{E}_{2}\right.$ über 4 Wochen, ER $\alpha$ und ER $\beta$-Agonist über 4 Wochen und $E_{2}$ plus ER $\beta$-Agonist in Stufenkombination) gar eine Gewichtsabnahme, was die Potenz der verabreichten Substanzen ( $E_{2}$ und ER $\alpha$ - Agonist) in Bezug auf Verringerung des Körpergewichtes verdeutlicht. Diese anorektische Wirkung der Östrogentherapie bei ovx Ratten (Asarian und Geary 2002) wurde durch diesen Versuch abermals bestätigt. Der ER $\alpha$-Agonist fiel hierbei im Vergleich zum ER $\beta$-Agonisten als das deutlich potentere Substrat zur Verhinderung der Gewichtszunahme nach Ovx auf (Seidlovà-Wuttke et al. 2008).

Die Hypothese, dass $E_{2}$ den Appetit, den Energieaufwand und die Fettakkumulation der Versuchstiere durch den ER $\alpha$ reguliert (Geary 2004, Shi et al. 2009), konnten wir indirekt über die Bestimmung des Körpergewichtes bestätigen. Die $\mathrm{E}_{2}$-Substitutionsbehandlung von Wild-Typ und ER $\beta$-KnockoutMäusen zeigte eine Reduzierung der Nahrungsaufnahme und des Körpergewichtes, wohingegen die Substitutionsbehandlung bei ER $\alpha$-Knockout-Mäusen keinen Effekt zeigte, was die These erhärtet, dass die oben beschriebenen Effekte durch den ER $\alpha$ vermittelt werden (Geary 2004). Des Weiteren wird diese Vermutung durch die Tatsache unterstützt, dass die Mengenverteilung der Rezeptoren im Fettgewebe von ER $\alpha$ und ER $\beta$ zu Gunsten des ER $\alpha$ ausfällt, was den von uns beobachteten lipolytischen Effekt bestätigen würde.

Die simultan zeitversetzte Applikation vom ER $\alpha$ - und ER $\beta$-Agonisten führte zwar noch zu einer signifikanten Gewichtsreduzierung im Verhältnis zu den nicht-therapierten Tieren, jedoch scheint der ER $\beta$-Agonist die östrogene Wirkung des ER $\alpha$-Agonisten hemmend beeinflusst zu haben. Anderenfalls wäre ein vergleichsweise hoher Wert von durchschnittlich 259,8g pro Tier nicht zu erklären. Im Gegensatz dazu steht das Ergebnis, das durch die simultane Gabe der beiden ER-Agonisten erzielt wurde, 
was den am meisten anorektischten Effekt bei allen Gruppen erzielte. Hier konnte somit keine hemmende Wirkung des ER $\beta$-Agonisten auf den ER $\alpha$-Agonisten nachgewiesen werden.

Insgesamt war in der Bewertung des Körpergewichtes die simultane kontinuierliche Therapie der Substanzen erfolgreicher als die simultane zeitversetzte Applikation mit dem ER $\beta$-Agonisten.

\subsection{Fettgewebe}

Durch den entstehenden Östrogenmangel in der Menopause kommt es zu einer Umverteilung der Fettreserven vom subkutanen Gewebe hin zu einer Vermehrung der intraabdominalen, zentralen Fettdepots. Diese Entwicklung ist mit einem höheren Erkrankungsrisiko für Diabetes, Dyslipidämie und Herz-Kreislauf Erkrankungen assoziiert (Metabolisches Syndrom) (Toth et al. 2001).

Dass es sich beim Fettgewebe um ein östrogen-sensibles Organ handelt, wurde durch das Vorkommen von ER $\alpha$ und ER $\beta$ belegt, was dem Fettgewebe die Fähigkeit verleiht Bindungen mit Östrogenen bzw. östrogen-ähnlichen Substanzen einzugehen. Somit kann durch Östrogene eine direkte Veränderung des Fettgewebes stattfinden (Pedersen et al. 2001). Der durch die Ovx von Ratten induzierte Östrogenmangel führt zu einer Vermehrung des intraabdominalen Fettes, was durch die periphere Gabe von E2 verhindert werden kann (Clegg et al. 2006).

Unsere pqCT-Untersuchung in Höhe des LWK 4 / 5 zeigte, dass die nicht therapierte Gruppe der ovxTiere (ovx-SF) die größte Vermehrung an intraabdominal lokalisiertem Fettgewebe aufwies. Diesbezüglich konnten wir die oben genannte These bestätigen (Toth et al. 2000), dass es durch einen Rückgang von Östrogenen zu einer Vermehrung des intraabdominalen Fett kommt. Für die Versuchstiergruppe, die mit $\mathrm{E}_{2}$ über 4 Wochen therapiert wurde, wurde der niedrigste Wert für intraabdominal gelegene Fettreserven gemessen. Im Vergleich zu dem Durchschnittswert, welcher vor der Ovx der Versuchstiere erhoben wurde, ist es gar zu einer Verringerung des Fettgewebsanteil gekommen. Neben der $E_{2}$ therapierten Gruppe, zeigten auch die mit dem ER $\alpha$-Agonisten, sowie die simultan zeitversetzt mit ER $\alpha$ - und ER $\beta$-Agonisten therapierten Versuchstiere eine Verringerung des intraabdominalen Fettgewebeanteils zum Ausgangswert auf. Die mit dem ER $\beta$-Agonisten therapierten Tiere zeigten keine signifikante Verringerung des Fettgewebes im Vergleich zur ovx-SF Gruppe bzw. zur physiologischen Vergleichsgruppe sham-ovx. Überraschenderweise erzielte die sham-ovx Vergleichsgruppe den zweitgrößten Wert für den prozentualen intraabdominalen Fettgewebeanteil von allen untersuchten Gruppen. Es konnte nachgewiesen werden, dass der alleinige Einsatz von $E_{2}$ und dem ER $\alpha$-Agonisten zu einer signifikanten Reduzierung des intraabdominalen Fettgewebsanteils führt. Diese therapeutische Wirkung durch $\mathrm{E}_{2}$ und einen ER $\alpha$-Agonisten auf die Verhinderung der quantitativen Zunahme des zentralen Fettdepots wurde bereits in der Literatur beschrieben (Harris et al. 2003). Der ER $\beta$-Agonist zeigte in der simultanen kontinuierlichen Applikation mit ER $\alpha$ Agonisten und $\mathrm{E}_{2}$ eine hemmende Wirkung. In der simultan zeitversetzten Therapie mit dem ER $\beta$ - 
Agonist wurde eine inhibitorische Wirkung mit dem $\mathrm{E}_{2}$ nachgewiesen, jedoch eine synergistische Auswirkung mit dem ER $\alpha$-Agonisten erzielt. Somit besteht für die kontinuierliche Kombinationstherapie mit ER $\beta$-Agonist eine Yin-Yang Beziehung beider ERs, für die simultane zeitversetzte Therapieform jedoch nicht.

Das Verständnis für die Mechanismen, welche für die Umverteilung des Fettgewebes vom peripheren zum intraabdominalen Kompartiment verantwortlich sind sowie die Rolle des Östrogenmangels in diesem Prozess, ist für die gesundheitlichen Auswirkung postmenopausaler Frauen von großer Bedeutung (Toth et al. 2000) und bietet noch große Möglichkeiten für weitere Forschungsarbeiten.

\subsection{Muskelgewebe}

\subsection{1 pqCT-Messung}

Während der Auswirkung von Östrogen auf Geschlechtsorgane und Knochen eine detaillierte Studienlage zugrunde liegt, sind andere Gewebetypen wie der Skelettmuskel in ihrer Östrogensensibilität und Wirkung noch nicht umfassend erforscht worden. Die Grundvoraussetzung, dass das Skelettmuskelgewebe wie die klassischen Zielorgane direkt auf östrogenen Einfluss Veränderung zeigt, ist durch die Existenz von ER $\alpha$ und ER $\beta$ bei Mensch und Ratte gegeben (Dahlberg 1982, Lemoine et al. 2003, McCormick et al. 2004). Tierexperimentelle Studien haben in der Vergangenheit demonstriert, dass es sich beim Skelettmuskel, um ein Zielorgan von Östrogenen handelt (Krempien et al. 1977; Lemoine et al. 2002; Wiik et al. 2003).

Die Ovx der Tiere in unserer Studie führte durchgehend bei allen Untersuchungsgruppen zu einer Zunahme der Muskelgewebefläche im Bereich des LWK 4/5 im Vergleich zum gemessenen Ausgangswert vor Versuchsbeginn. Dass Ratten nach Ovx eine Zunahme des Köpergewichtes und der Muskelmasse entwickeln, wurde bereits in anderen Versuchen bewiesen (McClung et al. 2006, Moran et al. 2007). Dieser Effekt wird durch die vermehrte Ausschüttung von GH und IGF-1 um bis zu 30\% erklärt (Fisher et al. 2000).

Lediglich die physiologische Vergleichsgruppe sham-ovx wies als einzige Gruppe eine Verkleinerung der abdominalen Muskelgewebefläche auf. Die computertomographisch erhobenen Ergebnisse korrelieren sehr eng mit den Ergebnissen, welche wir bei der Gewichtsbestimmung der einzelnen Testgruppen erhoben haben.

Der einzige Unterschied in Bezug auf die Signifikanz der Ergebnisse besteht darin, dass die Tiere der Versuchsgruppen, die nach 14 Tagen zusätzlich mit dem ER $\beta$-Agonisten therapiert wurden gegenüber 
der physiologischen Vergleichsgruppen einen signifikant höheren Anteil an abdominaler Muskelfläche zu verzeichnen hatten.

Der allein applizierte ER $\beta$-Agonist zeigte die schwächste östrogene Wirkung, da er nach der Gruppe der ovx + SF-Tiere den höchsten Wert aufwies.

Insgesamt ließ sich feststellen, dass alle Versuchsgruppen, bis auf den ER $\beta$-Agonisten, eine signifikante Verkleinerung der abdominal gemessenen Muskelgewebefläche im Vergleich zu den nicht therapierten Tieren ovx + SF hatten.

Die gemeinsame kontinuierliche und gemeinsame zeitversetzte Kombinationstherapie mit dem ER $\beta$ Agonisten zeigte ausschließlich einen synergetischen Effekt. Die simultane kontinuierliche Applikationstherapie zeigte eine stärkere östrogene Wirkung als die zeitversetzte Therapie. Auf Grund dieser Ergebnisse konnten wir keine inhibitorische Wirkung des ER $\beta$-Agonisten nachweisen, womit auch keine Ying-Yang Beziehung zwischen ER $\alpha$ und $\beta$, beim im pqCT gemessenen Muskelgewebe, besteht.

In der Literatur gibt es keine vergleichbaren tierexperimentellen Studien zu der unseren, bei der ein künstlich hervorgerufener Östrogenmangelzustand der Versuchstiere durch Ovx herbeigeführt wurde und eine parenterale Applikationstherapie mit $\mathrm{E}_{2}, \mathrm{ER} \alpha$ - und ER $\beta$-Agonisten über 4 Wochen durchführt wurde. Mittels pqCT wurde dann eine abdominale Dichtemessung zur Gewebebestimmung durchgeführt. Überaschenderweise zeigte die nicht-Ovx Vergleichsgruppe mit dem höchsten abdominalen Fettgewebsanteil und der niedrigsten Muskelgewebefläche die extremsten Ergebnisse dieser pqCT Diagnostik, womit im Vorfeld nicht zu rechnen gewesen ist.

\subsubsection{Histomorphometrische Messung}

Bei der histomorphometrischen Messung des Caput laterale des M. gastrocnemius zeigte sich ein anderes Ergebnis als bei der pqCT Messung der Muskelfaserfläche. Die mit $\mathrm{E}_{2}$ therapierten Tiere zeigten eine signifikante Verringerung der einzelnen Muskelfaserfläche im Vergleich zu der physiologischen Vergleichsgruppe sham-ovx. Ebenso wie bei der muskulären abdominalen Messung war die Muskelfaserfläche der nicht-therapierten ovx Tiere größer als die gemessene Fläche der $\mathrm{E}_{2}$ therapierten Tiere. Die stärkste östrogene Potenz in dieser Untersuchung wurde bei den Versuchsgruppen nachgewiesen, welche mit dem ER $\alpha$-Agonisten alleine oder in Kombination mit dem ER $\beta$-Agonisten durchgehend gemeinsam oder zeitversetzt therapiert wurden. Im Gegensatz dazu kam es bei der Applikation des ER $\beta$-Agonisten in Kombination mit $\mathrm{E}_{2}$ gar zu einer Vergrößerung der Muskelfaserfläche. Ein geringer hemmender Effekt des ER $\beta$-Agonisten auf die Wirkung von ER $\alpha$ konnte nachgewiesen werden. Im Gegensatz dazu bestand bei der Kombinationstherapie des $E_{2}$ mit dem ER $\beta$ Agonisten ein synergetischer Effekt. 
Es liegt nahe zu spekulieren, dass der Rückgang der Östrogenproduktion während des Alterns mit der Abnahme von Muskelmasse zusammenhängt, jedoch ist sie Studienlage zu diesem Thema schwer zu durchschauen und interpretieren, sowohl für die Ergebnisse für den Menschen als auch Daten aus tierexperimentellen Versuchsreihen, da mannigfaltige Einflussfaktoren berücksichtig werden müssen. Zahlreiche Studien existieren, die eine Verbindung zwischen Muskelmasse und Östrogenen unterstützen (Sorensen et al. 2001) und wiederum andere wissenschaftliche Arbeiten, die keinen Zusammenhang zwischen Muskelmasse und Östrogenen nachweisen konnten (Hansen et al. 2003). Nach durchgeführter Metaanalyse der Studienlage lässt sich insgesamt feststellen, dass die Beweise für einen anabolischen Effekt von Östrogenen auf den Skelettmuskel des Menschen, den Ergebnissen gegen eine östrogene Wirkung überwiegen (Brown 2008).

Tierexperimentell zeigte die Arbeit unter anderem von Kobori und Yamamuro bereits 1989, dass die durchschnittliche Muskelfasergröße und Masse des M. soleus bei ovx Ratten kleiner war, die eine Östrogen-Ersatztherapie erhalten hatten, als bei den Versuchstieren, welche keine Substitutionsbehandlung erhielten (Kobori und Yamamuro 1989; Warren et al. 1996). Diese Ergebnisse decken sich mit unseren Untersuchungsergebnissen, bei denen die Testgruppe ovx-SF größere Muskelfaserquerschnitte aufwies als die mit $\mathrm{E}_{2}$ oder ER $\alpha$-Agonisten therapierten Gruppen.

Dem entgegengesetzt steht die Aussage von Fisher et al. 2000, dass Ovx keinen Effekt auf den M. soleus in Muskelmasse und Muskelfasergröße hat.

Es gibt mehrere Faktoren, die einen Einfluss auf die Wirkung von Östrogenen auf den tierischen Skelettmuskel haben. Zu diesen Faktoren gehören unter anderem das Alter der Versuchstiere, die Möglichkeit der freien Nahrungsaufnahme während des Versuchszeitraums, der hormonelle Status der Tiere, der zu untersuchende Muskelfasertyp, die physische Aktivität der Versuchstiere und schließlich indirekte Wirkungsmechanismen. Allein die Anzahl der genannten beeinflussenden Faktoren lässt erahnen, welche Komplexität die Untersuchung von hormonellen Einflüssen auf das Muskelgewebe mit sich bringt. Eine Vergleichbarkeit von Studienergebnissen ist auf Grund dieser vielfältigen Einflussmöglichkeiten nur äußert schwer durchzuführen.

Bei ausgewachsenen, reifen Ratten hatte die Östrogensubstitution keinerlei Auswirkung auf die Muskelmasse (Fisher et al. 2000, Piccone et al. 2005), wohingegen eine Vielzahl von Studien die Östrogensensitivität des Skelettmuskelgewebes bei jungen, unreifen Nagetieren nachweisen konnte (Wattanapermpool und Reiser 1999; McCormick et al. 2004). Die unreifen Versuchstiere waren bei Versuchsende der genannten Studien stets jünger als 14 Wochen. Unsere Versuchstiere waren 13 Wochen bei Versuchsbeginn und 17 Wochen bei Versuchsende. Im Gegensatz zu den Autoren Picco- 
ne und Fisher konnten wir durch unsere Östrogensubstitution Auswirkung auf die Muskelmasse feststellen.

Weitere zu berücksichtigende Merkmale bei der Beurteilung des Einflusses von Östrogenen auf den Skelettmuskel scheinen die gesteigerte Nahrungsaufnahme, die reduzierte physische Aktivität der Versuchstiere (Shinoda et al. 2002) und die gesteigerte Menge an zirkulierenden Wachstumsfaktoren nach Ovx zu sein. Hierdurch wird insgesamt eine positive Energiebilanz produziert (Yeh et al. 1997). Das Körpergewicht, die Organgewichte wie auch die Größe des Skelettmuskelgewebes werden durch diesen Zustand erhöht (Fisher et al. 1998, McClung et al. 2006).

Die Ergebnisse von McCormick deuten darauf hin, dass durch die Verhinderung der durch Ovx induzierten gesteigerten Nahrungsaufnahme auch gleichzeitig eine Zunahme der Muskelmasse verhindert wird (McComick et al. 2004). Diese These wird auch von anderen Autoren wie Fischer unterstützt (Fisher et al. 2000). Jedoch haben Untersuchungen von Toth gezeigt, dass die Ovx zu einer Zunahme der fat-free mass und der Muskelproteinsynthese führte und dies unter Kontrolle der Nahrungszufuhr (Toth et al. 2001).

Ein weiterer Einflussfaktor, welcher bei der östrogenen Sensitivität des Skelettmuskelgewebes berücksichtigt werden muss, ist die Zusammensetzung des Muskelfasertyps des zu untersuchenden Muskels. Extremitätenmuskeln wie beispielsweise der M. gastrocnemius oder der M. soleus bestehen aus einem hohen Anteil aus Typ II-Fasern, wohingegen die paravertebrale Muskulatur (Höhe LWK 4 / L5) vornehmlich aus Typ I-Fasern besteht.

Die Auswirkung von Östrogenen auf den Skelettmuskel scheint sich von Muskel zu Muskel abhängig von seiner Muskelfasertyp Mischung zu unterscheiden.

Typ I-Muskelfasern bleiben meist über die gesamte Lebenszeit eines Menschen erhalten, wohingegen Typ II-Fasern mit Beginn der 5. Dekade zu atrophieren beginnen (Brown 2008). Muskelfasertyp II hat einen hohen Anteil an ER $\alpha$ Rezeptoren, durch den Östrogene direkten Einfluss auf den Skelettmuskel nehmen sollen. Die Bedeutung des später entdeckten ER $\beta$-Rezeptors in Bezug auf den Skelettmuskel ist jedoch noch weitgehend ungeklärt.

Die Substitution mit Östrogenen nach Ovx zeigte eine reduzierte Muskelfasergröße bei Muskelfaser Typ II (McCormick et al. 2004). Diese Veränderung der Fasergröße wurde jedoch nicht bei Tieren beobachtet, welche nur Ovx wurden. Diese Erkenntnis deckt sich auch mit unseren histomorphometrischen Untersuchungen.

Es ist möglich, dass gerade Typ II-Muskelfasern am besten auf östrogene Stimulation reagieren, was mit ihrer ER-Verteilung oder Sensitivität zu tun hat. Beides ist jedoch noch Gegenstand der Forschung und es wurde noch keine Studie zu diesem Thema veröffentlicht. Ungeachtet der Tatsache, ob Östro- 
gene über direkte oder indirekte Mechanismen auf den Skelettmuskel wirken, besteht der Verdacht, dass die Wirkung vom Muskelfasertyp abhängt (Piccone et al. 2005).

\subsubsection{IGF-1}

Die Wachstumsfaktoren IGF-1 und GH werden nach Ovx vermehrt gebildet und ausgeschüttet (Jansson et al. 1984, Borski et al. 1996). Über die Regulation dieser beiden Faktoren sollen Östrogene auch indirekt Einfluss auf den Skelettmuskel nehmen (Fisher et al. 1998).

Mit unserem Untersuchungsergebnis stimmen wir mit der Hypothese von Jansson überein. Durch die Ovx zeigte sich ein signifikanter Anstieg des IGF-1 im Vergleich zur physiologischen Vergleichsgruppe. Alle Substitutionstherapien führten zu einer signifikanten Verringerung des IGF-1 Serumwertes. Dass die Therapie von ovx Ratten mit $\mathrm{E}_{2}$ IGF-1 hemmt ist in anderen Untersuchungen bereits festgestellt worden (Fisher et al. 1998, Tsai et al. 2007).

$\mathrm{E}_{2}$ zeigte dabei von allen Applikationsschemen die schwächste östrogene Potenz mit dem höchsten Wert der Ovx-Tiergruppen. Alle Kombinationen mit dem ER $\alpha$-Agonisten zeigten gar eine Reduktion des Wertes unter die der physiologischen Vergleichsgruppe sham-ovx. Die Kombinationstherapie vom ER $\alpha$-Agonisten mit dem ER $\beta$-Agonisten zeigte sowohl in der gemeinsamen kontinuierlichen Form wie auch in der gemeinsamen zeitversetzten Gabe einen inhibitorischen Effekt auf die Wirkung des ER $\alpha$. Gegensätzlich war das Ergebnis für die Kombinationstherapie von $E_{2}$ mit dem ER $\beta$ Agonisten. Es zeigte sich eine synergistische Wirkung, welche bei der simultanen kontinuierlichen Therapie besser war als in der zeitversetzten Applikationsform.

In der Auswertung der Muskelfasergröße des M. gastrocnemius waren es die mit dem ER $\alpha$-Agonisten therapierten Tiere, welche die kleinsten Muskelfasergrößen aufwiesen. Hierin besteht demnach eine Korrelation mit der Aussage von Fisher. Demgegenüber stehen die Ergebnisse der Therapie mit dem ER $\beta$-Agonisten und der Kombinationstherapien von $\mathrm{E}_{2}$ mit dem $\mathrm{ER} \beta$-Agonisten, welche einen signifikant niedrigen IGF-1 Serumwert aufweisen, jedoch eine im Verhältnis große Muskelfaserdurchschnittsfläche in der histomorphometrischen Untersuchung vorwiesen.

Die Index Untersuchung des IGF-Serumwertes in Bezug auf die Körpergewichte der einzelnen Versuchsgruppen zeigte dabei dasselbe Ergebnis wie die einfache Bestimmung des IGF-1 Serumwertes.

\subsection{Serumparameter des metabolischen Syndroms}

Das Risiko, an einem Metabolischen Syndrom zu erkranken, ist für Frauen nach der Menopause erhöht, was im wesentlichen mit den metabolischen Veränderungen zusammenhängt, die Frauen in der Postmenopause erfahren (Carr 2003). Der Rückgang der Östrogenproduktion führt zu einem Anstei- 
gen der Triglyzerid-, Cholesterol- und LDL-Spiegel mit einer gleichzeitigen Reduktion des HDLWertes. Diese Veränderung des Fettstoffwechselprofils bis hin zur Dyslipidämie Erkrankung ist mit einem erhöhten Risiko für die Entwicklung eines Metabolischen Syndroms verbunden (Paul und Smith 2005). Die hohen Cholesterin Spiegel und die Anreicherung des intraabdominalen Fettgewebes nach durchgeführter Ovx, machen die Ratte trotzdem zu einem geeigneten Versuchstier um das Metabolische Syndrom zu erforschen (Seidlovà-Wuttke et al. 2010).

Mit den Serumanalysen der Lipidwerte wollten wir die Auswirkung der Applikationstherapie mit $\mathrm{E}_{2}$, dem ER $\alpha$ - und ER $\beta$-Agonisten auf einen weiteren Risikofaktor des Metabolischen Syndroms genauer beleuchten.

\subsubsection{Cholesterin}

Bei ovx Ratten konnte bereits nachgewiesen werden, dass es unter $\mathrm{E}_{2}$-Substitution zu einer Reduktion von HDL, LDL und Cholesterin kommt (Liu und Bachmann 1998).

Wir stellten fest, dass die Versuchsgruppen, welche allein mit dem ER $\alpha$ - oder ER $\beta$-Agonisten therapiert wurden, im Vergleich zu den nicht therapierten ovx Tieren eine signifikante Verringerung des Serum-Cholesterinwertes aufwiesen. Die Cholesterinwerte der Kombinationstherapie des ER $\alpha$ Agonisten simultan kontinuierlich und simultan zeitversetzt mit dem ER $\beta$-Agonisten waren ebenfalls signifikant niedriger. Dem ER $\beta$ wurde in diesem Fall eine synergistische Wirkung zu teil. Die stärkste östrogene Wirkung zeigte der isoliert applizierte ER $\beta$-Agonist. Aufgrund der Ergebnisse könnte man argumentieren, dass der ER $\alpha$ Agonist in diesem Fall die Wirkung des ER $\beta$-Agonisten zu einem gewissen Grade inhibiert hätte. Untersuchungen an Knockout-Mäusen stellten heraus, dass der Cholesterinstoffwechsel zumindest zum Teil über den ER $\alpha$ vermittelt wird, da $\alpha$ ERKO aber nicht BERKO-Mäuse erhöhte Serum-Cholesterinspiegel aufwiesen (Ohlsson et al. 2000). Dies konnten wir mit der Applikation der ER-Agonisten in unserer Untersuchung beweisen. Jedoch wurde zusätzlich auch eine potente Cholesterinsenkende Wirkung für den ER $\beta$-Agonisten nachgewiesen.

\subsubsection{HDL und LDL}

Die Biosynthese von Cholesterol wird direkt über den Cholesterol-Spiegel im Blut reguliert, auch wenn die homöostatischen Mechanismen, die zur Kontrolle des Cholesterinspiegels beitragen, noch nicht gänzlich erforscht sind.

Ein Rückgang der endogenen Östrogenproduktion ist gleichzeitig mit einem Rückgang der Anzahl der LDL-Rezeptoren verbunden, was höhere LDL Plasmaspiegel bedeutet (Bertolotti und Spady 1996). 
In der Gegenüberstellung zum Menschen zeichnet sich die Ratte dadurch aus, dass sie bei ihrer prozentuellen Speicherung des Cholesterols, den überwiegenden Teil in HDL und nur zu einem geringen Anteil in LDL speichert, wohingegen beim Menschen die LDL-Fraktion den größten Anteil der Cholesterolspeicherung ausmacht (Bertolotti und Spady 1996). Im Fettstoffwechsel der Ratte übernimmt HDL die Rolle des dominanten Lipoproteins. 60-70\% der Lipoproteine werden bei der Ratte vom HDL eingenommen (Lundeen et al. 1997). Beim Menschen findet sich dagegen das LDL in dieser Größenkonstellation wieder. Unter Östrogensubstitution sinkt nicht nur der LDL-Serumspiegel, sondern auch der Serumspiegel für HDL.

Bei der Untersuchung der Lipoproteine HDL und LDL zeigten sich ähnliche Ergebnisse. Die Kombinationstherapie gemeinsam kontinuierlich und gemeinsam zeitversetzt zwischen dem ER $\alpha$ und dem ER $\beta$-Agonisten sowie deren isolierte Applikation zeigten eine signifikante Reduktion des HDL Wertes zur Gruppe ovx + SF. Auch zur physiologisch intakten Gruppe sham-ovx wurde ein signifikant niedriger HDL-Wert festgestellt. Ein hemmender Effekt des ER $\beta$-Agonisten auf ER $\alpha$ und die $\mathrm{E}_{2}$ Substitution konnte für die HDL-Werte nicht festgestellt werden.

In dieser Studie sanken die LDL-Werte aller therapierten Gruppen signifikant im Vergleich zur ovxSF Gruppe. Wiederum war die Kombinationstherapie simultan kontinuierlich und simultan zeitversetzt zwischen dem ER $\alpha$ und ER $\beta$-Agonisten sowie ihre alleinige Therapie, die Therapieformen mit den am meisten supprimierenden LDL-Werten. Die Therapie der Ratten mit $\mathrm{E}_{2}$ oder $\mathrm{E}_{2}$ gemeinsam kontinuierlich und gemeinsam zeitversetzt in Kombination mit dem ER $\beta$-Agonisten sorgte zwar auch für eine signifikante Reduktion des LDL Serumwertes, jedoch nicht in der Potenz wie es die Agonisten $\alpha$ und $\beta$ zu beeinflussen vermochten.

Östrogene sind dafür bekannt, den Plasmaspiegel von LDL zu senken und den für HDL zu erhöhen. Der Rückgang des LDL-Wertes ist hierbei auf eine gesteigerte hepatische Expression von LDL Rezeptoren zurückzuführen, welche das Blut vermehrt von LDL befreien und die Sekretion von Cholesterol in die Galle bedingen (Nabulsi et al. 1993, Bertolotti und Spady 1996, Darabi et al. 2011). Die gefäßprotektive Senkung des LDL-Wertes durch $\mathrm{E}_{2}$ - und die ER-Agonisten konnten wir mit unserer Untersuchung nachweisen.

Bei der Auswertung des HDL Serumwertes stellten wir eine signifikante Reduktion fest, was jedoch mit der Cholesterol Fraktionsverteilung des Versuchtieres Ratte in Verbindung steht.

Aus früheren Untersuchungen ist bekannt, dass die östrogene Substitution das Gesamtcholesterol der Versuchstiere senkt und somit auch gleichzeitig die HDL-Fraktion signifikant reduziert (SeidlovàWuttke et al. 2003 a). Dieses Ergebnis konnten wir mit unserer Untersuchung bestätigen.

$\mathrm{E}_{2}$ zeigte im Vergleich zu den nicht-therapierten ovx Tieren eine Reduktion des Cholesterin, HDLund LDL-Wertes auf, diese war jedoch gering, so dass wir nachweisen konnten, dass die einzelnen ER-Agonisten oder ihre Kombination miteinander eine deutlich stärkere östrogene Wirkung besitzen und die Lipidwerte senken. 
Das Versuchstier Ratte bleibt ein etabliertes Modell zur Untersuchung der Lipidwerte, weil die Einflüsse, die durch die Applikation von $\mathrm{E}_{2}$ und östrogenen Substanzen auf das Gesamtcholesterol und das TG entstehen, mit den Veränderungen übereinstimmen, die bei Frauen unter östrogener Behandlung vorkommen würden.

\subsubsection{Atherogene-Index}

Die Hypoöstrogenität ist mit einem erhöhten atherosklerotischen Fettstoffwechsel-Profil assoziiert und wahrscheinlich dadurch für die erhöhten koronaren Herzerkrankungen bei menopausalen Frauen verantwortlich (Paul und Smith 2005).

Der atherogene Index, welcher aus Triglyzeride / HDL errechnet wird (Dobiasova 2004), sowie das Verhältnis im Serum zwischen LDL und HDL (Villa et al. 2008) gelten als Maß für das Atherosklerose-Risiko. Eine Erhöhung des LDL-Anteiles im Serum ist mit einem erhöhten Risiko für die Entwicklung von Atherosklerose verbunden. Im Gegensatz dazu sind hohe HDL-Werte mit einem verminderten Risiko für Atherosklerose assoziiert.

In unserer Untersuchung konnten wir keine signifikanten Verringerung des Atherosklerose Risikos für die parenterale Applikation von $\mathrm{E}_{2}$, ER $\alpha$ - und ER $\beta$-Agonisten bei ovx Ratten feststellen. Die Behandlung der Versuchstiere in der Kombination simultan kontinuierlich und simultan zeitversetzt zwischen dem ER $\alpha$ - und ER $\beta$-Agonisten führte gegenteilig zu einer deutlichen Erhöhung des Index zwischen Triglyzeriden und HDL, was eher einer gefäßschädlichen Eigenschaft für diese Gruppen entsprechen würde.

Diese beiden Versuchsgruppen zeigten bei der Auswertung der Triglyzerid-Werte die am höchsten gemessenen Werte. Die Kombination gemeinsam kontinuierlich und gemeinsam zeitversetzt zwischen dem ER $\alpha$ - und ER $\beta$-Agonisten zeigte eine signifikante Erhöhung der Triglyzerid-Werte gegenüber den ovx-SF Tieren.

Der Fettstoffwechsel steht im Fokus vieler Forschungsarbeiten und die vorteilhafte Wirkung von HRT auf das Fettstoffwechselprofil wurde als Erklärung aufgeführt, weshalb eine kardioprotektive Wirkung bei Beobachtungsstudien über HRT gefunden wurde (Hemelaar et al. 2008).

Randomisierte Klinische Studien mit definierten klinischen kardiovaskulären Risikofaktoren und Werten widersprachen den gewonnen Ergebnissen aus den Beobachtungsstudien. Die Heart and Estrogen /Progestin Replacement Study (HERS) (Grady et al. 2002) und die Women Health Initiative Trials 
(WHI) (Manson et al. 2003) konnten keine kardioprotektive Wirkung einer oralen HRT bei gesunden, postmenopausalen Frauen nachweisen.

Von entscheidender Bedeutung für die Wirkung der substituierten Östrogene ist die Art der Applikation. Transdermale HRT zeigt in der Gegenüberstellung zur oralen Therapie eine unterschiedliche Wirkung in Bezug auf den Fettstoffwechsel. Transdermal appliziertes Östrogen verursacht nicht nur eine Verringerung der Cholesterol- und LDL-Werte, sondern gar eine Reduzierung der Triglyzerid-Werte an statt einer Erhöhung (Godsland 2001). Durch die transdermale, intranasale oder subkutane Applikation von Östrogenen wird die Medikation direkt in den systemischen Blutkreislauf aufgenommen und umgeht somit den entero-hepatischen Kreislauf und dem damit verbundenen First-Pass-Effekt der Leber (Hemelaar et al. 2008). Bei der oralen Therapie von Östrogenen kommt es im Magen-Darm Trakt zur Absorption des Hormons, welches dann in der Leber die Expression von hepatischen Hormonen erhöht (Kuhl 1990).

\subsubsection{Glukose}

Eine weitere Veränderung, welche Frauen in der Menopause in Bezug auf die Erkrankung des Metabolischen Syndroms erfahren, ist die Hyperglykämie und die Hyperinsulinämie (Royer et al. 2007). Es existieren zahlreiche Studien die berichten, dass eine HRT Nüchtern-Glukose- und Insulinspiegel senken würde (Cooper et al. 2007). Dagegen argumentieren Ergebnisse anderer Untersuchungen, dass eine HRT keinerlei Auswirkung auf den Glukosehaushalt mit sich bringt (Vehkavaara et al. 2000). Wir konnten bei unserer Untersuchung keinen Unterschied bei den Glukosewerten der verschiedenen Untersuchungsgruppen feststellen. 


\section{Zusammenfassung}

Die Relevanz der Forschung an neuen selektiven Pharmazeutika, welche das Ziel verfolgen, die Symptome von postmenopausalen Frauen zu lindern oder gar zu beseitigen, ist durch die Tatsache bedingt, dass die westliche Bevölkerung stetig höhere Lebensalter erreicht und Frauen eine immer länger werdende Dauer ihres Lebens in einem Östrogenmangelzustand leben werden. Die zur Verfügung stehende, seit Jahrzehnten praktizierte traditionelle medikamentöse HRT ist in der Lage, diese Östrogenmangelsymptome einzugrenzen oder gar zu verhindern, ist aber gleichzeitig bei dauerhafter Therapie mit lebensbedrohlichen Nebenwirkungen assoziiert wie dem vermehrten Auftreten von Thromboembolien oder der Entstehung von Mamma- oder Endometriumkarzinomen. Der Nachweis eines zweiten ER eröffnete der Forschung neue Angriffspunkte für potentielle zukünftige Therapieformen. Die Gruppe der SERM, welche eine gewünschte östrogene Wirkung in einem östrogenen Zielgewebe ausüben können, jedoch die östrogene Wirkung in einem anderen Östrogen-sensiblen Gewebe inhibieren, war einen weiterer Schritt in der gezielten selektiven Therapie über ER erreicht. Weiter wurden schließlich spezielle, selektive und hoch potente Agonisten für den ER $\alpha$ und ER $\beta$ erschaffen. Durch die Vielzahl der Östrogen-sensiblen Gewebe im menschlichen Körper ist jedoch noch nicht jeder Gewebetyp des Körpers umfassend auf seine Reaktion auf die gezielte Applikation von ER $\alpha$ - und ER $\beta$-Agonisten untersucht worden.

In der vorliegenden Arbeit wurden die Effekte des ER $\alpha 16 \alpha-\mathrm{LE}_{2}$ (3,17-dihydroxy-19-nor-17 $\alpha$-pregna-

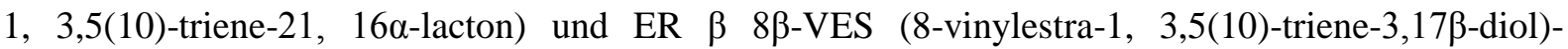
Agonisten sowie des Sexualhormons $E_{2}$ bezüglich ihrer Auswirkung auf das Skelettmuskel- und Fettgewebe untersucht. Im Detail wurden $\mathrm{E}_{2}$ und der ER $\alpha$-Agonist in Kombination mit dem ER $\beta$ Agonisten appliziert, um seine genaue Funktion im Zusammenspiel der beiden ERs zu erforschen und ob eine antagonisierende Wirkung für den ER $\beta$-Agonisten nachzuweisen ist. Die Auswirkung dieser Therapie auf Faktoren, welche mit der Entstehung eines Metabolischen Syndroms zusammenhängen, wurde ebenfalls untersucht.

Grundlage der Versuchsreihe war das wissenschaftlich etablierte tierexperimentelle Modell der ovx Ratte. Bei Versuchsbeginn und nach Beendigung der 4-wöchigen Therapiemaßnahmen wurde eine pqCT-Messung der Tiere in Höhe von LWK 4/5 durchgeführt. Weiter wurden den Versuchstieren nach Versuchsende das Caput laterale des M. gastrocnemius chirurgisch entfernt und histomorphometrisch ausgewertet. Aus dem gewonnenen Dekapitationsblut wurden die verschiedenen Serumparameter, welche im Zusammenhang mit dem Muskel- und Fettgewebe stehen, gemessen und ausgewertet. 
1. Mit unserer Untersuchung konnten wir beweisen, dass die verschiedenen Applikationsschemata von $\mathrm{E}_{2}$ und ER-Agonisten unterschiedliche therapeutische Kräfte in Bezug auf Gewebetypen und Serumwerte auslösen.

2. Eine antagonisierende Wirkung des ER $\beta$-Agonisten konnte nicht für alle Gewebetypen und Serumwerte festgestellt werden.

3. Die Gustafsson'sche Yin-Yang-Theorie konnte für den im pqCT gemessenen intraabdominalen Fettgewebsanteil und die Muskelfäche, die HDL-, Cholesterin- und LDL-Serumwerte sowie in der histomorphometrischen Vermessung widerlegt werden.

Der ER $\beta$-Agonist zeigte hier in Kombination zum Teil einen synergistischen Effekt zu $\mathrm{E}_{2}$ oder ER $\alpha$.

4. Es konnten in dieser Untersuchung divergierende Ergebnisse zwischen der kontinuierlichen und zeitversetzten Kombinationstherapie mit dem ER $\beta$-Agonisten herausgefunden werden. Teilweise führte die kontinuierliche Therapie zu einem synergistischen Effekt, während die zeitversetzte Therapie eine antagonisierende Wirkung auslöste. Dieses Phänomen gab es jedoch auch umgekehrt.

5. Wir konnten nachweisen, dass der Östrogenmangel bei den Versuchstieren zum Auftreten von typischen klimakterischen Beschwerden, wie z.B der Zunahme des Körpergewichtes, Zunahme des intraabdominalen Fettdepots und die Entwicklung eines gefäßschädlichen LipidProfils, führte.

6. Die Kombinationstherapien aus $\mathrm{E}_{2}$, ER $\alpha$ mit dem ER $\beta$-Agonisten zeigten, bis auf die Serumwerte für Cholesterin, HDL und LDL, keine bedeutenden Unterschiede in der Wirkung verglichen mit der reinen $\mathrm{E}_{2}$ Substitutionstherapie.

Abschließend bleibt zu erwähnen, dass für die Zukunft weitere Forschungsarbeiten über die selektive Wirkung von ER $\alpha$ - und ER $\beta$-Agonisten auf die unterschiedlichen Östrogen-sensiblen Gewebe des Körpers erfolgen sollten. Die Grundlage für die Entwicklung neuer sicherer Medikamente ist das lückenlose Verständnis über die Funktion und Interaktion der ER in den Östrogen-sensiblen Geweben des Körpers. 


\section{Anhang}

Tab. 2.1. Gruppeneinteilung und Injektionsplan

\begin{tabular}{|c|c|c|c|c|}
\hline Gruppe & Substanz & Konzentration & $\begin{array}{c}\text { Injektions } \\
\text { Art + Intervall }\end{array}$ & Zeitraum \\
\hline 1 & ovx $+\mathrm{SF}$ & 0,2 ml/Tier Benzylbenzoat/Rizinusöl,1/4 & s.c. täglich & $4 \mathrm{Wo}$ \\
\hline 2 & ovx $+E_{2}$ & $\begin{array}{l}1 \mu \mathrm{g} \mathrm{E}_{2} / \text { Tier in } 0,2 \mathrm{ml} \\
\text { gelöst in Benzylbenzoat/Rizinusöl, } 1 / 4\end{array}$ & s.c. täglich & $4 \mathrm{Wo}$ \\
\hline 3 & ovx + ER $\alpha$ & $\begin{array}{l}10 \mu \mathrm{g} \text { ER } \alpha / \text { Tier in } 0,2 \mathrm{ml} \text { gelöst in } \\
\text { Benzylbenzoat/Rizinusöl,1/4 }\end{array}$ & s.c. täglich & $4 \mathrm{Wo}$ \\
\hline 4 & ovx $+\mathrm{ER} \beta$ & $\begin{array}{l}50 \mu \mathrm{g} \text { ER } \beta / \text { Tier in } 0,2 \mathrm{ml} \text { gelöst in } \\
\text { Benzylbenzoat/Rizinusöl, } 1 / 4\end{array}$ & s.c. täglich & $4 \mathrm{Wo}$ \\
\hline 5 & $\begin{array}{c}\text { ovx }+E_{2} \\
\quad+\text { ER } \beta \\
4 \text { Wochen }\end{array}$ & $\begin{array}{l}1 \mu \mathrm{g} \mathrm{E}_{2} / \text { Tier }+50 \mu \mathrm{g} \text { ER } \beta / \text { Tier in } 0,2 \mathrm{ml} \\
\text { gelöst in Benzylbenzoat/Rizinusöl, } 1 / 4\end{array}$ & s.c. täglich & $4 \mathrm{Wo}$ \\
\hline 6 & $\begin{array}{r}\text { ovx }+ \text { ER } \alpha \\
+ \text { ER } \beta \\
4 \text { Wochen }\end{array}$ & $\begin{array}{l}10 \mu \mathrm{g} \text { E } \alpha / \text { Tier }+50 \mu \mathrm{g} \text { ER } \beta / \text { Tier in } 0,2 \mathrm{ml} \\
\text { gelöst in Benzylbenzoat/Rizinusöl, } 1 / 4\end{array}$ & s.c. täglich & 4 Wo \\
\hline 7 & $\begin{array}{l}\text { ovx }+\mathrm{E}_{2} \\
\text { nach } 14 \text { Tagen } \\
\quad+\text { ER } \beta\end{array}$ & $\begin{array}{l}1 \mu \mathrm{g} \mathrm{E}_{2} / \text { Tier in } 0,2 \mathrm{ml} \text { (gelöst in Benzylben- } \\
\text { zoat/Rizinusöl,1/4) } \\
\text { dann } \\
1 \mu \mathrm{g} \mathrm{E} \mathrm{E}_{2} / \text { Tier }+50 \mu \mathrm{g} \text { ER } \beta / \text { Tier in } 0,2 \mathrm{ml} \\
\text { gelöst in Benzylbenzoat/Rizinusöl, } 1 / 4\end{array}$ & s.c. täglich & $4 \mathrm{Wo}$ \\
\hline 8 & $\begin{array}{l}\text { ovx }+ \text { ER } \alpha \\
\text { nach } 14 \text { Tagen } \\
\quad+\text { ER } \beta\end{array}$ & $\begin{array}{l}10 \mu \mathrm{g} \text { ER } \alpha / \text { Tier in } 0,2 \mathrm{ml} \text { gelöst in } \\
\text { Benzylbenzoat/Rizinusöl,1/4 } \\
\text { dann } \\
10 \mu \mathrm{g} \text { ER } \alpha / \text { Tier }+50 \mu \mathrm{g} \text { ER } \beta / \text { Tier in } 0,2 \\
\mathrm{ml} \text { gelöst in Benzylbenzoat/Rizinusöl, } 1 / 4\end{array}$ & s.c. täglich & 4 Wo \\
\hline 9 & Sham ovx & 0,2 ml/Tier Benzylbenzoat/Rizinusöl,1/4 & s.c. täglich & $4 \mathrm{Wo}$ \\
\hline
\end{tabular}


Tab. 2.2 Einwirkzeiten zur Organentwässerung

\begin{tabular}{|l|l|}
\hline Substanz & Einwirkzeit \\
\hline $50 \%$ iger Alkohol & $1 \mathrm{~h}$ \\
\hline $75 \%$ iger Alkohol & $1 \mathrm{~h} 20 \mathrm{~min}$ \\
\hline $75 \%$ iger Alkohol & $1 \mathrm{~h} 20 \mathrm{~min}$ \\
\hline $96 \%$ iger Alkohol & $1 \mathrm{~h} 20 \mathrm{~min}$ \\
\hline $96 \%$ iger Alkohol & $1 \mathrm{~h} 20 \mathrm{~min}$ \\
\hline $100 \%$ iger Alkohol & $1 \mathrm{~h} 20 \mathrm{~min}$ \\
\hline $100 \%$ iger Alkohol & $1 \mathrm{~h} 20 \mathrm{~min}$ \\
\hline $100 \%$ iger Alkohol & $1 \mathrm{~h} 20 \mathrm{~min}$ \\
\hline Xylol & $1 \mathrm{~h} 20 \mathrm{~min}$ \\
\hline Xylol & $1 \mathrm{~h} 20 \mathrm{~min}$ \\
\hline Paraffin & $1 \mathrm{~h}$ \\
\hline Paraffin & $1 \mathrm{~h}$ \\
\hline
\end{tabular}


Tab. 2.3 Schema der HE-Färbung

\begin{tabular}{|l|l|}
\hline Substanz & Einwirkdauer \\
\hline Xylene & $5 \mathrm{~min}$ \\
\hline Xylene & $5 \mathrm{~min}$ \\
\hline Xylene & $5 \mathrm{~min}$ \\
\hline Ethanol 100\% & 2 min \\
\hline Ethanol 100\% & 2 min \\
\hline Ethanol 100\% & 2 min \\
\hline Ethanol 96\% & 2 min \\
\hline Ethanol 96\% & 2 min \\
\hline Ethanol 75\% & 2 min \\
\hline Aqua dest & 2 min \\
\hline Hämatoxylin & 1 min \\
\hline Leitungswasser & $5-10 \mathrm{~min}$ \\
\hline Eosin & $1 \mathrm{~min}$ \\
\hline Aqua bidest & $5-10 \mathrm{~s}$ \\
\hline Ethanol 75\% & $5 \mathrm{~s}$ \\
\hline Ethanol 96\% & $1 \mathrm{~min}$ \\
\hline Ethanol 96\% & $1 \mathrm{~min}$ \\
\hline Ethanol 100\% & $2 \mathrm{~min}$ \\
\hline Ethanol 100\% & $2 \mathrm{~min}$ \\
\hline Ethanol 100\% & $2 \mathrm{~min}$ \\
\hline Xylene & $5 \mathrm{~min}$ \\
\hline Xylene & $5 \mathrm{~min}$ \\
\hline Xylene & $5 \mathrm{~min}$ \\
\hline & \\
\hline
\end{tabular}




\section{Literaturverzeichnis}

Abeles ED, Cordeiro LM, Martins AS, Pesquero JL, Reis AM, Andrade SP, Botion LM (2012): Estrogen therapy attenuates adiposity markers in spontaneously hypertensive rats. Metabolism $\underline{61}(8), 1100-1107$

Ames RT: Yin and Yang. In: CUA A S (Hrsg.): Encyclopedia of Chinese Philosophy, New York 2003, 846

Asarian L, Geary N (2002): Cyclic estradiol treatment normalizes body weight and restores physiological patterns of spontaneous feeding and sexual receptivity in ovariectomized rats. Horm Behav $\underline{42}$ (4), 461-471

Bagchi M: Steroid Hormone Receptor Family; Mechanism of Action. In: Henry HL, Norman AW (Hrsg.): Encyclopedia of Hormones, Volume 3; Academic Press Elsevier Inc., San Diego 2003, 403-409

Bamman M, Shipp JR, Jie J, Gower BA, Hunter GR, Goodman A, McLafferty Jr. CL, Urban JR (2001): Mechanical load increases muscle IGF-I and androgen receptor mRNA concentrations in humans. Am J Physiol Endocrinol Metab $\underline{280}$ (3), 383-390

Barbieri M, Ferrucci L, Ragno E, Corsi A, Bandinelli S, Bonafe M, Oliveri F, Giovagnetti S, Fanceschi C, Guralnik JM, Paolisso G (2003): Chronic inflammation and the effect of IGF-I on muscle strength and power in older persons. Am J Physiol Endocrinol Metab 284 (3), 481487

Barkhem T, Carlsson B, Nilsson Y, Enmark E, Gustafsson JA, Nilsson S (1998): Differential response of estrogen receptor alpha and estrogen receptor beta to partial estrogen agonists/antagonists. Mol Pharmacol 54 (1), 105-112

Beckett T, Tchernof A, Toth MJ (2002): Effect of ovariectomy and estradiol replacement on skeletal muscle enzyme activity in female rats. Metabolism $\underline{51}$ (11), 1397-1401

Beral V (2003): Breast cancer and hormone-replacement therapy in the Million Women Study. Lancet $\underline{362}$ (9382), 419-427

Bertolotti M, Spady DK (1996): Effect of hypocholesterolemic doses of 17 alpha-ethinyl estradiol on cholesterol balance in liver and extrahepatic tissues. J Lipid Res $\underline{37}$ (8), 1812-1822

Biolo G, Declan Fleming RY, Wolfe RR (1995): Physiologic hyperinsulinemia stimulates protein synthesis and enhances transport of selected amino acids in human skeletal muscle. J Clin Invest 95 (2), 811-819

Bodine SC, Stitt TN, Gonzalez M, Kline WO, Stover GL, Bauerlein R, Zlotchenko E, Scrimgeour A, Lawrence JC, Glass DJ et al. (2001): Akt/mTOR pathway is a crucial regulator of skeletal muscle hypertrophy and can prevent muscle atrophy in vivo. Nat Cell Biol $\underline{3}$ (11), 1014-1019

Borski RJ, Tsai W, DeMott-Friberg R, Barkan AL (1996): Regulation of somatic growth and the somatotropic axis by gonadal steroids: primary effect on insulin-like growth factor I gene expression and secretion. Endocrinology 137 (8), 3253-3259 
Breckwoldt M: Geschlechtsspezifische Funktionen und ihre Störungen. In: Pfleiderer A, Breckwoldt M, Martius G (Hrsg.): Gynäkologie und Geburtshilfe, 4. Auflage; Georg-Thieme Verlag, Stuttgart 2001, 47-77

Brown M (2008): Skeletal muscle and bone: effect of sex steroids and aging. Adv Physiol Educ $\underline{32}$ (2), 120-126

Brzozowski AM, Pike AC, Dauter Z, Hubbard RE, Bonn T, Engström O, Ohman L, Greene GL, Gustafsson JA, Carlquist M (1997): Molecular basis of agonism and antagonism in the oestrogen receptor. Nature $\underline{389}$ (6652), 753-758

Burger HG (1999): The endocrinology of the menopause. J Steroid Biochem Mol Biol 69 (1-6), 31-35

Burger HG, Dudley EC, Robertson DM, Dennerstein L (2002): Hormonal changes in the menopause transition. Recent Prog Horm Res 57, 257-275

Burger HG, Hale GE, Robertson DM, Dennerstein L (2007): A review of hormonal changes during the menopausal transition: focus on findings from the Melbourne Women's Midlife Health Project. Hum Reprod Update 13 (6), 559-565

Burks TN, Cohn RD (2011): Role of TGF- $\beta$ signaling in inherited and acquired myopathie. Skelet Muscle May 4 (1), 19

Cammisotto PG, Levy E, Bukowiecki LJ, Bendayan M (2010): Cross-talk between adipose and gastric leptins for the control of food intake and energy metabolism. Prog Histochem Cytochem $\underline{45}$ (3), 143-200

Carr MC (2003): The emergence of the metabolic syndrome with menopause. J Clin Endocrinol Metab $\underline{88}$ (6), 2404-2411

Carter CS, Marzetti E, Leeuwenbrugh C, Manini T, Foster TC, Groban L, Scarpace PJ, Morgan D (2012): Usefulness of preclinical models for assessing the efficacy of late-life interventions for sarcopenia. J Gerontol A Biol Sci Med Sci Jan (67), 17-27

Cauley JA, Norton L, Lippman ME, Eckert S, Krueger KA, Purdie DW, Farrerons J, Karasik A, Mellstrom D, Ng KW et al. (2001): Continued breast cancer risk reduction in postmenopausal women treated with raloxifene: 4-year results from the MORE trial. Multiple outcomes of raloxifene evaluation. Breast Cancer Res Treat $\underline{65}$ (2), 125-134

Christoffel J, Rimoldi G, Wuttke W (2006): Effects of 8-prenylnaringenin on the hypothalamopituitary-uterine axis in rats after 3-month treatment. J Endocrinol 188, 397-405

Clegg DJ, Brown LM, Woods SC, Benoit SC, Woods S (2006): Gonadal hormones determine sensitivity to central leptin and insulin. Diabetes 55 (4), 978-987

Collins P, Flather M, Lees B, Mister R, Proudler AJ, Stevenson JC (2006): Randomized trial of effects of continuous combined HRT on markers of lipids and coagulation in women with acute coronary syndromes. Eur Heart J 27 (17), 2046-2053

Cooper BC, Burger NZ, Toth MJ, Cushman M, Sites CK (2007): Insulin resistance with hormone replacement therapy: associations with markers of inflammation and adiposity. Am J Obstet Gynecol $\underline{196}(2), 123$ e 1-7

Couse JF, Korach KS (1999): Estrogen receptor null mice: what have we learned an where will they lead us. Endocr Rev 20 (3), 358-417 
Crandall C (2003): Low-dose estrogen therapy for menopausal women: a review of efficacy and safety. J Womens Health (Larchmt) 12 (8), 723-747

Cree MG, Newcomer BR, Katsanos CS, Sheffield-Moore M, Chinkes D, Aarsland A, Urban R, Wolfe RR (2004): Intramuscular and liver triglycerides are increased in the elderly. J Clin Endocrinol Metab $\underline{89}$ (8), 3864-3871

Dahlberg E (1982): Characterization of the cytosolic estrogen receptor in rat skeletal muscle. Biochim Biophys Acta 717 (1), 65-75

Dahlman-Wright K, Koehler K, Gustaffson JA: Estrogen Receptor-ß Structure and Function. In: Henry HL, Norman AW (Hrsg.): Encyclopedia of Hormones, Volume 3; Academic Press Elsevier Inc., San Diego 2003, 599-608

Dahlman-Wright K, Cavailles V, Fuqua SA, Jordan VC, Katzenellenbogen JA, Korach KS, Maggi A, Muramatsu M, Parker MG, Gustafsson JA (2006): International Union of Pharmacology. LXIV. Estrogen receptors. Pharmacol Rev 58 (4), 773-781

Darabi M, Rabbani M, Ani M, Zarean E, Panjehpour M, Movahedian A (2011): Increased leukocyte ABCA1 gene expression in post-menopausal women on hormone replacement therapy. Gynecol Endocrinol 27 (9), 701-705

Dela F, Kjaer M (2006): Resistance training, insulin sensitivity and muscle function in the elderly. Essays Biochem $\underline{42}, 75-88$

Dieudonne MN, Leneveu MC, Giudicelli Y, Pecquery R (2004): Evidence for functional estrogen receptors $\alpha$ and $\beta$ in human adipose cells: regional specificities and regulation by estrogens. Am J Physiol Cell Physiol 286 (3), 655-661

Diffee GM, Caiozzo VJ, Herrick RE, Baldwin KM (1991): Contractile and biochemical properties of rat soleus and plantaris after hindlimb suspension. Am J Physiol 260 (3 Pt 1), 528-534

Dobiasova M (2004): Atherogenic index of plasma [log(triglycerides/HDL-cholesterol)]: theoretical and practical implications. Clin Chem $\underline{50}$ (7), 1113-1115

Doherty M (2001): Risk factors for progression of knee osteoarthritis. Lancet $\underline{358}$ (9284), 775-776

Downs JL, Wise PM (2009): The Role of the brain in female reproductive aging. Mol Cell Endocrinol $\underline{5}$ (299), 32-38

Draper MW, Chin WW (2003): Molecular and clinical evidence for the unique nature of individual selective estrogen receptor modulators. Clin Obstet Gynecol $\underline{46}$ (2), 265-297

Durbin PW, Williams MH, Jeung N, Arnold JS (1966): Development of spontaneous mammary tumors over life-span of the female Charles River (Sprague-Dawley) rat: The influence of ovariectomy, thyroidectomy, and adrenalectomy-ovariectomy. Cancer Res $\underline{26}$ (3), 400-411

Eckel LA, Houpt TA, Geary N (2000): Spontaneous meal patterns in female rats with and without access to running wheels. Physiol Behav $\underline{70}$ (3-4), 397-405

Emmen JM, Korach KS (2003): Estrogen receptor knockout mice: phenotypes in the female reproductive tract. Gynecol Endocrnol 17 (2), 169-176

Eng CM, Smallwood LH, Rainiero MP, Lahey M, Ward SR, Lieber RL (2008): Scaling of muscle architecture and fiber types in the rat hindlimb. J Exp Biol 211 (14), 2336-2345 
Expert Panel on Detection and Treatment of High Blood Cholesterol in Adults (2001): Executive Summary of The Third Report of The National Cholesterol Education Program (NCEP) Expert Panel on Detection, Evaluation, And Treatment of High Blood Cholesterol In Adults (Adult Treatment Panel III). JAMA $\underline{285}$ (19), 2486-2497

Ferrando AA, Sheffield-Moore M, Yeckel CW, Gilkison C, Jiang J, Achacosa A, Lieberman SA, Tipton K, Wolfe RR, Urban RJ (2002): Testosterone administration to older men improves muscle function: molecular and physiological mechanisms. Am J Physiol Endocrinol Metab $\underline{282}(3), 601-607$

Fisher JS, Hasser EM, Brown M (1998): Effects of ovariectomy and hindlimb unloading on skeletal muscle. J Appl Physiol $\underline{85}$ (4), 1316-1321

Fisher JS, Kohrt WM, Brown M (2000): Food restriction suppresses muscle growth and augments osteopenia in ovariectomized rats. J Appl Physiol $\underline{88}$ (1), 265-271

Fitzgerald CT, Seif MW, Killick SR, Elstein M (1994): Age related changes in the female reproductive cycle. Br J Obstet Gynaecol 101 (3), 229-233

Flues K, Paulini J, Brito S, Sanches IC, Consolim-Colombo F, Irigoyen MC, De Angelis K (2010): Exercise training associated with estrogen therapy induced cardiovascular benefits after ovarian hormones deprivation. Matruritas $\underline{65}$ (3), 267-271

Ford ES, Giles WH, Dietz WH (2002): Prevalence of the metabolic syndrome among US adults: findings from the third National Health and Nutrition Examination Survey. JAMA 287 (3), 356-359

Fritzemeier KH, Kollenkirchen U, Kosemund D, Müller G (2000): 19 - Nor - 17 alpha - pregna 1,3,5 (10) - trien - 17 beta - ols of a 21,16 alpha - lactone ring. Patent application WO0226763

Fryburg DA, Barrett EJ, Louard RJ, Gelfand RA (1990): Effect of starvation on human muscle protein metabolism and its response to insulin. Am J Physiol 259 (4 Pt 1), 477-482

Gal D, Weiselberg L, Runowicz CD (1994): Endometrial cancer in tamoxifen-treated breast cancer patients: findings from the National Surgical Adjuvant Breast and Bowel Project (NSABP) B14. J Natl Cancer Inst $\underline{86}$ (16), 1252-1253

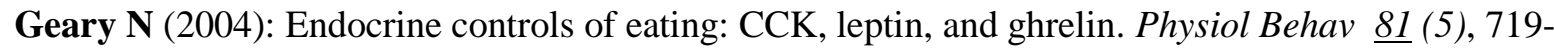
733

Gentil P, Lima RM, Jaco de Oliveira R, Pereira RW, Reis VM (2007): Association between femoral neck bone mineral density and lower limb fat-free mass in postmenopausal women. J Clin Densitom $\underline{10}$ (2), 174-178

Glass DJ (2003): Signalling pathways that mediate skeletal muscle hypertrophy and atrophy. Nat Cell Biol $\underline{5}$ (2), 87-90

Glenmark B, Nilsson M, Gao H, Gustafsson JA, Dahlman-Wright K, Westerblad H (2004): Difference in skeletal muscle function in males vs. females: role of estrogen receptor-beta. $\mathrm{Am}$ J Physiol Endocrinol Metab 287 (6), 1125-1131

Godsland IF (2001): Effects of postmenopausal hormone replacement therapy on lipid, lipoprotein, and apolipoprotein (a) concentrations: analysis of studies published from 1974-2000. Fertil Steril 75 (5), 898-915 
Grady D, Herrington D, Bittner V, Blumenthal R, Davidson M, Hlatky M, Hsia J, Hulley S, Herd A, Khan $S$ et al. (2002): Cardiovascular disease outcomes during 6.8 years of hormone therapy: Heart and Estrogen/progestin Replacement Study follow-up (HERS II). JAMA 288 (1), 49-57

Gronemeyer H, Laudet V (1995): Transcription factors 3: nuclear receptors. Protein Profile 2 (11), 1173-1308

Hansen FM, Fahmy N, Nielsen JH (1980): The influence of sexual hormones on lipogenesis and lipolysis in rat fat cells. Acta Endocrinol 95, 566-570

Hansen RD, Raja C, Baber RJ, Lieberman D, Allen BJ (2003): Effects of 20-mg oestradiol implant therapy on bone mineral density, fat distribution and muscle mass in postmenopausal women. Acta Diabetol 40 Suppl (1), 191-195

Harris HA, Katzenellenbogen JA, Katzenellenbogen BS (2002): Characterization of the biological roles of the estrogen receptors, $\mathrm{ER} \alpha$ and $\mathrm{ER} \beta$, in estrogen target tissues in vivo through the use of an ER $\alpha$-selective ligand. Endocrinology 143 (11), 4172-4177

Harris HA, Albert LM, Leathurby Y, Malamas MS, Mewshaw RE, Miller CP, Kharode YP, Marzold J, Komm BS, Winneker RC et al. (2003): Evaluation of an estrogen receptor-beta agonist in animal models of human disease. Endocrinology 144 (10), 4241-4249

Helterbrand JD, Higgs RE, Iversen PW, Tysarczyk-Niemeyer G, Sato M (1997): Application of automatic image segmentation to tibiae and vertebrae from ovariectomized rats. Bone 21 (5), 401-409

Hertrampf T, Seibel J, Laudenbach U, Fritzemeier KH, Diel P (2008): Analysis of the effects of oestrogen receptor alpha (ERalpha) - and ERbeta - selective ligands given in combination to overiectomized rats. Br J Pharmacol 153 (7), 1432-1437

Hemelaar M, van der Mooren MJ, Rad M, Kluft C, Kenemans P (2008): Effects of non-oral postmenopausal hormone therapy on markers of cardiovascular risk: a systematic review. Fertil Steril $\underline{90}$ (3), 642-672

Hillisch A, Peters O, Kosemund D, Muller G, Walter A, Schneider B, Reddersen G, Elger W, Fritzemeier KH (2004): Dissecting physiological roles of estrogen receptor alpha and beta with potent selective ligands from structure-based design. Mol Endocrinol $\underline{18}$ (7), 1599-1609

Horn F: Molekulare Hormonwirkung - Intrazelluläre Rezeptoren. In: Horn F (Hrsg.): Biochemie des Menschen, 2. Auflage; Georg-Thieme Verlag, Stuttgart 2003, 347-348

Iizuka K, Machida T, Hirafuji M (2014): Skeletal muscle is an endocrine organ. J Pharmacol Sci of Physiology $\underline{125}$ (2), 125-131

Ishihara A, Taguchi S (1991): Histochemical Differentiation of Fibers in the Rat Slow and Fast Twitch Muscle. Japanese Journal of Physiology 41 (2), 251-258

James PT, Rigby N, Leach R (2004): The obesity epidemic, metabolic syndrome and future prevention strategies. Eur J Cardiovasc Prev Rehabil 11 (1), 3-8

Janssen I, Heymsfield SB, Ross R (2002): Low relative skeletal muscle mass (sarcopenia) in older persons is associated with functional impairment and physical disability. J Am Geriatr Soc $\underline{50}$ (5), 889-896

Jansson JO, Ekberg S, Isaksson OG, Eden S (1984): Influence of gonadal steroids on age- and sexrelated secretory patterns of growth hormone in the rat. Endocrinology 114 (4), 1287-1294 
Järvinen TL, Sievänen H, Khan KM, Heinonen A, Kannus P (2008): Shifting the focus in fracture prevention from osteoporosis to falls. BMJ $\underline{336}$ (7636), 124-126

Jensen EV, Jacobsen HI (1962): Basic guides to the mechanism of estrogen action. Rec Prog Horm Res $18,387-414$

Katzenellenbogen BS, Katzenellenbogen JA (2002): Biomedicine. Defining the "S" in SERMs. Science 295 (5564), 2380-2381

Kiechle MB: Weibliches Hormonsystem. In: Kiechle MB (Hrsg.) Gynäkologie und Geburtshilfe, 1. Auflage; Elsevier Urban \& Fischer Verlag, München 2007, 99-109

Klein NA, Illingworth PJ, Groome NP, McNeilly AS, Battaglia DE, Soules MR (1996): Decreased inhibin B secretion is associated with the monotropic FSH rise in older, ovulatory women: a study of serum and follicular fluid levels of dimeric inhibin A and B in spontaneous menstrual cycles. J Clin Endocrionol Metab 81 (7), 2742-2745

Kobori M, Yamamuro T (1989): Effects of gonadectomy and estrogen administration on rat skeletal muscle. Clin Orthop Relat Res (243), 306-311

Korach KS, Course JF, Curtis SW, Washburn TF, Lindzey J, Kimbro KS, Eddy EM,

Migliaccio S, Snedeker SM, Lubahn DB, Schomberg DW et al. (1996): Estrogen receptor gene disruption: molecular characterization and experimental and clinical phenotypes. Recent Prog Horm Res $\underline{51}, 159-186$

Krempien B, Friedrich G, Geiger G, Ritz E (1977): Factors influencing the effect of parathyroid hormone on endosteal cell morphology. A scanning electron microscope study. Calcif Tissue $\operatorname{Res} \underline{22}, 164-168$

Kuh D, Langenberg C, Hardy R, Kok H, Cooper R, Butterworth S, Wadsworth ME (2005): Cardiovascular risk at age 53 years in relation to the menopause transition and use of hormone replacement therapy: a prospective British birth cohort study. BJOG $\underline{112}$ (4), 476-485

Kuhl H (1990): Pharmacokinetics of oestrogens and progestogens. Maturitas 12 (3), 171-197

Kuiper GG, Enmark E, Pelto-Huikko M, Nilsson S, Gustafsson JA (1996): Cloning of a novel receptor expressed in rat prostate and ovary. Proc Natl Acad Sci U S A $\underline{93}$ (12), 5925-5930

Kumagai S, Holmäng A, Björntorp P (1993): The effects of oestrogen and progesterone on insulin sensitivity in female rats. Acta Physiol Scand $\underline{149}$ (1), 91-97

Latour MG, Shinoda M, Lavoie JM (1985): Metabolic effects of physical training in ovariectomized and hyperestrogenic rats. J Appl Physiol $\underline{90}$ (1), 235-241

Laudenslager ML, Wilkinson CW, Carlisle HJ, Hammel HT (1980): Energy balance in ovariectomized rats with and without estrogen replacement. Am J Physiol 238 (5), 400-405

Leidenberger F: Einführung in die Endokrinologie. In: Leidenberger F (Hrsg.): Klinische Endokrinologie für Frauenärzte, 2. Auflage; Springer Verlag, Berlin 1997, 3-22

Leitman DC, Paruthiyil S, Vivar OL, Saunier EF, Herber CB, Cohen I, Tagliaferri M, Speed TP (2010): Regulation of specific target genes and biological responses by estrogen receptor subtype agonists. Curr Opin Pharmacol $\underline{10}$ (6), 629-636

Lelovas PP, Xanthos TT, Thoma SE, Lyritis GP, Dontas IA (2008): The laboratory rat as an animal 
model for osteoporosis research. Comp Med $\underline{58}$ (8), 424-430

Lemoine S, Granier P. Tiffoche C, Berthon PM, Thieulant ML, Carre F, Delamarche P (2002): Effect of endurance training on oestrogen receptor alpha expression in different rat skeletal muscle type. Acta Physiol Scand $\underline{175}$ (3), 211-217

Lemoine S, Granier P, Tiffoche C, Rannou-Bekono F, Thieulant ML, Delamarche P (2003): Estrogen receptor alpha mRNA in human skeletal muscles. Med Sci Sports Exerc 35 (3), 439-443

Lim VS, Yarasheski KE, Crowley JR, Fangman J, Flanigan M (2003): Insulin is protein-anabolic in chronic renal failure patients. J Am Soc Nephrol $\underline{14}$ (9), 2297-2304

Lindberg MK, Moverare S, Skrtic S, Gao H, Dahlman-Wright K, Gustafsson JA, Ohlsson C (2003): Estrogen receptor (ER)-beta reduces ERalpha-regulated gene transcription, supporting a "ying yang" relationship between ERalpha and ERbeta in mice. Mol Endocrinol 17 (2), 203-208

Linke W, Pfitzer G: Kontraktionsmechanismen. In: Schmidt RF (Hrsg.): Physiologie des Menschen, 30. Auflage; Springer Verlag, Heidelberg 2007,112-115

Liu D, Bachmann K (1998): An Investigation of the Relationship Between Estrogen, Estrogen metabolites and Blood Cholesterol Levels in Overiectomized Rats. JPharmacol Exp Ther 286 (1), 561-568

Lobo MJ, Remesar X, Alemany M (1993): Effect of chronic intravenous injection of steroid hormones on body weight and composition of female rats. Biochem Mol Biol Int 29 (2), 349358

Lowe DA, Baltgalvis KA, Greising SM (2010): Mechanisms behind estrogen's beneficial effect on muscle strength in females. Exerc Sport Sci Rev $\underline{38}$ (2), 52-59

Lu JKH: Changes in ovarian function and gonadotropin and prolactin secretion in aging female rats. In: Meites J (Hrsg): Neuroendocriology of aging. Plenum Press, New York 1983, 103-122

Lu KH, Hopper BR, Vargo TM, Yen SS (1979): Chronological changes in sex steroid, gonadotropin and prolactin secretions in aging female rats displaying different reproductive states. Biol Reprod 21 (1) , 193-203

Lundeen S, Carver JM, McKean ML, Winneker RC (1997): Characterization of the Ovariectomized Rat Model for the Evaluation of Estrogen Effects on Plasma Cholesterol Levels. Endocrinology $\underline{138}$ (4), 1552-1558

Machida S, Booth FW (2004): Regrowth of skeletal muscle atrophied from inactivity. Med Sci Sports Exerc $\underline{36}$ (1), 52-59

Maltais ML, Desroches J, Dionne IJ (2009): Changes in muscle mass and strength after menopause. J Musculoskelet Neuronal Interact 9 (4), 186-197

Manson JE, Hsia J, Johnson KC, Rossouw JE, Assaf AR, Lasser NL, Trevisan M, Black HR, Heckbert SR, Detrano R et al. (2003): Estrogen plus progestin and the risk of coronary heart disease. $N$ Engl J Med $\underline{349}$ (6), 523-534

Martin KA, Manson JE (2008): Approach to the patient with menopausal symptoms. J Clin Endocrinol Metab 93 (12), 4567-4575 
Matt DW, Kauma SW, Pincus SM, Veldhuis JD, Evans WS (1998): Characteristics of luteinizing hormone secretion in younger versus older premenopausal women. Am J Obstet Gynecol 178 (3), 504-510

Matthews J, Gustafsson IF (2003): Estrogen signaling: a subtle balance between ER alpha and ER beta. Mol Interv $\underline{3}$ (5), 281-292

McClung JM, Davis JM, Wilson MA, Goldsmith EC, Carson JA (2006): Estrogen status and skeletal muscle recovery from disuse atrophy. J Appl Physiol $\underline{100}$ (6), 2012-2023

McCormick KM, Burns KL, Piccone CM, Gosselin LE, Brazeau GA (2004): Effects of ovariectomy and estrogen on skeletal muscle function in growing rats. J Muscle Res Cell Motil 25 (1), 2127

McNeil CJ, Doherty TJ, Stashuk DW, Rice CL (2005): Motor unit number estimates in the tibialis anterior muscle of young, old, and very old men. Muscle Nerve 31 (4), 461-467

Miranda PJ, DeFronzo RA, Califf RM, Guyton JR (2005): Metabolic syndrome: definition, pathophysiology, and mechanisms. Am Heart J $\underline{149}$ (1), 33-45

Mohamed MK, Abdel-Rahmann AA (2000): Effect of long-term ovariectomy and estrogen replacement on the expression of estrogen receptor gene in female rats. Eur J Endocrinol $\underline{142}$ (3), 307-314

Montague CT, Farooqi IS, Whitehead JP, Soos MA, Rau H, Wareham NJ, Sewter CP, Digby JE, Mohammed SN, Hurst JA et al. (1997): Congenital leptin deficiency is associated with severe early-onset obesity in humans. Nature $\underline{387}$ (6636), 903-908

Moran AL, Nelson SA, Landisch RM, Warren GL, Lowe DA (2007): Estradiol replacement reverses ovariectomy-induced muscle contractile and myosin dysfunction in mature female mice. $J$ Appl Physiol 102(4), 1387-1393

Mosselman S, Polman J, Dijkema R (1996): ER beta: Identification and characterization of a novel human estrogen receptor. FEBS Lett $\underline{392}$ (1), 49-53

Musaro A, McCullagh KJ, Naya FJ, Olson EN, Rosenthal N (1999): IGF-1 induces skeletal myocyte hypertrophy through calcineurin in association with GATA-2 and NF-ATc1. Nature $\underline{400}$ (6744), 581-585

Nabulsi AA, Folsom AR, White A, Patsch W, Heiss G, Wu KK, Szklo M (1993): Association of hormone-replacement therapy with various cardiovascular risk factors in postmenopausal women. The Atherosclerosis Risk in Communities Study Investigators. N Engl J Med $\underline{328}$ (15), 1069-1075

Ohlsson C, Hellberg N, Parini P, Vidal O, Bohlooly YM, Rudling M, Lindberg MK, Warner M, Angelin B, Gustafsson JA (2000): Obesity and disturbed lipoprotein profile in estrogen receptor-a-deficient male mice. Biochemical and Biophysical Research Communications 278 (3), 640-645

Paech K, Webb P, Kuiper GG, Nilsson S, Gustafsson J, Kushner PJ, et al. (1997): Differential ligand activation of estrogen receptors ERalpha and ERbeta at AP1 sites. Science 277 (5331), 15081510

Palacios S (2008): Advances in hormone replacement therapy: making the menopause manageable. BMC Womens Health $\underline{8}, 22$ 
Patten RD, Pourati I, Aronovitz MJ, Baur J, Celestin F, Chen X, Michael A, Haq S, Nuedling S, Grohe $\mathrm{C}$ et al. (2004): 17beta-estradiol reduces cardiomyocyte apoptosis in vivo and in vitro via activation of phospho-inositide-3 kinase/Akt signaling. Circ Res 95 (7), 692-699

Paul S, Smith L (2005): The metabolic syndrome in women: a growing problem for cardiac risk. $J$ Cardiovasc Nurs 20 (6), 427-432

Pedersen BK (2011): Muscles and their myokines. J Exp Biol 15 (214 Pt 2), 337-346

Pedersen SB, Bruun JM, Hube F, Kristensen K, Hauner H, Richelsen B (2001): Demonstration of estrogen receptor subtypes alpha and beta in human adipose tissue: influences of adipose cell differentiation and fat depot localization. Mol Cell Endocrinol 182 (1), 27-37

Perez-Lopez FR, Chedraui P, Gilbert JJ, Perez-Roncero G (2009): Cardiovascular risk in menopausal women and prevalent related co-morbid conditions: facing the post-Women's Health Initiative era. Fertil Steril 92 (4), 1171-1186

Peters O, Hillisch A, Thieme I, Elger W, Hegele-Hartung C, Kollenkirchen U, Fritzemeier KH (2000): 8 beta - Hydrocarbyl - substituted estratrienes for use as selective estrogen. Patent Application, WO0177139, 12-4-2000

Piccone CM, Brazeau GA, McCormick KM (2005): Effect of oestrogen on myofibre size and myosin expression in growing rats. Exp Physiol $\underline{90}$ (1), 87-93

Practice Committee of American Society for Reproductive Medicine (2008): The menopausal transition. Fertil Steril $\underline{90}$ (5), 61-65

Ramsey TL, Risinger KE, Jernigan SC, Mattingly KA, Klinge CM (2004): Estrogen receptor beta isoforms exhibit differences in ligand-activated transcriptional activity in an estrogen response element sequence-dependent manner. Endocrinology 145 (1), 149-160

Reckelhoff JF, Fortepiani LA (2004): Novel mechanisms responsible for postmenopausal hypertension. Hypertension $\underline{43}$ (5), 918-923

Redinger RN (2008): The prevalence and etiology of nongenetic obesity and associated disorders. South Med J $\underline{101}$ (4), 395-399

Rennie MJ, Tipton KD (2000): Protein and amino acid metabolism during and after exercise and the effects of nutrition. Annu Rev Nutr 20, 457-483

Richardson SJ, Senikas V, Nelson JF (1987): Follicular depletion during the menopausal transition: evidence for accelerated loss and ultimate exhaustion. J Clin Endocrinol Metab 65 (6), 12311237

Roepke TA, Bosch MA, Rick EA, Lee B, Wagner EJ, Seidlovà-Wuttke D, Wuttke W, Scanlan TS, Rønnekleiv OK, Kelly MJ (2010): Contribution of a membrane estrogen receptor to the estrogenic regulation of body temperature and energy homeostasis. Endocrinology 151 (10), 4926-4937

Rolland Y, Abellan van Kan G, Benetos A, Blain H, Bonnefoy M, Chassagne P, Jeandel C, Laroche M, Nourhashémi F, Orcel P et al. (2008): Frailty, osteoporosis and hip fracture: causes, consequences and therapeutic perspectives. J Nutr Health Aging $\underline{12}$ (5), 335-346

Rosenberg IH (1989): Summary comments. Am. J. Clinical Nutrition $\underline{11}$ (50), 1231-1233 
Rossouw JE, Anderson GL, Prentice RL, LaCroix AZ, Kooperberg C, Stefanick ML, Jackson RD, Beresford SA, Howard BV, Johnson KC et al. (2002): Risks and benefits of estrogen plus progestin in healthy postmenopausal women: principal results From the Women's Health Initiative randomized controlled trial. JAMA 288 (3), 321-333

Royer M, Castelo-Branco C, Blumel JE, Chedraui PA, Danckers L, Bencosme A, Navarro D, Vallejo S, Espinoza MT, Gómez G et al. (2007): The US National Cholesterol Education Programme Adult Treatment Panel III (NCEP ATP III): prevalence of the metabolic syndrome in postmenopausal Latin American women. Climacteric 10 (2), 164-170

Ryall JG, Schertzer JD, Lynch GS (2008): Cellular and molecular mechanisms underlying age-related skeletal muscle wasting and weakness. Biogerontology $\underline{9}$ (4), 213-228

Saengsirisuwan V, Pongseeda S, Praasannarong M, Vichaiwong K, Toskulkao C (2009): Modulation of insulin resistance in ovariectomized rats by endurance exercise training and estrogen replacement. Metabolism Clinical and Experimental 58 (1), 38-47

Scarbrough K, Wise PM (1990): Age-related changes in pulsatile luteinizing hormone release precede the transition to estrous acyclicity and depend upon estrous cycle history. Endocrinology $\underline{126}$ (2), 884-890

Seidlovà-Wuttke D, Hesse O, Jarry H, Christoffel V, Spengler B, Becker T, Wuttke W (2003 a): Evidence for selective estrogen receptor modulator activity in a black cohosh (Cimicifuga racemosa) extract: comparison with estradiol-17beta. Eur J Endocrinol 149 (4), 351-362

Seidlovà-Wuttke D, Jarry H, Becker T, Christoffel V, Wuttke W (2003 b): Pharmacology of Cimicifuga racemosa extract BNO 1055 in rats: bone, fat, and uterus. Maturitas $\underline{44}$ (1), 39-50

Seidlovà-Wuttke D, Prelle K, Fritzemeier KH, Wuttke W (2008): Effects of estrogen receptor alphaand beta-selective substances in the metaphysis of the tibia and on serum parameters of bone and fat tissue metabolism of ovariectomized rats. Bone $\underline{43}$ (5), 849-855

Seidlovà-Wuttke D, Ehrhardt C, Wuttke W (2010): Metabolic effects of 20-OH-Ecdysone in ovariectomized rats. J Steroid Biochem Mol Biol 119 (3-5), 121-126

Sengupta P (2013): The Laboratory Rat: Relating Its Age With Human's. Int J Prev Med 4 (6), 624-630

Sheffield-Moore M, Urban RJ (2004): An overview of the endocrinology of skeletal muscle. Trends Endocrinol Metab $\underline{15}$ (3), 110-115

Sheffield-Moore M, Urban RJ, Wolf SE, Jiang J, Catlin DH, Herndon DN, Wolfe RR, Ferrando AA (1999): Short-term oxandrolone administration stimulates net muscle protein synthesis in young men. J Clin Endocrinol Metab $\underline{84}$ (8), 2705-2711

Shelly W, Draper MW, Krishnan V, Wong M, Jaffe RB (2008): Selective estrogen receptor modulators: an update on recent clinical findings. Obstet Gynecol Surv $\underline{63}$ (3), 163-181

Shi H, Seeley RJ, Clegg DJ (2009): Sexual differences in the control of energy homeostasis. Front Neuroendocrinol $\underline{30}$ (3), 396-404

Shinoda M, Latour MG, Lavoie JM (2002): Effects of physical training on body composition and organ weights in ovariectomized and hyperestrogenic rats. Int J Obes Relat Metab Disord 26 (3), 335-343 
Sitnick M, Foley AM, Brown M, Spangenburg EE (2006): Ovariectomy prevents the recovery of atrophied gastrocnemius skeletal muscle mass. J Appl Physiol 100 (1), 286-293

Skouby SO, Endrikat J, Düsterberg B, Schmidt W, Gerlinger C, Wessel J, Goldstein H, Jespersen J (2005): A 1-year randomized study to evaluate the effects of a dose reduction in oral contraceptives on lipids and carbohydrate metabolism: 20 microg ethinyl estradiol combined with 100 microg levonorgestrel. Contraception $\underline{71}$ (2), 111-117

Sluijmer AV, Heineman MJ, De Jong FH, Evers JL (1995): Endocrine activity of the postmenopausal ovary: the effects of pituitary down-regulation and oophorectomy. J Clin Endocrinol Metab $\underline{80}$ (7), 2163-2167

Solomon AM, Bouloux PM (2006): Modifying muscle mass - the endocrine perspective. J Endocrinol 191 (2), 349-360

Sorensen MB, Rosenfalck AM, Hojgaard L, Ottesen B (2001): Obesity and sarcopenia after menopause are reversed by sex hormone replacement therapy. Obes Res $\underline{9}(10), 622-626$

Sowers M, Zheng H, Tomey K, Karvonen-Gutierrez C, Jannausch M, Li X, Yosef M, Symons J (2007): Changes in body composition in women over six years at midlife: ovarian and chronological aging. J Clin Endocrinol Metab 92 (3), 895-901

Staron RS, Kraemer WJ, Hikida RS, Fry AC, Murray JD, Campos GE (1999): Fiber type composition of four hindlimb muscles of adult Fisher 344 rats. Histochem Cell Biol $\underline{111}(2): 117-123$

Stevenson JC (2004): Hormone replacement therapy: review, update, and remaining questions after the Women's Health Initiative Study. Curr Osteoporos Rep $\underline{2}$ (1), 12-16

Stevenson JC (2007): HRT and the primary prevention of cardiovascular disease. Maturitas $\underline{57}$ (1), $31-34$

Stevenson JC, Crook D, Godsland IF (1993): Influence of age and menopause on serum lipids and lipoproteins in healthy women. Atherosclerosis $\underline{98}(1), 83-90$

Szulc P, Beck TJ, Marchand F, Delmas PD (2005): Low skeletal muscle mass is associated with poor structural parameters of bone and impaired balance in elderly men - the MINOS study. J Bone Miner Res $\underline{20}$ (5), 721-729

Taylor AH, Al-Azzawi F (2000): Immunolocalisation of oestrogen receptor beta in human tissues. $J$ Mol Endocrinol 24 (1), 145-155

Teschner A, Hinrichsen M: Weibliches Hormonsystem - Hormone des Ovars, Östrogene. In: Stauber M, Weyerstahl T (Hrsg.): Gynäkologie und Geburtshilfe, 2. Auflage; Georg-Thieme Verlag, Stuttgart 2005, 85-87

Tezini GC, Becari C, Zanotto CZ, Salgado MC, Passaglia RC, Souza HC (2013): Ageing is the main determinant of haemodynamics and autonomic cardiac changes observed in post-menopausal female rats. Auton Neurosci $\underline{174}$ (1-2), 36-41

Tora L, White J, Brou C, Tasset D, Webster N, Scheer E, Chambon P (1989): The human estrogen receptor has two independent nonacidic transcriptional activation functions. Cell $\underline{59}$ (3), 477487

Torricelli P, Fini M, Giavaresi G, Giardino R (2004): In vitro models to test orthopedic biomaterials in view of their clinical application in osteoporotic bone. Int J Artif Organs $\underline{27}$ (8), 658-663 
Toth MJ, Tchernof A, Sites CK, Poehlman ET (2000): Effect of menopausal status on body composition and abdominal fat distribution. Int J Obes Relat Metab Disord 24 (2), 226-231

Toth MJ, Poehlman ET, Matthews DE, Tchernof A, MacCoss MJ (2001): Effects of estradiol and progesterone on body composition, protein synthesis, and lipoprotein lipase in rats. Am J Physiol Endocrinol Metab $\underline{280}$ (3), 496-501

Tsai WJ, McCormick KM, Brazeau DA, Brazeau GA (2007): Estrogen Effects on Skeletal Muscle Insulin-Like Growth Factor-1 and Myostatin in Ovariectomized Rats. Exp Biol Med 232 (10), $1314-1325$

Van den Beld AW, Lamberts SW (2002): Endocrine aspects of healthy ageing in men. Novartis Found Symp 242, 3-16

Vasarhelyi EM, MacDonald SJ (2012): The Influence of obesity on total joint arthroplasty. $J$ Bone Joint Surg Br $\underline{94}$ (11 Suppl A), 100-102

Vehkavaara S, Westerbacka J, Hakala-Ala-Pietilä T, Virkamäki A, Hovatta O, Yki-Järvinen H (2000): Effect of estrogen replacement therapy on insulin sensitivity of glucose metabolism and preresistance and resistance vessel function in healthy postmenopausal women. J Clin Endocrinol Metab 85 (12), 4663-4670

Villa P, Sagnella F, Perri C, Suriano R, Costantini B, Macri F, Ricciardi L, Lanzone A (2008): Low and standard -estrogen dosage in oral therapy: dose - dependent effects on insulin and lipid metabolism in healthy postmenopausal women. Climacteric 11 (6), 498-508

Villanueva EC, Myers MG Jr (2008): Leptin receptor signaling and the regulation of mammalian physiology. Int J Obes (Lond) $\underline{32}$ (Suppl 7), 8-12

Volpi E, Sheffield-Moore M, Rasmussen BB, Wolfe RR (2001): Basal muscle amino acid kinetics and protein synthesis in healthy young and older men. JAMA 286 (10), 1206-1212

Volpi E, Kobayashi H, Sheffield-Moore M, Mittendorfer B, Wolfe RR (2003): Essential amino acids are primarily responsible for the amino acid stimulation of muscle protein anabolism in healthy elderly adults. Am J Clin Nutr $\underline{78}$ (2), 250-258

Wakeling AE, Valcaccia B (1983): Antioestrogenic and antitumour activities of a series of nonsteroidal antioestrogens. J Endocrinol 99 (3), 455-464

Wang Y, Simpson JA, Wluka AE, Teichtahl AJ, English DR, Giles GG, Graves S, Ciciuttini FM (2009): Relationship between body adiposity measures and risk of primary knee and hip replacement for osteoarthritis: a prospective cohort study. Arthritis Res Ther 11 (2), R 31

Warren GL, Lowe DA, Inman CL, Orr OM, Hogan HA, Bloomfield SA, Armstrong RB (1996): Estradiol effect on anterior crural muscles-tibial bone relationship and susceptibility to injury. J Appl Physiol $\underline{80}$ (5), 1660-1665

Wattanapermpool J, Reiser PJ (1999): Differential effects of ovariectomy on calcium activation of cardiac and soleus myofilaments. Am J Physiol 277 (2 Pt 2), 467-473

Weber MM (2002): Effects of growth hormone on skeletal muscle. Horm Res $\underline{58}$ (Suppl 3), 43-48

Weigel N: Steroid Receptor Crosstalk with Cellular Signaling Pathways. In: Henry HL, Norman AW (Hrsg.): Encyclopedia of Hormones, Volume 3; Academic Press Elsevier Inc., San Diego 2003, 420-427 
Weiss G, Skurnick JH, Goldsmith LT, Santoro NF, Park SJ (2004): Menopause and hypothalamic pituitary sensitivity to estrogen. JAMA 292 (24), 2991-2996

Wiik A, Glenmark B, Ekman M, Esbjörnsson-Liljedahl M, Johansson O, Bodin K, Enmark E, Jansson E (2003): Oestrogen receptor beta is expressed in adult human skeletal muscle both at the mRNA and protein level. Acta Physiol Scand 179 (4), 381-387

Wiik A, Ekman M, Morgan G, Johansson O, Jansson E, Esbjörnsson M (2005): Oestrogen receptor beta is present in both muscle fibres and endothelial cells within human skeletal muscle tissue. Histochem Cell Biol $\underline{124}$ (2), 161-165

Wise PM, Smith MJ, Dubal DB, Wilson ME, Rau SW, Cashion AB, Böttner M, Rosewell KL (2002): Neuroendocrine modulation and repercussion of female reproductive aging. Recent Prog Horm Res $\underline{57}, 235-256$

World Health Organization (2013): Obesity and overweight. In: Fact Sheet Number 311, http://www.who.int/mediacentre/factsheets/fs311/en/

Wuttke W: Endokrinologie. In: Schmidt RF, Thews G (Hrsg.): Physiologie des Menschen, 26. Auflage; Springer Verlag, Berlin 1995, 370-402

Wuttke W: Reproduktion. In: Schmidt RF, Lang F, Heckmann M (Hrsg.): Physiologie des Menschen mit Pathophysiologie, 30. Auflage; Springer Verlag, Berlin 2007, 504-520

Yeh JK, Chen MM, Aloia JF (1997): Effects of estrogen and growth hormone on skeleton in the ovariectomized rat with hypophysectomy. Am J Physiol 273, 734-742

Yen SCC: The human menstrual cycle: Neuroendocrine regulation. In: Yen SCC, Jaffe RB, Barbieri RL (Hrsg.): Reproductive endocrinology: Physiology, Pathophysiology, and Clinical Management, $4^{\text {th }}$ Edition; W.B Saunders, Philadelphia 1999, 191-217

Zanner R, Brenner B, Ovtscharoff W, Föhr K, Ruth P, Hofmann F: Muskelgewebe. In: Junqueira LCU, Carneiro J, Kelley RO, Gratzl M (Hrsg.): Histologie, 5. Auflage; Springer Verlag, Berlin u.a. 2002, 144-155

Zengura B, Guzic-Salobir B, Sebestjen M, Keber I (2006): The effect of various menopausal hormone therapies on markers of inflammation, coagulation, fibrinolysis, lipids and lipoproteins in healthy postmenopausal women. Menopause $\underline{13}$ (4), 643-650

Zhao C, Dahlman-Wright K, Gustafsson JA (2008): Estrogen receptor beta: An overview and update. Nucl Recept Signal I (6), 003 


\section{Abbildungsverzeichnis}

Abb. 1.1 Vergleich zwischen der Struktur und Homologie zwischen ER $\alpha$ und ER $\beta$. Menschlicher ER $\alpha$ enthält 595 Aminosäuren wohin gegen ER $\beta$ 530 Aminosäuren enthält. Die DNA-Bindungsdomäne ist annährend identisch wohin gegen die A/B-Domäne und die LBD, welche AF-1 und AF-2 enthalten, die wenigste Homologie aufweisen (Litman et al. 2010)

Abb. 1.2 Synthesestrategie für die Identifikation von ER Isotyp-Selektiven

Agonisten (Hillisch et al. 2004)

Abb. 2.1 s.c. Injektion in die linke Flanke

Abb. 2.2 Histometrische Untersuchung eines Muskelpräparates

Abb. 2.3 pqCT-Vermessung LWK 4/5 unter volatiler Narkose

32

Abb. 2.4 CT-Bild Höhe LWK 4/5 mit den farblich abgestuften Dichtegraden der unterschiedlichen Gewebe

Abb. 3.1 Durchschnittliches Körpergewicht der ovarektomierten Ratte nach 4wöchiger s.c. Substitutionstherapie

Abb. 3.2.1 Durchschnittlicher Prozentanteil des Fettgewebes im Bereich LWK 4/5 der ovarektomierten Ratte nach 4-wöchiger s.c. Substitutionstherapie

Abb. 3.2.2 Durchschnittlicher Anteil der Fläche des Muskelgewebes im Bereich LWK 4/5 der ovarektomierten Ratte nach 4-wöchiger s.c. Substitutionstherapie

Abb. 3.3.1 Durchschnittliche Muskelfasergröße des M. gastrocnemius der ovarektomierten Ratte

Abb. 3.4.1 Durchschnittlicher Serum-Cholesterinwert der ovarektomierten Ratte nach 4-wöchiger s.c. Substitutionstherapie

Abb. 3.4.2 Durchschnittlicher HDL-Serumwert der ovarektomierten Ratte nach 4wöchiger s.c. Substitutionstherapie 
Abb. 3.4.3 Durchschnittlicher LDL-Serumwert der ovarektomierten Ratte nach 4wöchiger s.c. Substitutionstherapie

Abb. 3.4.4 LDL/HDL ratio der ovarektomierten Ratte nach 4-wöchiger s.c. Substitutionstherapie

Abb. 3.4.5 Durchschnittlicher Triglyzerid-Serumwert der ovarektomierten Ratte

Abb. 3.4.6 Triglyzerid/HDL ratio der ovarektomierten Ratte nach 4-wöchiger s.c. Substitutionstherapie

Abb. 3.4.7 Durchschnittlicher IGF-Serumwert der ovarektomierten Ratte nach 4wöchiger s.c. Substitutionstherapie

Abb. 3.4.8 Serum-IGF-Index auf 100g Körpergewicht der ovarektomierten Ratte nach 4-wöchiger s.c. Substitutionstherapie

Abb. 3.4.9 Durchschnittlicher Glukose-Serumwert der ovarektomierten Ratte nach 4-wöchiger s.c. Substitutionstherapie 


\section{Tabellenverzeichnis}

Tab. 2.1 Gruppeneinteilung und Injektionsplan

Tab. 2.2 Einwirkzeiten zur Organentwässerung

Tab. 2.3 Schema der HE-Färbung 


\section{Danksagung}

Für die Erstellung meiner Dissertationsarbeit bin ich dem Ehepaar Wuttke, Prof. Dr. med. W. Wuttke und PD Dr. med. D. Seidlovà-Wuttke zu tiefem Dank verpflichtet. Ihre kombinierte fachliche Kompetenz gab mir stets das Gefühl, bestens aufgehoben und unterstützt zu sein. Nur durch ihre jahrelange Erfahrung in der Betreuung von Doktoranden kann ich mir erklären, wie die Tugenden der Geduld und Nachsichtigkeit eine solche Größe erreichen können. Ihre wiederholte konstruktive Kritik war entscheidend, dass ich meine Dissertationsarbeit in dieser Form beendet habe.

Weiter möchte ich der MTA Frau Heidi Brüggemann-Meyer danken, dass sie mir einen Einblick in ihre tägliche Arbeit ermöglicht hat und mir bei meinem ersten Gehversuchen der medizinischen Laborarbeit zur Seite stand. Ihr humorvolles Gemüt machte die gemeinsame Zeit stets zu einer Freude für mich. 